\title{
Tourism bisnis and "making ples" An ethnography of ni-Vanuatu bungalow and tour owners on Malekula
}

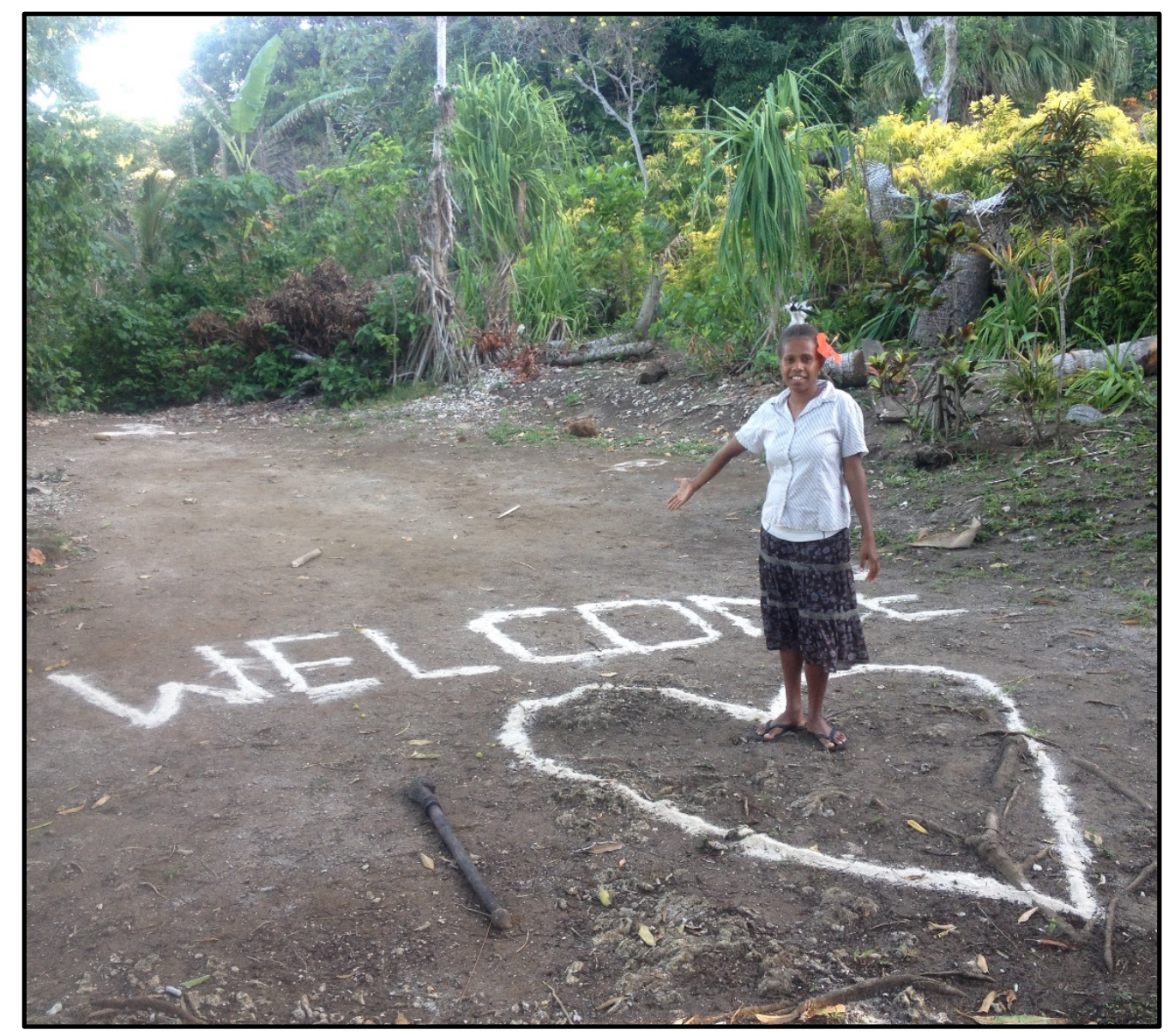

Annabel Bennett

A thesis submitted to Victoria University of Wellington in fulfilment of the requirements for the degree of Masters of Arts in Cultural Anthropology 
Cover Photo: Veronique

Source: Annabel Bennett 2016 


\section{Abstract}

Since tourism has become a leading contributor to growth in Vanuatu, local entrepreneurs on outer islands have been starting their own small bisnis (business) to take greater part in the industry and the cash economy. This has involved new and challenging negotiations with ples - a Bislama word that refers to land, history, and kastom (traditional values and practices) so integrally entangled with personal and group identity for indigenous ni-Vanuatu. This thesis documents the lived and told experiences of a number of ni-Vanuatu tourism entrepreneurs living on Malekula Island. These accounts are based on seven weeks of ethnographic fieldwork when I stayed at seven bungalows and conducted participant observation and storian (semi-structured interviews) with the owners and other members of the surrounding community. I argue that when building and running a tourism bisnis, ni-Vanuatu engage in a process of 'making ples' with a unique purpose of attracting tourists, one which involves a continuous dialogue with their environment, history and community, and ultimately results in a "politics of value” during the tourist encounter. Using participant stories, the ethnographic account explores owners' motivations to start a bisnis and the building process, the ples-based challenges they face, and how different kinds of value are mediated between tourists and locals when they meet. This thesis reveals that understandings of tourism and its values are interwoven with understandings of, and relationships with, ples. 


\section{Acknowledgements}

I am indebted to a number of people and organisations, without whose support, love and encouragement, I would not have completed this thesis. Firstly thank you to my supervisors, Lorena Gibson and Graeme Whimp. Lorena, you are such an inspiration to me and I am so thankful for your wealth of knowledge and thorough advice that guided me through every stage of this project. Your encouragement and help navigating through the preparations for overseas fieldwork and your faith in me being able to embark on such an adventure, are things I will always remember. Graeme and your green pen, your expertise and commitment to reading countless drafts has been an invaluable contribution to the final product. Not only this, the emotional support you have generously given me along the way is more than I could have hoped for and I am so grateful that you have been a part of this journey. I special thank you also to Brigitte Bönisch-Brednich, you have had a great impact on my academic journey at Victoria University over the last five years.

I would like to thank the New Zealand Aid Programme for the Postgraduate Field Research Scholarship, which provided me the opportunity to undergo fieldwork in Vanuatu, and the Vanuatu Cultural Centre who granted me permission to do research in Malekula. A special thank you must go to the Malampa Travel call centre for helping to organise the beginning of my trip, putting me in contact with some initial participants, and being a base to be able to continue that communication. Leina Isno, I admire your strength and ambition and you have been a joyful support for me for many years, but especially throughout this project, tankyu tumas. I would also like to thank Jane Wright, who originally introduced me to the tourism office on Malekula; your texts, emails, and phone calls have really spurred me on.

I would not be where I am today without the love and support of my closest friends and family. To my mum and dad, for your long phone calls, much needed life tips, and unwavering belief in me, thank you. To Beau, who made me food and was endlessly patient in those final weeks of mayhem, I'm so lucky to have you. And to my friends, the Anth library crew, and my proof readers: Hannah, Jared, Amy, Emma, and Jonathan, you are all such a happy part of my Masters journey.

Lastly and most importantly I would like to thank my participants. Mi wantem talem tankyu tumas long ol ni-Vanuatu man mo woman we oli tekem part long projek ia. Yufala i welkamem mi i kam insaed long haos, kastom, nasara, mo famle laef blong yufala. Yumi storian, yumi serem kakae. Bae mi no save forgetem fulap samting we yumi bin serem tugeta olsem wan famle. Mi ting se bae wanem we mi raetem insaed long buk ya bae hemi talem storian mo vois blong yufala ol stret kastom man mo woman long ol wan wan nakamal blong yufala. Yufala i olsem stampa blong wok blong mi insaed long buk ya we hemi gat bigfala mining. 


\section{Contents}

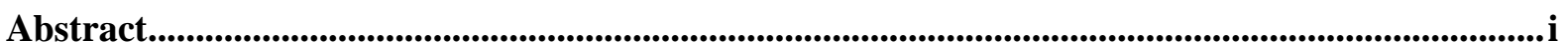

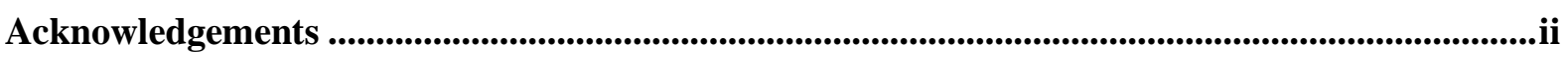

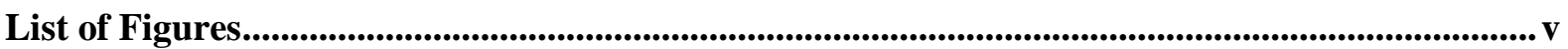

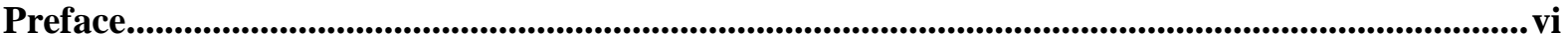

\section{Chapter 1}

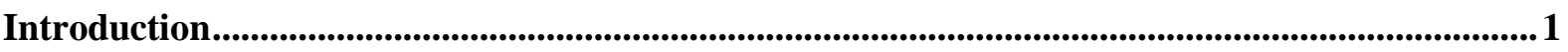

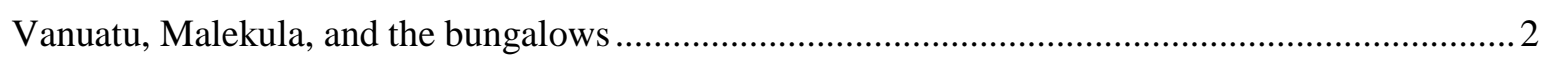

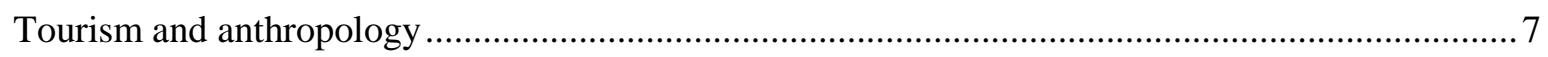

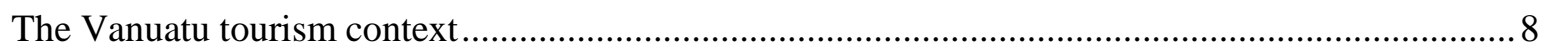

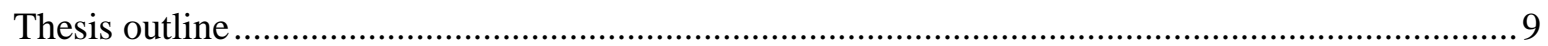

\section{Chapter 2}

Fieldwork and methods .........................................................................................................................11

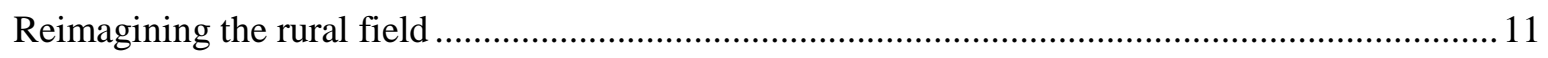

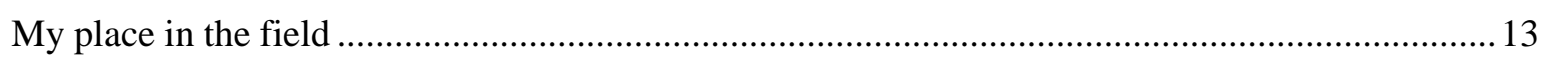

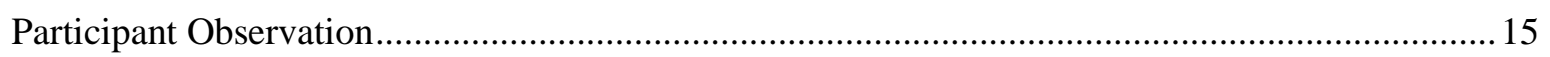

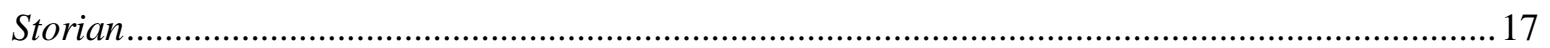

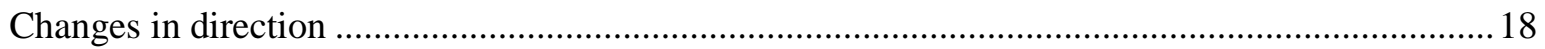

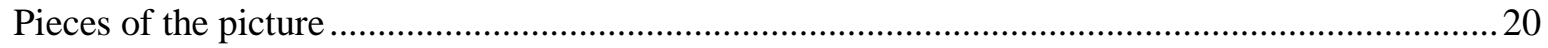

\section{Chapter 3}

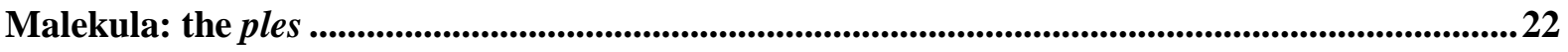

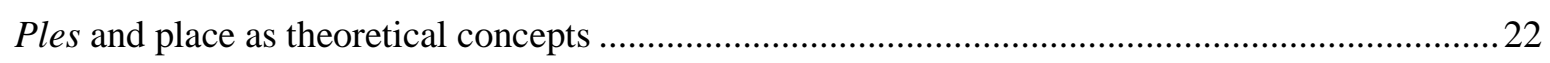

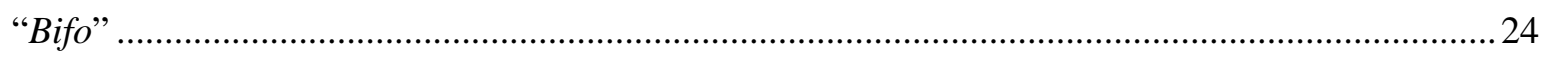

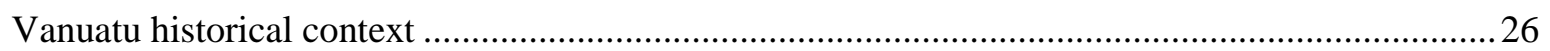

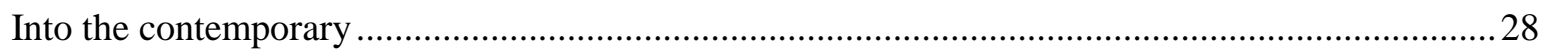

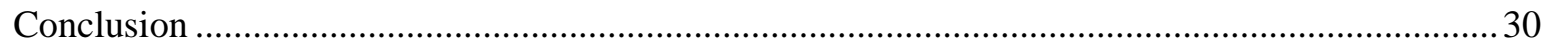

\section{Chapter 4}

Starting a bisnis: motivations and the building process .............................................................................31

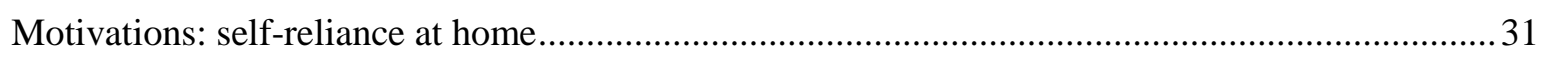

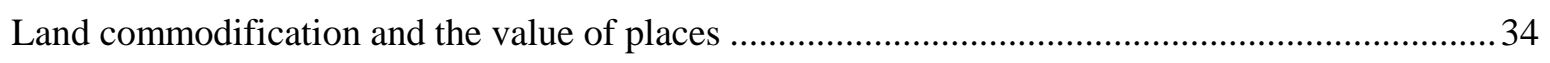

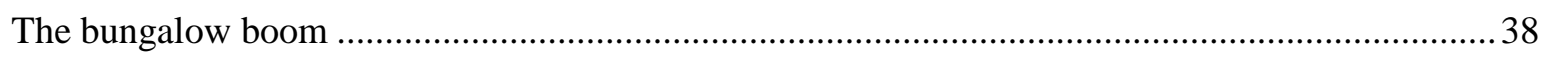


Building to the standards

Conclusion

\section{Chapter 5}

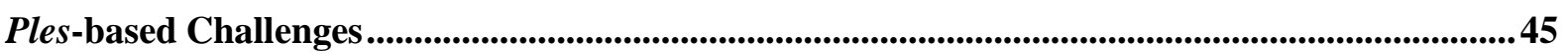

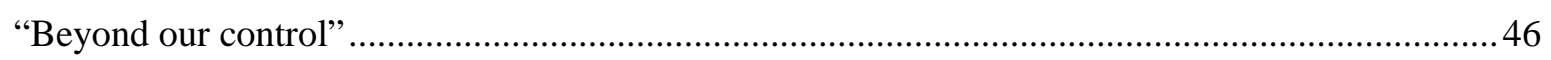

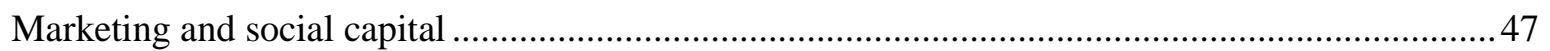

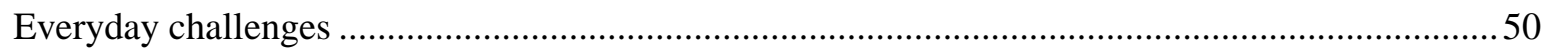

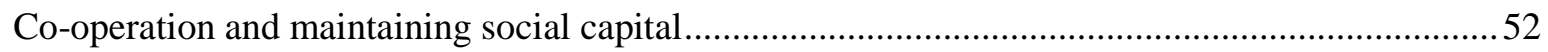

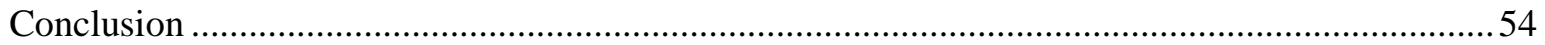

\section{Chapter 6}

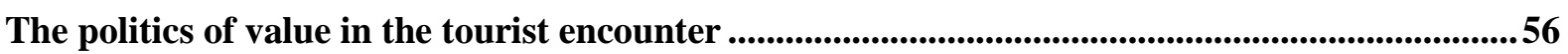

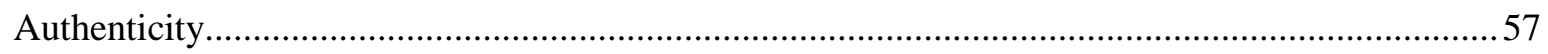

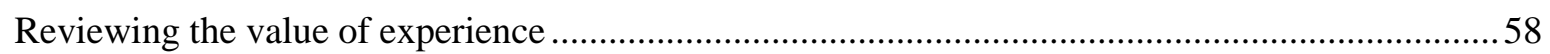

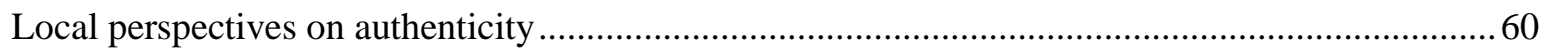

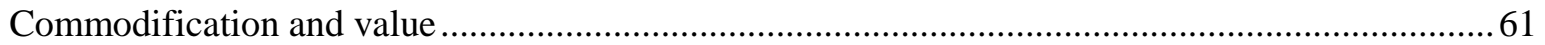

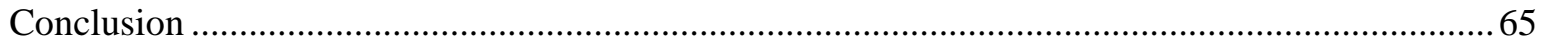

\section{Chapter 7}

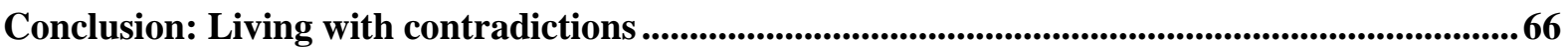

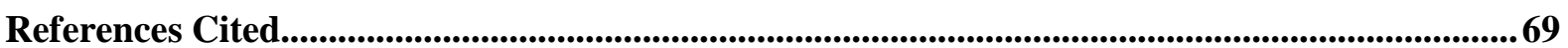

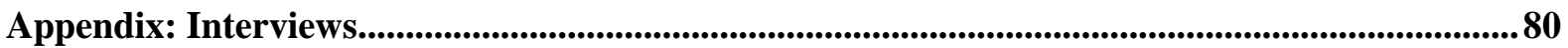




\section{List of Figures}

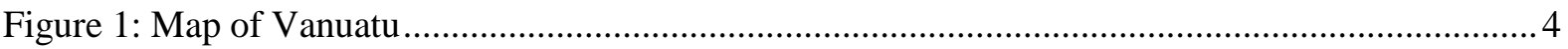

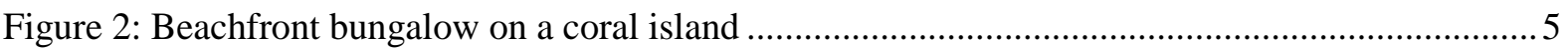

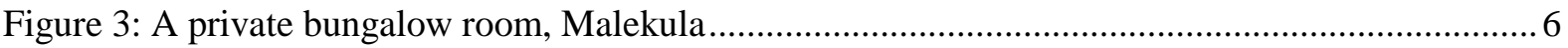

Figure 4: Mother Mary statue in Vanuatu national colours .....................................................................2 27

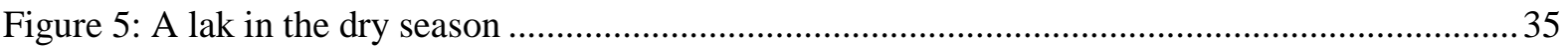

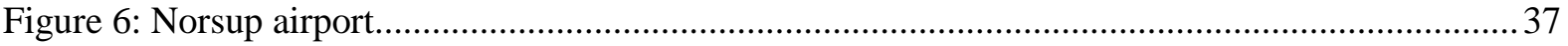

Figure 7: Giant clam shell bathroom sink ......................................................................................... 40

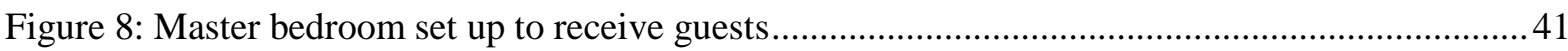

Figure 9: Bucket-flushing toilet with a soak-away septic system......................................................42 


\section{Preface}

\section{Moments in ples}

Pop. Pop pop. Pop.

Popcorn in steel bowl, cooking on charcoal.

My mami* puts heart and soul into preparations

for my $24^{\text {th }}$ birthday party, just like she did five years ago

on my first visit to Malekula

Heat.

All encompassing, smothering, merciless heat.

Dust on our feet, on our foreheads sweat starts to bead dirt under nails, our hands in the hot crusty soil of their land.

My taui* and I plant corn for her family to eat

We jump over waves waiting for the biggest

this one, no next one

this one...

this one!

We dive feeling its power thrust us.

Salt in our throats, in our noses, in our eyes

we emerge letting out cries of delight and go back for more 
Sitting in the truck bed on a pile of taro tightly packed, skin to skin, knees at my chin. We bump and rattle and veer and jolt. It begins pelting with rain and we laugh and we joke and we sing and we grin at the trucks overtaking us in the night.

Balancing on the edge of rock pools

waves lapping at our thighs

hoisted skirts, clenched fists, sharp eyes.

We scour the water with torch light and flame.

Looking for the small thread-like worms

that only appear one night a year.

The night of the sea worm

\author{
Sunset and Celine Dion \\ my sista* hums along
}

perched on a plank, watching the village wind down.

Gently touching shoulders, we agree on:

tonight, like every other,

the kava is strong.

This poem recounts special moments from my fieldwork on Malekula, Vanuatu. They all involve people and events that had a big impact on me personally. Although these did not make it into my thesis as 'data', I know that without these experiences, the 'data' I did bring back would not have been the same.

* Taui translates to in-law, in this case sister-in-law, in Bislama. All kinship terms in this poem refer to fictional kinship ties I forged with close friends during my fieldwork and on previous visits to Vanuatu. 


\section{Chapter 1}

\section{Introduction}

This thesis explores how tourism bisnis owners in Malekula negotiate relationships with their ples, histories, and communities, through their told and lived experiences of building and running a bungalow or cultural tour. ${ }^{1}$ The thesis is informed by my desire to give priority to local voices in academic writing about tourism, namely incorporating indigenous motivations, achievements, challenges, and values into the conversation. Malcom Crick (1989, 311), Amanda Stronza (2001, 262), and Sharon Gmelch (2004, 10) all note that historically tourism literature has focussed on two main areas: what motivates tourists to travel (Cassidy and Brown 2010; Graburn 2004; MacCannell 1976) and the negative impact of tourism on host communities (Greenwood 1989; Pattullo 2003; T. D. Wilson 2008). While these are valuable areas of study, my research follows others to contribute to writing that gives attention to local voices expressing their motivations, experiences, and understandings of tourism in the place they call home (see others Adams 2006; Alexeyeff and Taylor 2016; Cheer 2014; G. Gmelch 2012; Trau 2012, 2013). I argue that through building a bisnis, ni-Vanuatu engage in a process of "making ples", which results in complex negotiations with their lived environments and ultimately a politics of value during the tourist encounter. This thesis is based on two months of ethnographic fieldwork on Malekula during 2016, when I stayed with various bungalow owners and conducted participant observation and storian (an indigenous mode of communication akin to a semi-structured interview, where the power relations between interviewer and informant are less pronounced than a structured interview). ${ }^{2}$

I use ples to frame my argument in an attempt to respond to Pacific scholars' continued calls for academic use of indigenous epistemology when doing research in, and drawing conclusions about, the Pacific (Hau'ofa 1975, 1994; Huffer and Qalo 2004; Gegeo and Watson-Gegeo 2001). Ples is a foundational part of ni-Vanuatu identity, kastom, and history, and I use the concept to theoretically underpin my argument. ${ }^{3}$ It is widely documented by scholars of Vanuatu that ni-Vanuatu connect with their land in unique and important ways that continually influence each other (Bolton 2003; Jolly 1997; Mondragón 2013; Taylor 2008). Further afield, "place” as an anthropological concept is returning to anthropologists' attention, and there are exciting explorations in the ways that people and place relate and make each other, and of the multiplicity of places (Bönisch-Brednich and Trundle 2010; Convery, Corsane, and Davis 2012; Ingold 2000; Rodman 1992). In this thesis I show how through their engagement with tourism, ni-Vanuatu are simultaneously motivated and constrained by the conditions of their ples, and are thus engaged in a process of making, understanding, and transforming ples. I also explore how the multiple ways that different people (loosely grouped into tourist and local) understand and value place, can lead to a politics of value in the tourist encounter (Graeber 2001).

Bisnis is another Bislama term I draw on throughout this thesis, which emerges from understandings of ples in Vanuatu and the recognition that different localities engage with capitalism in unique ways.

\footnotetext{
${ }^{1}$ Throughout this thesis, all foreign language words in italics are Bislama unless otherwise stated. They are either followed by an English translation in brackets or a further explanation of the term in a footnote.

2 I was a recipient of the New Zealand Aid Programme Postgraduate Field Research Scholarship. I had to apply for research permit from the Vanuatu Cultural Centre, a regulation brought in when Vanuatu re-opened its borders in 1994 following a nine year moratorium on foreign researchers (Bolton 1999; Regenvanu 1999; for more on my experience see Bennett 2016).

${ }^{3}$ Kastom encompasses a range of practices and traditions that ni-Vanuatu consider to be uniquely their own, existing prior to European contact and colonisation. I discuss the term in more depth in Chapter 3.
} 
Bisnis may translate to the English word business, but I have resisted translating because of the distinctive meaning that I believe it conveys. While business implies a wide range of activities with the goal of profit accumulation and growth within the capitalist market economy, bisnis has important social and cultural dimensions within Vanuatu life. On Malekula, the array of bisnis community members set up include bungalows, bakeries, kava bars, and stores. Similar to George Curry’s (2007) findings in Papua New Guinea, a key component of bisnis is its social embeddedness, meaning it does not and cannot exist in isolation from its social context. For most families, a bisnis was not their only source of income, and it was sometimes intended only as a temporary endeavour. Furthermore, a niVanuatu entrepreneur may not see profit accumulation as their primary or only goal. Other scholars of the Asia-Pacific have suggested that the strong kin-based values of equality and sharing in some societies re-orientates profit accumulation as a selfish endeavour that should not take precedence over supporting family members and other social expectations (Farrelly 2009, 320; Yang 2013, 217).

Running a bisnis however, does achieve other goals such as social status within the community, particularly if it is a tourism bisnis where owners have the opportunity to meet and make connections with people from around the world. Across the Pacific, development practitioners have encouraged small-scale businesses as an opportunity to economically empower poor people through microenterprise schemes (Cox et al. 2007; Ellis et al. 2009). However, due to overlooking the differences between the indigenous and western understandings, organisations have deemed projects a failure if they do not generate an income or close down, when in fact locals may not perceive it as a failure themselves (Curry 2007; Johnston, Swain, and Howson 2012; Scheyvens and Russell 2013). Kate Barclay and Jeff Kinch $(2013,108)$ open their chapter in Engaging with Capitalism: Cases from Oceania (McCormack and Barclay 2013a) by stating that "engagements with capitalism are inevitably shaped by the particular configurations of local, national and global influences in those engagements". By using the word bisnis I attempt to move a step in the direction of acknowledging and revealing these local variations of capitalism in a Malekula setting.

When a global industry like tourism is picked up and used by local entrepreneurs in their locality, there becomes an integration and competing of different value systems, which I follow David Graeber (2001, 88) in calling a "politics of value". In many ways the politics of value aligns with the broader project of the politics of everyday life. The stories I tell in this thesis contribute towards what I believe is the aim of ethnography: to write something of peoples' lives in all its complexity, ambivalence, and messiness. This results in making visible, rather than tidying up, the politics and struggles of everyday life. In the introduction, I introduce Vanuatu and the bungalows, I provide a literature review of the contextual categories of tourism and anthropology that informed my research, discussing this broadly then more specifically to Vanuatu. I conclude the chapter with an outline for the rest of the thesis.

\section{Vanuatu, Malekula, and the bungalows}

Vanuatu - meaning 'our land' - is an archipelago of 83 islands in the South Pacific region defined as Melanesia. In 2009 the national census measured the population to be 234,023, most of whom live rurally but the urban population is rapidly increasing (Vanuatu National Statistics Office 2009). Urban settlements are located in Port Vila (the capital), wider Efate, and Luganville on Espiritu Santo. Vanuatu is well known for its incredible cultural diversity and language variation, with over 100 languages across the islands. The nation is located in the tropical zone, and therefore has a monsoon and a dry season. The driest and coolest time of the year runs from May to October and this coincides with peak tourist season. Vanuatu is divided into six provinces for administration and governance purposes, and 
Malekula is one of three islands that makes up Malampa Province (the others being Ambrym and Paama).

Malekula (also spelt Malakula) is the second largest island by area, and its main town Lakatoro is the provincial capital of Malampa Province. Malekula is easily identifiable on a map because it is shaped like a sitting dog, and locals refer to places using this geographical metaphor (e.g. head, neck, nose of the dog, see Figure 1). Many settlements are located on the flat regions closer to the coast and on the small islands, and there are more villages in the rugged and mountainous interior. The northeastern part of the island and down the east coast is relatively accessible by road; some parts, especially further south are only accessible by boat or foot. There are three airports on the island, the biggest with most frequent flights being Norsup, and smaller ones in Lamap and South West Bay. In terms of kastom, Malekula is divided into two main tribal groups: Big Nambas and Small Nambas (or Smol Nambas). Nambas means penis sheath, and big and small relate to the size of the sheath. The two tribes practice different kastom, dances, and songs, but even within the groups there is a great diversity of practices and languages depending on location. Small Nambas span a wider geographical area, stretching from South Malekula to Northeast. The Big Nambas live in the Northwest region of the island. I stayed only in Small Nambas territory, and visited a family that ran a cultural tour involving dancing and reenactment of a way of life bifo. ${ }^{4}$ The tour guide's name was Nellie and she became a valuable participant. $^{5}$

\footnotetext{
${ }^{4}$ Bifo was a temporal preposition that generally did not precede a noun in conversation with ni-Vanuatu, but they used it to refer to the time before Europeans, missionaries, and colonisation.

${ }^{5}$ Most names in this thesis are pseudonyms, unless my participants wished to have their real names. In some cases I have changed other identifying details to ensure confidentiality at the request of my participants. A full list of interview dates with participants can be found in the Appendix .
} 


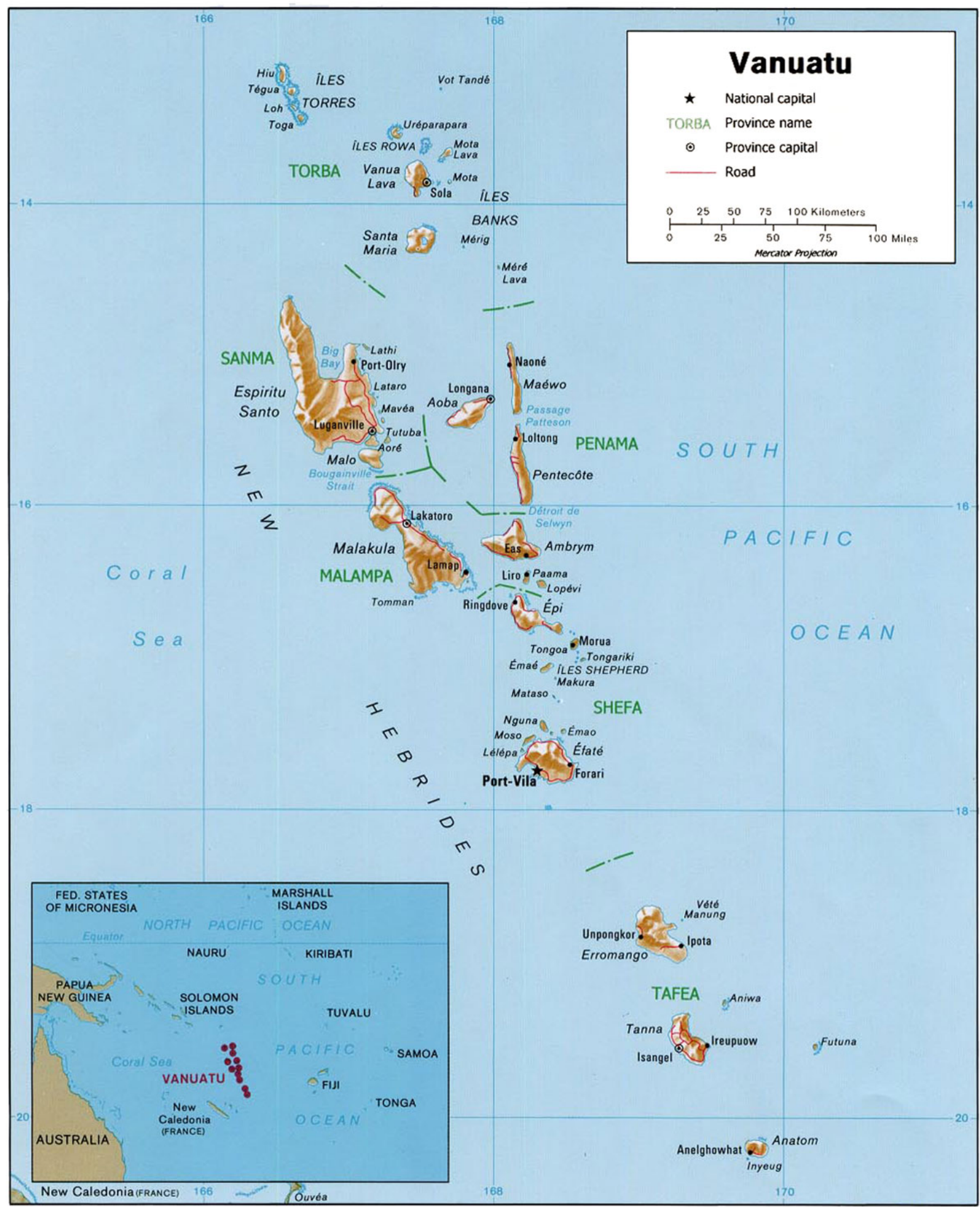

Source: Nationsonline (2017). Reproduced under Creative Commons Licence.

The bungalows were my main site of fieldwork, so I now introduce those that feature in the following ethnographic account. I have changed the names of bungalows for confidentiality reasons, and have used words from the local Uripiv/Wala/Rano language as replacements. Bungalow is a term used to describe the entire accommodation complex, but in actual fact these were made up of a number of 
smaller houses, private bungalows, bathrooms, and dining houses. Nowi Bungalow, for example, was made up of a few houses sprawled along the beach front of the small island it occupied. Each private sleeping house was made in a classic tourist bungalow style: a hybrid of a concrete foundation and lower wall, and a "traditional" built upper wall of woven bamboo and a natangora roof. ${ }^{6}$ In front of the kitchen was a covered eating area and in front of that a wooden platform that extended over the sand and gave a fantastic view of the ocean and mainland. Small paths that linked the buildings were lined with coral and clam shells. Another small island bungalow was Matur. This was situated on the windward side of the island giving it a fresh and wild feeling. The small houses were laid out in a similar way, with my bedroom having two single beds with mosquito nets, a small bedside table and a mirror. The landscape was dotted with wild pandanus trees holding hammocks made from old fishing nets strung between them. ${ }^{7}$

\section{Figure 2: Beachfront bungalow on a coral island}

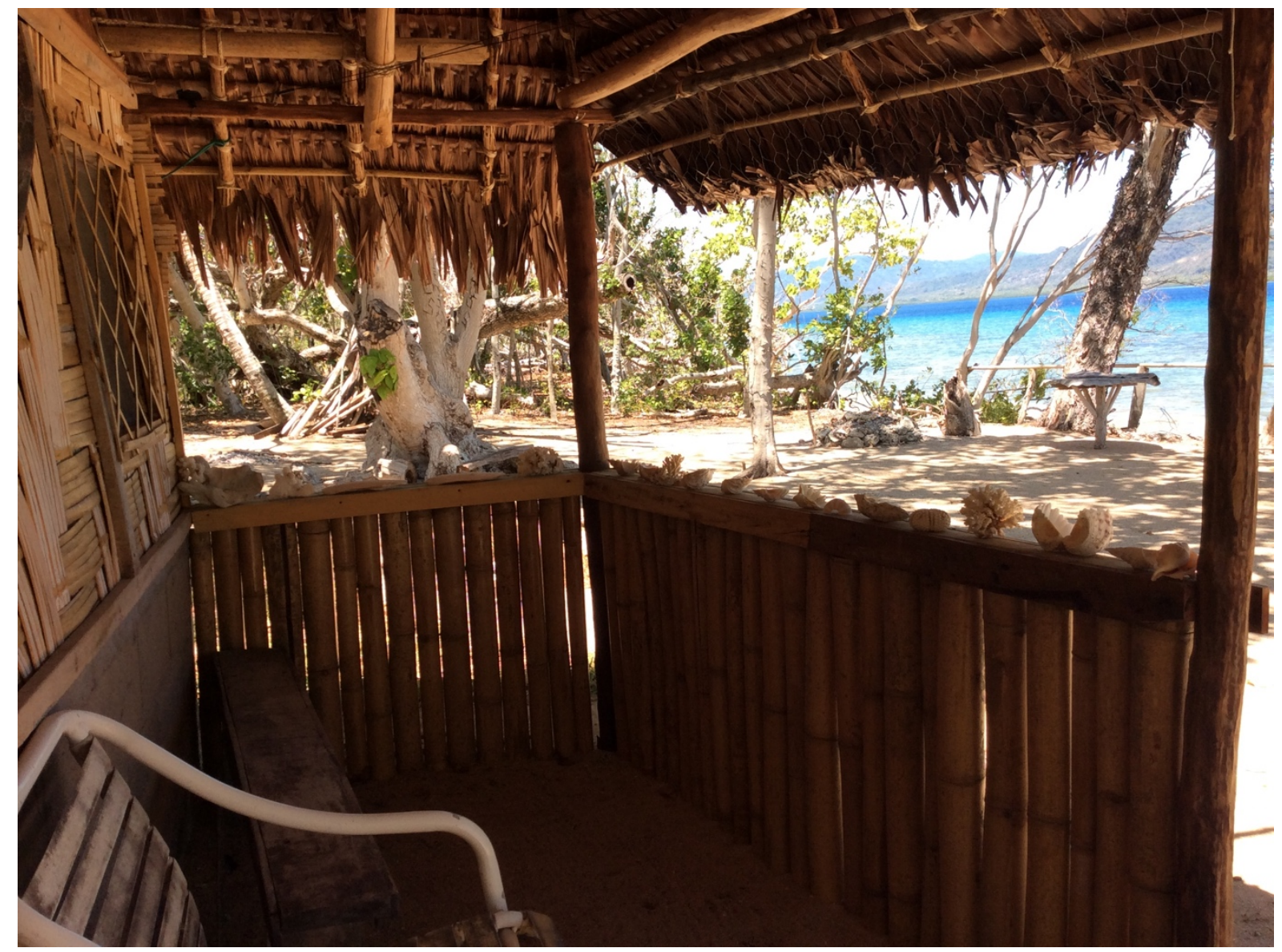

Source: Annabel Bennett (2016b)

Nesa Bungalow was a group of houses nestled in mature and manicured gardens. Nesa had access to mains electricity, so there was a fridge and sink in the kitchen. The dining room interior was decorated

\footnotetext{
${ }^{6}$ Natangora is the name of a tree and its leaf - similar to a palm tree but shorter and with thicker leaves. The leaves are folded and threaded onto a bamboo rod when they are green. Once dried they turn a silvery brown colour and provide waterproof protection as roofing for up to 20 years.

${ }^{7}$ Pandanus leaves are used to weave mats. Wild pandanus are generally found on exposed windward coastlines.
} 
with cultural artefacts like masks and tam tam drums purchased from the surrounding area. ${ }^{8}$ Tutun Bungalow was built into the hillside of Lakatoro, and was laid out slightly different to the others, it was more of a lodge. The main house where I slept had three bedrooms and a common area with chairs and a small kitchen for guests to prepare their own food. Tutun had a busy, coming-and-going feel; other guests included volunteers or government employees visiting the town for work. Navul Bungalow followed a similar structure, with a main house including four bedrooms and a bathroom, and a front porch area with a large table and chairs. Surrounding the area was a rocky cliff down to a reef. Mesal Bungalow was made up of dusty pink concrete houses, decorated meticulously with freshly picked flowers inside and out.

Figure 3: A private bungalow room, Malekula

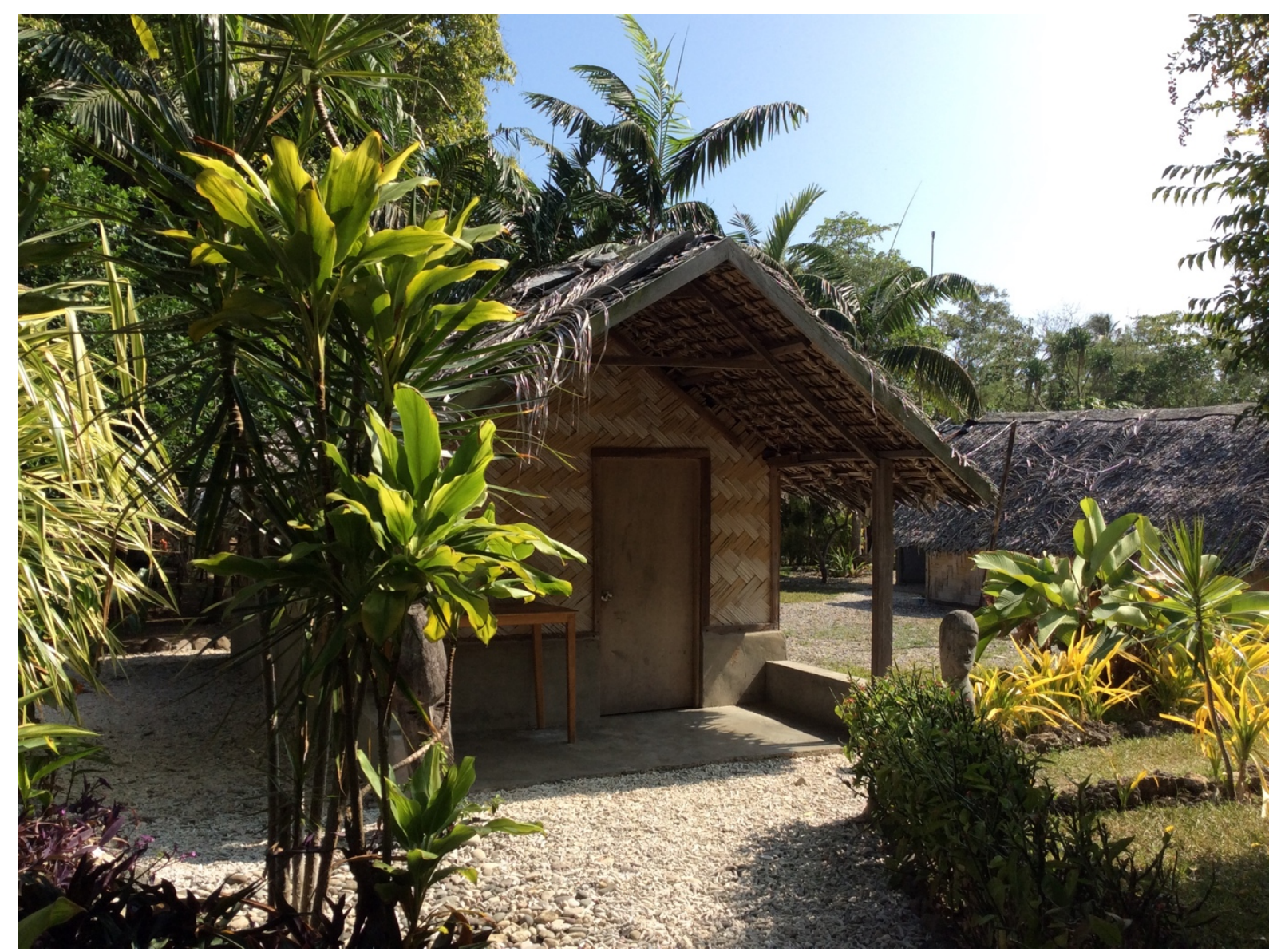

Source: Annabel Bennett (2016a)

\footnotetext{
${ }^{8}$ Tam tam drums are carved, wooden, hollow cylinders with a slit down the middle that is hit with a stick rhythmically to make music.
} 


\section{Tourism and anthropology}

Though as anthropologists we may be loath to admit any relationship to the sandal-footed, camera-toting legions in our midst, the truth is that tourism can be an ideal context for studying issues of political economy, social change and development, natural resource management, and cultural identity and expression. Indeed, many of the major questions that concern anthropologists appear in the study of tourism.

(Stronza 2001, 261)

The above quote from Amanda Stronza's review of anthropology and tourism hints to the slow and tentative entry of tourism into anthropological study. Tourism and anthropology emerged as a field of study in the 1970s, before which time tourism was usually an aside in ethnography rather than being the main focus of inquiry. Dean MacCannell (1976) and Valene Smith (1989) wrote the two most influential works, along with other scholars who helped to theorise the sub-discipline over the next few decades (Crick 1989; Cohen 2004; Nash 1996). Although in its initial stages, the study of tourism might have been undervalued and seen as unworthy of study because of its focus on leisure, the sub-field is now firmly established (Cole 2008; S. Gmelch 2004). In Malcom Crick's opinion, rather than "evolve into a science of tourism", the sub-field's worth lies in its ambiguity and multiplicity, a phenomena that "should be absorbed" into an array of disciplines (1989, 312). And indeed the topic has been taken in so many different directions. Recent anthropological works have brought tourism more or less to the centre of their arguments about mobility (Alexeyeff and Taylor 2016; Salazar 2010), environmental conservation (Walley 2004), paid employment (Gmelch 2012), art and material culture (Adams 2006), and indigenous entrepreneurship (Farrelly 2009).

Some scholarship has explored the complex relationships between local and global that are illuminated and complicated through the study of tourism (Alexeyeff and Taylor 2016; Cole 2008; MacCarthy 2014; Scheyvens 2007; Trau 2012). This is where my research fits in, with an emphasis on local perspectives and relationships with ples and how this both shapes and is transformed by tourism. The focus on host community impacts and the local articulation of global tourism flows usually involves a discussion of how tourism in "developing countries" was originally (and to some extent, remains) intended as a tool for development. Regina Scheyvens (2007) traces this history from its promotion in the 1950s by international institutions like the World Bank and the World Tourism Organisation as a catalyst for economic growth, to tourism's entanglement with a neoliberal globalisation agenda in the 1990s. By this time, Scheyvens notes, trade liberalisation and foreign investment in the tourism industry was leading to unequal economic benefits, environmental degradation, and the exploitation of countries' natural and cultural resources through commodification. There were also a growing number of critiques that tourism may not be delivering the intended economic and social benefits to the poor in "developing countries” (Scheyvens 2007, 238).

Growing critiques led to a surge in "alternative tourism” (Cohen 1987), producing a confounding number of buzzwords in the literature: sustainable tourism (Sofield 2003), ecotourism, pro-poor tourism (J. Mitchell and Ashley 2010), and community-based tourism (Salazar 2012). While each category has its own particular dimensions, their advocates share common ground in differentiating themselves from mass tourism and its negative effects on host communities. Adam Trau (2012) argues that although an alternative like pro-poor tourism tries to offer a fairer deal for locals and break free of the negative connotations of mass tourism, it is still founded on the same underlying principles and logic. That is "a globalising neoliberal capitalist economic system driving increasing wealth disparity between exogenous agencies (e.g. foreign-owned tourism companies) and local indigenous communities" (Trau 2012:153). They all inevitably reproduce the structures they seek to undermine. 
I was not convinced by the casting of any type of tourism as either a positive or negative force in local communities. Rather, I agree with Trau (2012) that tourism is a complex negotiation in constant flux, being shaped and re-shaped by globalisation, tourists, and local people. By situating my analysis in ples I move away from limiting my conclusions to only the negative impacts of tourism, instead I see the process as far more dynamic, instigated both by global forces and local entrepreneurs. My aim was to prioritise local voices, full of their messiness and contradictions that is reality in their everyday experiences, and write this into the literature on tourism. In this thesis I do not refer to activities as eco, sustainable-, community-based tourism; as I have already explained such distinctions are arbitrary. I call it simply tourism because that is what my ni-Vanuatu participants called it.

\section{The Vanuatu tourism context}

The tourism issue is perhaps particularly pertinent and interesting in Vanuatu for a number of reasons, which originally attracted my attention and other scholars in the past (Stefanova 2008; Johnston, Swain, and Howson 2012; Scheyvens and Russell 2013; Wittersheim 2011; Trau 2012). Tourism is the fastest growing sector in Vanuatu and significantly contributes to the country's Gross Domestic Product (Turner 2015; VIPA 2010). The industry experienced fast growth in the first decade of the millennium - with a 120\% increase in visitors between 2001 and 2010 - and the boom continues today (Johnston, Swain, and Howson 2012, 11).

Efate, Santo and Tanna are the three islands with the most intensive tourism development, and receive the vast majority of international tourists. It is here that foreign investors also dominate the industry, leaving little room for ni-Vanuatu entrepreneurs. This is due to a liberal and largely unregulated trade and investment environment that the Vanuatu government adopted in the 1990s (Slatter 2006; Trau 2012). The World Tourism Organisation and United Nations Development Programme drafted a Tourism Master Plan for Vanuatu in 1995, which set the conditions for trade and investment liberalisation and established the Vanuatu Investment Promotion Authority (VIPA) in 1998. Claire Slatter argues that although VIPA's role is to regulate foreign direct investment, its "regulatory role appears to be secondary to its investment facilitation and liberalisation role” (2006, 4). Resorts and restaurants only offer low-paid employment opportunities for ni-Vanuatu, while profits leave the shores of Vanuatu into overseas pockets through leakages.

The exploitation of Vanuatu's assets is largely facilitated by an unfair land tenure system that allows foreigners to lease indigenous land for well below market value. Selling land to foreigners remains illegal, but 75-year leases (a legacy from independence in 1980 designed to protect pre-independence foreign leaseholders) provide a loophole for expatriates to access land for tourism development (Stefanova 2008). At the end of the lease, the owner is legally bound to pay back any capital improvements made to the land. So if the leaseholder had built a resort on it for example, it is unlikely a ni-Vanuatu farmer could afford to regain possession over their land. Numerous other issues and legislation act to further disenfranchise ni-Vanautu from their land, and now $90 \%$ of coastal Efate is alienated from the indigenous owners (Stefanova 2008).

A report for the New Zealand Aid Programme concludes that "there needs to be greater ownership and control over tourism by ni-Vanuatu if they are to benefit significantly from economic opportunities tourism brings" (Scheyvens and Russell 2013, 71). This is reflected in the New Zealand Aid Programme and Vanuatu government's latest Tourism Action Plan (New Zealand Ministry of Foreign Affairs and Trade 2016; Vanuatu Government 2013). VIPA set aside 'reserved investments' that are areas of tourism exclusive to citizen ownership. They include small-scale enterprises below a certain annual turnover, guest houses with less than 50 beds, bungalows, cultural tours/feasts, and road transport operations. This opportunity was taken up by many outer island residents, but only one in four tourists 
who arrived by air ventured to the outer islands in 2015, with the rest staying on the main island Efate (VNSO 2016). The Vanuatu Tourism Office launched a "Discover What Matters" slogan to encourage visitors to explore beyond Efate, and cruise ships with their ability to access remote locations are already changing this trend. As part of supporting outer island tourism, each province had its own provincial tourism office that managed marketing, business development, training and certification. For Malekula this was the Malampa tourism office, located in Lakatoro. Malampa was unique in that it also had a notfor-profit call centre set up in 2012 in partnership with a Volunteer Services Abroad (VSA) volunteer; the call centre managed communications and acted as a booking agency (Johnston, Swain, and Howson 2012).

As this section has explained, the existing work around tourism focusses on the foreign domination in the industry, the lack of regulations, and a very concerning land alienation issue. While these are pertinent issues that demand attention to expose inequality and exploitation, my thesis aims to elevate local experiences in the conversation about tourism in Vanuatu. Many of the existing studies do not have the scope to explore locally-owned tourism ventures, and as a result relegate the discussion of them to an anecdotal side note. Apart from a few important exceptions (for example Cheer 2014 and Trau 2013), there is a lack of ethnographic investigations of how ni-Vanuatu themselves understand their agency and participation in the tourism industry, and what this means for their wider community and values. In this thesis I aim to give academic value to these entrepreneurs' stories and the complexity of their experiences.

\section{Thesis outline}

The rest of this thesis begins with my methods and fieldwork in Chapter 2. As is expected with ethnographic research, fieldwork was transformative for my initial research questions and thesis overall. I quickly realised that the literature I read could not alone prepare me for the uncertainty and serendipity that fieldwork brings. Through conducting interviews, participant observation, and general conversations that strayed far from tourism and (sometimes) returned back to the topic, my research questions multiplied and diversified. In Chapter 2 I reflexively discuss the methods I used during fieldwork with an emphasis on my positionality.

In Chapter 3 I discuss theories of place and how I use them, and introduce Malekula and Vanuatu's history and politics - crucial in any ethnographic account. Ples is an important part of ni-Vanuatu identity and has a profound influence on gender, kinship, language, and experience in everyday life. Ples became a theoretical underpinning for my argument, and in Chapter 3 I unpack the concept and explain how it frames the overall thesis. I situate Malekula in its historical and political context, in an effort to bring temporality into the ethnographic analysis of place.

Chapter 4 is the first chapter grounded in my ethnographic material, and describes bungalow owners I met, their motivations for starting a bisnis, and their experiences in building their bungalows to the standards. I suggest that ples simultaneously had an impact on my participants' decisions, actions, and experiences, as well as being fundamentally altered by the growing tourism industry on the island. This was evident in the way that land was re-evaluated with the prospect of tourism ventures, which could lead to land disputes. Tourism also meant that a shared culture could be capitalised on, which I argue is a partial explanation for the rapid increase of small family owned start-ups on the outer islands since 2000.

Chapter 5 is dedicated to a topic that repeatedly came up when talking to owners: the various challenges of running a tourism bisnis on Malekula. I call these ples-based challenges because they all relate in some way to operating within the realities of their ples. This creates challenges of geographical, social, 
environmental, and technical scope, that ni-Vanuatu respond to and cope with. I identify social capital as a resource that many entrepreneurs worked to build up so they could expend it in ways that would help them thrive in the Malekula tourism industry.

In Chapter 6 I bring tourists themselves into a discussion of how value is negotiated cross-culturally during the tourist encounter. When tourists visit a place they carry expectations about authenticity and commodification, which can align or compete with local views, causing a politics of value to emerge. I discuss this in relation to both host and guest experiences during the tourist encounter, and in reflection of it in online reviews.

I conclude the thesis in Chapter 7 by providing a summary of the main points and argument, and suggesting future areas for potential research. 


\title{
Chapter 2
}

\section{Fieldwork and methods}

\author{
Reimagining the rural field
}

\begin{abstract}
Tropes of “accidental discovery” in ethnographic texts not only serve to mystify anthropologists’ own agency in arriving at particular fields of research, but, far more seriously, they also occlude the agency of local people and institutions in directing or influencing the attentions and intentions of anthropologists... In doing so, then, they also tend to eclipse important connections that link the world of the anthropologist with that of the site of research.
\end{abstract}

(Taylor 2008, 17)

I joined the Air Vanuatu check in queue in Auckland Airport at the end of a snaking line of almost all ni-Vanuatu men. They were bundled up in hoodies and beanies, pushing trolleys laden down with duffle bags. Many knew each other, and they exchanged glances across aisles or shouted to get others' attention as we waited. The atmosphere was unusually convivial for an airport queue, and I found it easy to strike up conversation with the men next to me. I learned that most of them were seasonal fruit pickers on their way home after seven months of living and working in New Zealand. For some of them it was their first time, but for many an annual journey made many times prior. An observation a manMalekula once told me echoed powerfully in my head: "ni-Vanuatu gokambak (come and go) from New Zealand like it's their garden".

-Fieldnote vignette, 2016

In the opening quote John Taylor dismantles the arrival story motif that has a tendency to make discovering a fieldsite appear as a serendipitous stumbling upon, rather than a historically situated and careful journey of twists, turns, influences and decisions. The vignette that followed was my alternative arrival story - a leaving New Zealand story - to disrupt the stereotypes of anthropological fieldwork being situated in a remote and untouched location (Gupta and Ferguson 1997). In this chapter I take heed of Taylor's warning and openly trace my journey towards my chosen topic and the influences that helped to shape my research questions. The title of this section frames my attempt to move beyond bounded notions of a rural island fieldsite, and reflexively position myself within the research. Throughout this thesis I make an effort to write myself into the findings, in recognition that any conclusions I make are subjective to my fieldwork and interpretation, not objective fact. This chapter is dedicated to exploring my methods and place within the field; it is, in John Van Maanen's terms, my “confessional tale” (2011:93). 
Although Malekula fits the archetypal fieldsite - a singular island setting - Raymond Madden (2010:39) and Ulf Hannerz (2010:79) warn against assuming that this makes a fieldsite necessarily isolated and remote in every sense. Boarding the A320 to Port Vila, and later the Twin Otter plane to Malekula, I followed a path well-trodden by missionaries, colonisers, local and international tourists, researchers, and return migrants (Taylor 2008:17). Akhil Gupta and James Ferguson (1997, 13) argue that rural locations in classic ethnographies evoke the exotic and isolated, contributing to developing a "hierarchy of purity” in fieldsites depending on their distance from the ethnographer's home. ${ }^{9}$ On the contrary, my rural island field was dynamic, connected to other islands and the rest of the world in a way that demonstrated the ways in which flows of people and ideas are never unidirectional. People and place in localities connect with national, regional and global systems (Appadurai 1996), and it was precisely these interactions and integrations that drew me to the topic and the location. Another attraction of tourism as a research focus that is worth mentioning is its pragmatic advantages for fieldwork. Exploring tourism offered an appropriate way to access a fieldsite and potential participants; by staying in tourist accommodation I would not be a burden on families and would immediately be embedded in my fieldsite - vital given my relatively short fieldwork time period of seven weeks.

My relationship with Vanuatu first began in 2011 when I applied for a volunteer teaching placement there as an ignorant and enthusiastic 18 year old, keen to "make a difference" and maybe even "change the world”. I arrived in Malekula not knowing a single person, the language, or much about my new job. Over the next six months I went through a steep learning curve about what humanitarian aid work really involves - the good and the bad - and by the end was quite critical of something I initially thought (and had been told by family and friends countless times) was virtuous. Over the course of my undergraduate degree, which began in development studies and gradually moved toward cultural anthropology, I became increasingly critical and ashamed of my gap year experience. I realised there was a wealth of critical comment about "voluntourism" and the "white saviour complex" of which I was more than a little guilty (Mohamud 2013; Mostafanezhad 2013; Zakaria 2014). However, what remained was my interest in development (and then anthropology) and my ongoing relationship with friends and family in Malekula. We talked on the phone, exchanged letters, and I sent parcels to the people who had welcomed me into their families and seemed to have genuinely enjoyed my company as much as I enjoyed theirs. Over the next few years I returned two times for short visits, and focussed all my research assignments on Vanuatu or the Pacific whenever possible.

My first encounter with the Malampa tourism office was in 2015 during my third trip to Malekula. My flight to Port Vila had been cancelled and two VSA volunteers kindly offered to have me for the night. One of them worked at the tourism office so I got to go inside, meet the other staff, and learn a bit about the place. The two room European-style house was perched at the top of the hill overlooking Lakatoro, flanked by other bureaucratic buildings like the police station and health centre. ${ }^{10}$ Inside, fans helped to circulate the warm air and staff tapped away on computers - three permanent ni-Vanuatu staff and two temporary New Zealand volunteers. They were surrounded by documents and lever arch folders; posters promoting Malampa tourism businesses lined the walls. Outside, the company truck - a white Toyota Hilux - sported the slogan "Turisim hemi bisnis blong yumi evriwan" ("Tourism is everybody's business"). The phrase resonated with me because I had had other conversations with people about their intentions to start a tourism bisnis on the island, where that could be and what it might involve. From

\footnotetext{
${ }^{9}$ Malinowski (1922), Chagnon (1968), and Geertz (1973a) provide classic examples of this, especially in their opening scene descriptions of their fieldsite.

${ }^{10}$ See Rousseau (2012) for an interesting analysis of how the designation of space and state institutions shapes sociality in Lakatoro.
} 
this I thought that tourism could be a useful topic to explore due to people's interest in it, and I was motivated to better understand whether and how tourism could really be everybody's business.

I chose the northeastern area of Malekula as my field for my Master's thesis because of easier access by road, the relatively dense collection of tourism operators, and the history of cruise tourism in the area. During the final week of fieldwork my parents visited and we travelled together to South West Bay where I had another tourism operator contact to visit. For the first ten days I experienced the area in a similar way to a tourist, staying a couple of nights in a bungalow then moving on. I was able to stori with the owners who were happy to participate, and scoped out a potential bungalow to spend the remaining five weeks.

At the start of my enrolment my initial research questions were: to what extent are local business owners empowered through tourism? And what are the social and economic impacts of these interactions in the wider community? This was before I commenced fieldwork, an experience that caused my research questions to evolve, multiply and diversify. I was strongly influenced by two texts during pre-fieldwork reading: Sharing the riches of tourism in Vanuatu (Scheyvens and Russell 2013) and Turism blong yumi evriwan (Johnston, Swain, and Howson 2012). These publications, combined with my interest in development and anthropology, led me to question how equally tourism was benefitting indigenous people in Vanuatu, following strong critiques of the industry that I covered in Chapter 1. Entering the field with this in mind, I admit I was surprised to learn that almost everybody I met thought tourism was undeniably good, although the management of it could certainly be problematic. Participants thought that foreign investment at a reasonable level and increased cruise ship tourism should be encouraged, despite the negative effects that both of these have had in Vanuatu (Slatter 2006; Stefanova 2008; Wittersheim 2011). I realised that it was not productive to bring conversations that concerned Port Vila and Efate over to Malekula, and instead I adapted to the ples I was in and the issues that presented themselves to me. My initial questions became obsolete because I had not afforded my potential participants enough agency - they were already empowered. Ni-Vanuatu did not see themselves as passive victims of a global capitalist system that favoured the rich and powerful. Rather, they saw themselves as taking a challenging but rewarding opportunity to partake in the tourism industry by running their own bisnis. Acknowledging their agency, I focussed much of my fieldwork questions and consequently this thesis on entrepreneurial motivations, challenges, and accomplishments of making ples.

\section{My place in the field}

Nothing that God ever made is the same thing to more than one person. That is natural. There is no single face in nature, because every eye that looks upon it, sees it from its own angle. So every man's spice-box seasons his own food.

Naturally, I picked up the reflections of life around me with my own instruments, and absorbed what I gathered according to my inside juices.

(Hurston 1942, 61)

It is now widely recognised within ethnography that the observer plays an integral role in co-creating fieldwork data, meaning their presence is generally more foregrounded in the subject matter than in other disciplines that strive for neutrality and objectivity (Hobbs and Wright 2006; Rabinow 1977). To 
use Zora Neale Hurston's (1942, 61) metaphor, my spice-box of prior experiences, intentions and knowledge seasoned my observations, conversations, and fieldnotes in a unique way.

My interpreted status was ambiguous and fluid, changing from person to person and over time. When I first met people they would ask if I was Peace Corp or a volunteer. This is not surprising seeing as volunteers made up the vast majority of white people on the island and I was similarly young, travelled alone, and spoke Bislama. Consequently, people would ask "how do you think we can get more tourists to Malekula" or "what do you think we should be doing to improve tourism?” I would have to explain - while trying not to come across as dismissive - that my role was not to help or advise, but to listen to their own opinions about tourism. I also fielded the occasional question about whether I was able to write funding letters or if I had connections to marketing opportunities in New Zealand. This of course became less frequent over time as people got to know me, but defining my identity and feeling like I was not meeting expectations remained a struggle for me personally and in my research decisions. Taylor (2008:33) makes a similar observation of how the misconception as a foreign aid worker during fieldwork in Pentecost "became entirely entangled with [his] own constant struggle to define [his] field research, which was already being negotiated for [him] on a local level”.

My white woman status affected my movements through ples and meant I received privileges that niVanuatu women did not. For example I was allowed to go into the nakamal (sacred Chiefs' meeting house), upheld as a men only space, because I was white. Women can drink kava but usually stay on the periphery of the kava bar, however I moved through freely and talked to men. I was also able to hang out with men one-on-one without causing a scandal (although there was the occasional tease). In other words, my whiteness stood me outside the usual code of conduct for women in the village. I was reminded how gender and race can never be separated when understanding the workings of power and privilege. Ultimately though - apart from the kava - I participated in female-centred activities like cooking and going to the garden and built faster rapport with women, who made up the majority of my participant base and friends.

Given my position as an outsider and short-term stay in the community, I was not privy to certain events and information. I missed out on a few tourism-related meetings because of this; I was either simply not invited or told to wait outside. In these situations I was torn between curiosity and not wanting to be rude or ruin trust. I decided that respecting my participants' privacy and their control over the research was more important, so I refrained from asking too many prying questions about these meetings, assuming that if people wanted me to know they would tell me.

It is common practice in Vanuatu to "make family" with visitors, whether it is foreigners or ni-Vanuatu from another island. For me this happened pretty casually; I became close with a family and after a while someone said to me "you should call me mama now" and so on. Initially I was hesitant, having already made family in Lambubu on my first trip to Malekula; I wanted to respect those ties and maintain researcher distance. Lynn Hume and Jane Mulcock (2012, 10) outline this dilemma for fieldworkers:

By resisting total integration and commitment to the social domains we are researching, by attempting to maintain our intellectual distance while also indicating our desire to "belong", we choose a socially anomalous identity that is fraught with inconsistency and ambiguity, both for ourselves and for our research participants.

However I ended up "surrendering to the field", as Hannerz $(2010,75)$ calls it, and engaged in fictive kinship bonds. Not only would it have been wildly inappropriate to refuse, but it was quite acceptable 
to use kinship names with more than one family (calling a good friend sista for example), and did not bring many formal obligations.

As I was incorporated into the web of kinship that structures social relations and village life I felt a sense of acceptance and belonging. I wanted to participate in the cycle of reciprocity and give something in return for people's generosity and openness towards me. Not only did people give their time, but a visit to someone's house would always involve an offer of a meal, and I would regularly get kava bought for me. I found I was living in an uneasy balance, wanting to reciprocate and help in appropriate ways, but also not wanting to over-commit myself in ways that would be more suited to a long-term volunteer. I managed to find small ways of reciprocating that I knew I could follow through on, for example getting business cards made, distributing advertising in the Port Vila hostel I stayed in, printing brochures and photos and sending them back, or leaving good reviews on Trip Advisor. I gave in a more general way by paying for people's transport when we went somewhere together, and gifting items from the store like flour and sugar or vegetables bought from the market when I visited houses.

Ensuring informed consent was a challenge I faced in a location where participants are not so familiar with academia, with the added complication of a language barrier (Besnier 2009). ${ }^{11}$ However, as Madden maintains, this is no excuse for anthropologists and he advises that "even if linguistic and knowledge-system barriers make comprehensive explanations difficult, you must try to encapsulate and explain your research in terms the participants can genuinely understand" (2010:90). Nevertheless this remained a struggle, as did the power relations that came to the fore when I asked for consent. On two occasions I received the response " $i$ stap long yu" ("it's up to you”). When approaching the issue of consent within participant observation things became even more complicated, and I employed an ongoing process. As my research interests developed I explained to those around me that even the everyday topics and activities unrelated to tourism were still useful. I made it known on trips to the garden or drinking kava that I was still in my researcher role and learning about society more generally was important to my project. When my fieldnotes were based on my own experiences, for example at an event, on a truck, or at the market, I would not ask for explicit permission from people. If conversations moved towards people telling me about their own experiences, I would choose an opportunity to ask permission.

\section{Participant Observation}

To hear the voices of those silenced in island conversations requires listening with all of one's senses. Multivocality often involves multilocality. Polysemic places bespeak people's practices, their history, their conflicts, their accomplishments. Narratives of places are not just told with words; they can be told and heard with senses other than speech and hearing.

(Rodman 1992, 649)

Participant observation is the cornerstone of ethnographic fieldwork, and it was my primary method of data collection. As Margaret Rodman's quote suggests, paying attention to all the senses rather than just speech is especially valuable in understanding and expressing a sense of place in anthropological work. The method involves the researcher immersing herself in a place and taking an active role in daily life in order to gain a deeper understanding of what is meaningful and important to people. For me, participant observation was about getting into the rhythm of daily life both in the guest house and the wider village. My interest in ples and the messiness and contradictions of everyday life in Malekula

\footnotetext{
${ }^{11}$ I received university ethics approval for this project in July 2016. I gathered consent orally from participants because many were not confident reading and writing, and speaking was the expected form of communication.
} 
meant that I could not have gathered the same insight or depth of understanding from interviews alone. As Rodman $(1992,649)$ aptly puts it, "narratives of places are not just told with words"; indeed it was the smells, glances, laughs, sounds, and feelings that brought my fieldwork and - in the end - my thesis to life.

My day-to-day activities involved some previously organised meet ups, hanging out, and more formal arrangements for storian, but apart from this my days were largely unstructured. In a tropical country like Vanuatu, I found that island life (and consequently my fieldwork) was very much dictated by the climate. For example, during the hottest hours in the middle of the day, the pace of life slowed and this was usually when I became more restless. Hours of inactivity during the day would frustrate me and cause fieldwork anxieties to surface, as would meetings with people that fell through and never happened. I was plagued with the worry that I was simply hanging out with people and was not directing my fieldwork enough towards answering my research questions. However, it proved counter-productive to rush or force things. I understood on a deeper level why long-term immersion for ethnographic fieldwork is advocated for, although the optimal length is not always specified (Madden 2010; Hannerz 2010). It became fruitful to meet with people on multiple occasions, as their stories would grow a little each time we conversed. While there was some repetition, a little bit would be added on each time, like I was earning it with my patience. Overall, it was the unplanned meetings, the friendships, and the times-in-between, which shaped my fieldwork experience in a profound way. Because I could not always incorporate these moments into my thesis, I chose to encapsulate them in a prologue.

My ambiguity in the most common categories - tourist, volunteer, and local - shaped my participant observation. For example, when I helped Ellen prepare food for tourists I was participant observer. When I travelled to South West Bay with my parents, and at other times acted more like a tourist, I moved into what Harvey Bernard $(2011,279)$ calls an observing participant role. Rather than being a diminishing factor, switching roles helped me to see things from different perspectives and widened my observation experiences. I had planned to go on more organised tours (as an observing participant), but ended up only attending one cultural tour. There were other tours offered in the area but as I became aware of some underlying tensions and political factors surrounding the management of these I decided not to take part. ${ }^{12}$ In the end I found that chatting to people through everyday casual encounters was more successful than going on organised tours which felt awkward and forced.

I barely ever used a note book during participant observation. I relied heavily on what Simon Ottenberg (1990) calls headnotes, meaning the thoughts and observations that do not always make it into written fieldnotes but ethnographers still draw on in shaping their ideas. When I got the chance I wrote down a few words as jottings, to be expanded into a detailed fieldnote later. Emerson, Fretz and Shaw state that since jottings are the means of getting experience down onto paper, it is useful to get in the habit of "envisioning scenes as written" (2011:31). To attempt this, I chose words or snapshots of dialogue that would later evoke more detailed vivid description to flow from that memory jogger. This method of inscribing social life, as with any, is of course subjective; even before interpretation gets layered on top I was already making unconscious and inevitable decisions of what to write down and what to miss out in my fieldnotes. Furthermore fieldnotes "present or frame events in particular ways" in accordance with the fieldworker's own sensitivities and understandings (Emerson, Fretz, and Shaw 2011:13). This leads to my assertion that as ethnographers we must acknowledge that there is no such thing as neutral, objective, raw data, nor do I think we should have this as a goal to be striving towards.

\footnotetext{
${ }^{12}$ Ongoing land disputes at one tour site meant some residents thought it unacceptable to continue running a tourist bisnis there. I observed power struggles between tour operators in other instances and worried that my participation might be viewed as taking sides.
} 


\section{Storian}

I used the Bislama term storian to describe my interviews for two reasons: firstly it was the way participants referred to our talks; and, secondly, to illustrate the distinctions between storian and a more western-style interview. Terry Crowley $(2003,263)$ defines storian as “to chat, yarn, swap stories" and it can range in formality from meetings to everyday chats. Olivia Warrick describes storian in the research context as "an umbrella term indicating semi-structured interview, informal interview, and opportunistic discussion as part of observation. Irrespective of specific method, the central feature of storian is building rapport with participants" $(2009,83)$. Storian has many similarities with talanoa; both indigenous methodologies privilege an empathic relationship between researcher and participant, requiring respect and the mutual sharing of information (Farrelly and Nabobo-Baba 2014). One distinction of storian is that it encompasses more forms of communication than just a formal meeting or interview; it could equally refer to a casual chat. I utilised all forms of storian when adopting the indigenous method, and found that the nature of storian varied widely depending on context. In total I had eleven official storian, seven of these I recorded and later transcribed; a full list can be found in the Appendix.

The recorded interviews were most like a semi-structured interview; we arranged an approximate time, sat down and dedicated time, and I had a general set of questions that we would move away from as the storian developed. Due to this formality objectified in the recording device, pens, and paper, there was a feeling of awkwardness and nerves on both sides. I asked a lot of questions and got concise, targeted answers from participants. I wondered at these points whether my participants were unwilling to stray too far from my questions because they wanted to give the information that would satisfy me and my inquiry, and possibly also better equip me as an advocate for them (see Rabinow 1977). On more than one occasion when talking to couples, a usually gregarious wife whispered to her husband "you talk!" after my first question, before starting to interrupt with input further into the storian. As fieldwork progressed I used the recorder less and noticed that conversation flowed more easily, the informality meaning we could stray far from the topic and then circulate back.

"Opportunistic discussion” happened during participant observation and felt the most natural (Warrick 2009, 83). Conversation was participant-led focussing on their own concerns and communicative protocol. When meeting somebody for the first time we would spend some time learning about each other's family - how many brothers and sisters, if our parents are alive, if we are married and if so how many children. It was also normal to engage in small talk about where one had come from that day, who they had seen, and perhaps where they were going. These sorts of chats were not so tedious once I realised how they preceded further conversation and friendship, but just as importantly helped weave the social fabric of daily life. People's whereabouts and activities were widely known and this was useful not only in locating people, but also maintaining community cohesion, connectivity, and a feeling of belonging within it. Engaging in this kind of small talk during storian proved the most effective way to build rapport. It is worth noting that during the more formal recorded storian we did not talk about each other's family until the end, if at all. I think this added to the artificial feeling of the recorded interviews, and I did not manage to build rapport so well in some cases.

Speaking in Bislama was an important component of storian. As can be expected, using participants' language helped to build rapport and balance the power relationship between researcher and participant. Although I began fieldwork competent in Bislama, and my confidence grew with every storian, it was still a second language for me and a first language for my participants; I felt nervous and uncomfortable and made an effort to confirm that I had understood things correctly. I had to learn the body language 
and conventions to fit in with social norms of conversation, like the empathy expressed in using the word sori during conversations particularly with other women (Meyerhoff 1999), or hand slapping with women after telling a joke. Furthermore, speaking in Bislama kept me grounded in participants' language practice and subsequently life worlds. It kept me from using too much jargon that would have potentially confused participants and alienated them from the topic we were discussing. Only in one storian did we begin in Bislama and then gradually transition to speaking completely in English by the end. Listening back to this recording I noticed how the type of questions I asked changed and the jargon crept back into our discussion as we transitioned to English.

When transcribing interviews conducted in Bislama, I translated directly to English and inserted these translations as quotes into my thesis. Because of the similar vocabulary and sentence structure from Bislama to English, I would often translate automatically in my head when listening back to the recording. I felt that for the most part, the meaning was not significantly altered when translating between the languages, so I did not include the Bislama version in my quoted material. The exception to this was when I felt a Bislama word had no adequate translation in English, or the Bislama version was fundamentally important to the meaning portrayed, in which case I put it in italics and bracketed the English translation.

\section{Changes in direction}

Before leaving for fieldwork I planned on using focus groups and photo elicitation as additional methods. ${ }^{13}$ Once on Malekula I decided not to use these methods as they were not as appropriate for the realities of the field. Talking to people about tourism issues individually was more reliable in terms of organisation, and people would be more talkative about their opinions. ${ }^{14}$ After establishing there were some conflicting opinions and ongoing discussions over various tourism issues, I did not want my focus group to be interpreted as a place to reignite those tensions, or worse, for people to not feel comfortable turning up or expressing their opinion at all. As I was continually being labelled a volunteer, I also did not want my focus group to be understood as a workshop (frequently run by tourism office staff and other development-related organisations), implying that attendees be taught something by the convener. I also moved away from photo elicitation which I had initially considered as a potentially creative way for people to express how tourism affected their everyday lives. It became apparent that there were not enough tourists visiting Malekula for it to affect people's everyday lives in a way that could be visually captured in a photograph, rendering the method inappropriate. I kept photography for the already accepted purposes in Vanuatu: creating marketing materials, making memories, and having fun with friends.

A new method I adopted on my return to New Zealand was to bring online data into my analysis. Because of the relatively low number of tourists per week I was not able to meet many to get their perspectives. Many returned tourists would leave long and informative comments on hotel review websites, which turned out to be a treasure trove of tourist impressions and experiences from their holidays on Malekula. The emergence of online ethnography has raised important ethical questions of informed consent and the boundaries of public, private, and personal identities (Boellstorff and Nardi 2012). In using this method I had to tackle these issues according to the online public review sites I drew from. Hotel review websites are undeniably a public space on the internet and contributors deliberately design their post to be read by anybody (you do not have to be a member). Therefore I did not obtain consent to read such content or use it in a general sense for my research. I ensure anonymity

\footnotetext{
${ }^{13}$ Photo elicitation is the use of photographs or any other visual medium in an interview (Harper 2002). My initial idea was to ask participants to take photos of how tourism affects their lives, and use these in an interview to encourage conversation.

${ }^{14}$ Warrick $(2009,82)$ encountered similar issues when attempting group activities during her research in Vanuatu.
} 
by not using names and not quoting directly, as this could be Google-searched and traced back to the original post. 


\section{Pieces of the picture}

One October evening I wrote in my notes:

It's impossible to piece together the bits to make one coherent picture, because there isn't one whole picture to find, and I suppose that's the point you realise during fieldwork.

At the point of writing this, I had talked to many different people with sometimes contradictory stories and I was starting to uncover conflict that was simmering just beneath the surface of an outwardly cooperative indigenous tourism industry. I did not know who to believe, and worried my bias towards people I was making friends with was influencing how I interpreted other people's stories (see also Beech et al. 2009). The small island across from where I stayed was the site of a major dispute in 2013 regarding cruise ship tourism. There was alleged corruption and foul play, and the conflict remains unresolved in court, with cruise ships no longer making a stop at the island. I did not set out to investigate the situation, which would have resulted in a one-sided and inevitably simplistic portrayal. However, I still found myself comparing new information with what I had already learned in some desperate attempt to determine its validity. Thankfully a participant and friend reminded me that I was not trying to solve the conflict or find the truth of what had already happened, but instead listening to people's stories and experiences to understand how they feel about tourism.

After returning from fieldwork with a bag full of messy and diverse experiences, conversations, and observations, I struggled for a long time with how to write them into a coherent thesis. I was wary of linking together my findings artificially for the sake of a singular argument, and I felt uncomfortable imposing an outside theory on the very personal and particular experiences of my participants. However, I could not avoid this as it is one of the tasks of anthropology: to link ethnographic accounts into wider conversations about what it means to be human. I did not code in a scientific sense, I typed up my fieldnotes, read, re-read, and ordered them systematically. I listened to my interview recordings and re-read the transcriptions. I focussed on pulling out certain topics that re-occurred, linking these together across the data. After some time, I drew out the theme of ples as a force that simultaneously had an impact on my participants' decisions, actions, and experiences, as well as being fundamentally altered by the growing tourism industry on the island. I decided to ground my analysis in this theoretical discussion of ples in Vanuatu, and the concept of "place" more generally in anthropology. The next chapter explores the theoretical concepts of place and ples in depth.

James Clifford asserts that "ethnographic truths are inherently partial - committed and incomplete" (1986, 7). Furthermore, they are just one version, uniquely interpreted and inscribed by the ethnographer (Geertz 1973b). By choosing a theoretical grounding that shapes my analysis, it is inevitable that other aspects of the fieldwork data are left out. I made a decision early in the writing process not to foreground the intricacies of local-level politics and power struggles that were starting to surface on Malekula as a result of tourism. I made this decision mainly because of my short length of fieldwork; I felt I would need to stay much longer to understand the political issues well enough to do them justice in my representation. All of my participants were so open in cooperating and sharing knowledge with me, and I did not wish to ruin trust by exposing tensions I did not have a full understanding of in a document that could be used to fuel those tensions in the future. So, acknowledging the limitations and incompleteness, I have done my best to write the messiness and contradictions into the following story as I saw it and as my participants told it to me. 


\section{Chapter 3}

\section{Malekula: the ples}

The identity of places is very much bound up with the histories which are told of them...

The past is present in places...

(Massey 1995, 186)

The nose of our canoe crunched into the sand and we tugged it up to sit parallel with the others. Now on the island, my tidy vision of its landscape was disrupted and many smaller aspects came to my attention. I saw people, sitting chatting or playing guitar, waiting for the motor boat to take them to church on the mainland. There was some rubbish - a soft drink can and plastic bags - caught on coral and being pulled by the waves. Of most interest to me were the material reminders of past cruise ship days. A panelled hut with a falling apart roof had a service window and a fading sign that read 'kava - the local brew'. A concrete pot with painted red flames at the base - large enough for a tourist to stand in and pose - put Malekula's cannibalistic past on joking display. Two churches an old, dilapidated shell, and the new, clean concrete church, built with community funds earned from tourists during the years the cruise boats visited. They sat side by side, as if to attest to its own transformation. Set back from the beach loomed an ominous concrete structure painted mint green. I later found out this was the toilet block for cruise ship visitors, currently locked and unused, just sitting in silent anticipation of their possible return.

-Fieldnote vignette, 2016

A place owes its character to the experiences it affords to those who spend time there - to the sights, sounds and indeed smells that constitute its specific ambience. And these, in turn, depend on the kinds of activities in which its inhabitants engage. It is from this relational context of people's engagement with the world, in the business of dwelling, that each place draws its unique significance.

(Ingold 2000, 192)

\section{Ples and place as theoretical concepts}


This thesis draws on understandings of place as the theoretical underpinnings for the way that niVanuatu experience tourism bisnis in Malekula. This chapter gives a theoretical overview of ples as a ni-Vanuatu way of understanding the world as well as place a concept of academic interest, and how I use it to support my argument that rural tourism operators are in a continual negotiation with their land, culture, and history when making ples. This argument is predicated on the recognition that places are temporal, relational, and polyvocal. ${ }^{15}$ My opening vignette serves to illustrate the temporality of place, and how the past can be embodied in the materiality of the landscape, as well as the stories that are told of it. I also draw on the relational context of people and place, and multiple senses of place as key themes grounding my thesis. Later in this chapter I give historical context to Malekula and Vanuatu as my place of research.

I wanted to respond to numerous Pacific scholars' calls to utilise indigenous epistemology when theorising in the Pacific (Gegeo and Watson-Gegeo 2001; Hau'ofa 1975, 1994, 1998; Huffer and Qalo 2004). Ples in Vanuatu is arguably an indigenous epistemology. ${ }^{16}$ Ples plays a crucial part in constructing ni-Vanuatu identity, to the point where in the absence of kinship, it is a person's ples that defines social relations in a group (Bolton 2003; Curtis 1999; Jolly 1997, 1999). Land is the originator of kastom, history, and people (Jolly 1992; Rodman 1987). Furthermore, ni-Vanuatu's continual relationship with ples is evident in the language they use to describe their movements through it. Villages located in the hills are referred to as ontop, and a movement to and from is to go up or go down depending on the landscape (Bolton 2003, 68-69). Because of the centrality of ples in ni-Vanuatu constructions of personhood, history, and everyday life, I found it a useful framework to work inside with my research.

In academia, discussions of place hold significance in geography, philosophy and anthropology. ${ }^{17}$ Place is distinct from space, as Edward Casey writes that while space is an abstract and homogenous category, place is "the immediate environment of my lived body - an arena of action that is at once physical and historical, social and cultural” (2001, 683; see also Ingold 2000). I depart from Tim Ingold's use of place in suggesting that while landscape is the physical environment that we see, hear and touch, place and ples encompasses much more than this, expanding to emotional, spiritual and historical aspects, which can be (but do not have to be) embodied materially in the landscape. This is more a personal matter of language choice due to the meaning of ples in my particular fieldsite.

The first theme I draw on in my thesis is a point of focus in this chapter, it is the temporality of place. Landscapes are not a static physicality, but are dynamic through time as it "continually comes into being” (Ingold 2000, 153; Ashworth and Graham 2005). Doreen Massey draws attention to this in her fluid approach to places and their histories, arguing that "if the past transforms the present, helps thereby to make it, so too does the present make the past" $(1995,187)$. I opened this chapter with a fieldnote vignette to show an example of how the temporality of place materialised in my fieldsite. My own research did not focus on cruise ship visitors, primarily because cruise ships had stopped visiting the fieldsite three years prior. There was enduring social conflict over this issue and the case was still in court, but as I mentioned in Chapter 2, while I had many conversations about the cruise ships and their legacy was often tangible, I did not make it my mission to uncover what had "really" happened on the

\footnotetext{
${ }^{15}$ I use the word polyvocal to imply that a place has multiple voices or meaning. This follows Margaret Rodman’s (1992, 640) assertion based on ethnographic fieldwork in Vanuatu, that anthropologists should be approaching place within in a similar framework to how they understand the concept of voice.

${ }^{16}$ See Oli Wilson (2014) for a similar argument made about ples as an indigenous epistemology in Papua New Guinea.

${ }^{17}$ Many studies concerning place draw on phenomenology as a way to emphasize individual subjectivity, the body, and lived experience (Ingold 2000; Casey 2001; Jackson 1995). This could be a fruitful way to engage with place-based interactions with global tourism in future research.
} 
small island those years ago. Therefore, I used this vignette to show how the past in general, and tourism more specifically, becomes incorporated into the landscape through time and helps to make up the present sense of a place. I return to temporality in my historical account of Malekula and Vanuatu later in this chapter.

A relational context of people and place is the assertion that there can be no distinction between the two, as both are in a constant process of making each other. Rather than seeing landscape as a blank slate that humans build upon, Martin Heidegger (1971) argues that humans are always dwelling in a place before they build, making the decision and process that follows dialectical. Ingold draws on Heidegger and articulates this argument through a weaving metaphor:

Human beings do not, in their movements, inscribe their life histories upon the surface of nature as do writers upon the page; rather, these histories are woven, along with the life-cycles of plants and animals, into the texture of the surface itself $(2000,198)$

The understanding that humans are always creating "from within the world, not upon it" (Ingold 2000, 347) closely relates to ni-Vanuatu perceptions of the world. The term man-ples is powerful in showing an almost total integration of a person's identity and their place (Bolton 2003; Jolly 1992; 1997; Rodman 1992; 1987; Lindstrom 2011; Taylor 2015). Person and their place of origin are condensed in the identifying term, for example man-Tanna or woman-Malekula. This aligns with Casey's $(2001,684)$ assertion that "there is no place without self and no self without place", and is a good indicator that niVanuatu do indeed dwell in their ples which shapes the way they act and build within it. Aspects of a relational place in regard to tourism businesses are illustrated through ples-based motivations and plesbased challenges that influence entrepreneurs' decisions and activities in Chapters 4 and 5.

The final theme is how senses of place vary between individuals or groups and are therefore multiple, layered and polyvocal (Appadurai 1996; Corsane and Bowers 2012; Massey 1995; Meethan 2001; Rodman 1992). Analysing senses of place involves investigating different perceptions of the same place that are dependant on the individual, their values and background. In an ethnographic context this meant having conversations with tourists and locals about their understanding of a place and what being in it meant for them. For example, the landscape in Malekula may appear at first as unidentified coconut palm and jungle, but for man-ples these same features carry meaning that shapes social life, kinship, and gender norms. Other anthropologists have similarly commented on how on first entering a fieldsite one sees a particular place before learning the locals point of view and thus constructing a nuanced and deeper understanding imbued with historical and social experiences (Keesing 1978; Anderson 2011). Gerard Corsane and Jared Bowers point out that the complex layering of perspectives (that were influenced by and continue to influence other perspectives) sometimes compete or align at "vertical points of continuity" (2012, 249). I found this during my fieldwork particularly regarding issues of value, which I discuss at length in Chapter 6. I agree with Margaret Rodman $(1992,643)$ that "it is time to recognize that places, like voices, are local and multiple. For each inhabitant, a place has a unique reality, one in which meaning is shared with other people and places”.

\section{"Bifo"}

When talking about the island's history, Malekula residents would often demarcate time using the Bislama word bifo (before). While seemingly ambiguous and vague, for ni-Vanuatu bifo is laden with complex and significant meaning (Lightner 2007). In most instances bifo referred to the period before Christianity in Malekula, and was usually linked with ideas of kastom and ples. Kastom is the Bislama word that refers to "the knowledge and practices that ni-Vanuatu understand to be authentically their 
own, deriving from their pre-colonial past and from their place” (Bolton 2003, 6). The word kastom came into use around the same time as European contact. Lissant Bolton $(2003,6)$ describes the term as having no one specific use; it could often refer to features of pre-colonial practice that belonged to a group, for example kastom blong olgeta man-Malekula (the kastom of the Malekula islanders). Margaret Jolly $(1999,1997)$ adds that kastom is rooted in the land, making land integral to identity and cultural practice. Kastom does not, however, refer to a whole way of life, like the English word culture implies for anthropologists. Haidy Geismar $(2009,223)$ concludes that "kastom resists translation into both English and local languages; it retains power by application rather than definition, maintaining a powerful and extremely flexible ambiguity”.

Some of my participants used bifo to describe a time period when they believed kastom was stronger, meaning people could still draw on magic in their rituals and practices. For example, a participant walked me through her nasara (dancing grounds) explaining the different spaces designated for men and women during meetings. At the highest point on the small island we passed huge coral stones up to $1.5 \mathrm{~m}$ in height that had been erected, and she informed me that "bifo, our ancestors had access to magic, so they were able to lift these heavy stones up here. But now since Christianity we have lost this, so we do not have the strength to lift them anymore”. Bifo thus signifies a nostalgia for a time and practice that has been lost, perhaps in this way similar to the perpetual lament Matt Tomlinson observed in Fiji regarding kava consumption (2004; see also Farrelly 2009). Histories are built into the landscape and continue to define sociality in the present, for example through gender rules and the repurposing of nasara as an important tourist attraction. In this way, bifo also shows that the environment is in a constant state of becoming, as people continue to apply new meaning to the land which builds on the old.

Northeastern residents also used bifo to describe a time of conflict and violence that strongly defined the region. This was known as the conflict between people who lived by the ocean - man-solwaraand people who lived up in the hills - man-bush. Man-bush would attack man-solwara and would sometimes engage in cannibalism. These cannibal sites where victims were cooked and eaten are now sold to tourists in marketing material as representations of a "savage past" (Harewood 2009, 2). In an interview with an apu (grandfather) of the village, he told me about man-solwara being very afraid of random attacks, especially when visiting their gardens in the bush, and eventually fled to the small islands off the coast of the mainland for safety. Around a similar time to when the first missionaries arrived in Malekula (it was difficult to discern the exact timing or if it was causal), the two fighting groups made peace with each other. A chief from each group led the peace-making process, which was solidified by exchanging land, creating fictional kinship bonds, and marriages between groups.

When I did my fieldwork, the division between bush and ocean was not so pronounced, and several generations of intermingling kinship had sustained the peace. However, just as landscapes continue to embody their pasts, the bush was still seen by residents as more traditional and less connected to the outside world. People referred to ontop - bush villages - as places where cell phone reception was patchy, road access could be compromised, and women still could not drink kava. I did not hear the name man-bush being used to describe the residents of these places, but it had morphed into a somewhat comical name for someone (often but not always a young boy) who was wild or badlybehaved. Villages by the sea, on the other hand, had more access to amenities, main towns, and migrants from other islands, and were therefore considered overall more modern and connected than ontop.

The third way that people used bifo in conversations was in relation to technology, specifically how people used to conduct daily activities before the introduction of foreign technology. When helping to 
make laplap with a friend, she explained to me how, before the metal graters, people would use a specific rough palm bark to grate yams into a soft pulp. ${ }^{18}$ During a Small Nambas cultural tour, performers demonstrated how they made fire without matches, and scratched out coconut meat using shells. This re-enactment and story-telling of indigenous knowledge again illustrates the temporal aspect of place and peoples' interactions with it.

\section{Vanuatu historical context}

Vanuatu has had a long history of foreign visitors and residents, as early as the $16^{\text {th }}$ Century when a Spanish/Portuguese explorer documented a visit (Larcom 1980). However, as the bifo phrase implies, missionisation was the foreign influence that brought the most significant cultural shift for islanders in recent history. The Presbytarian, Anglican, and Catholic churches had enormous influence and through a process that has been called "psychological warfare" succeeded in converting the majority of the population to Christianity (Regenvanu 2005, 39). ${ }^{19}$ This led Joan Larcom $(1980,3)$ to suggest that foreign influence in Vanuatu is unique because missionisation caused a much greater cultural change in the everyday lives of villagers (especially on outer islands) than did the period of colonisation that followed it.

In 1906 the British and French colonial governments joined to administer the Condominium of what was then called the New Hebrides. This unique situation involved both governments independently operating their own education and judicial systems, but because its main purpose was controlling foreigners, islanders maintained a relatively high level or autonomy in everyday life (compared to other colonies). However, there were still significant transformations to ples, for example areas of the islands became categorised as either Francophone or Anglophone depending on the education system and dominant language at the local school. English, French and Bislama were the three national languages, and still are today. On Malekula, the language regions would often align with the dominant church in the area - Protestant was English, Catholic was French - adopting the mission schools already set up (Bolton 2003). In Northeast Malekula there was a strong Catholic influence, with a Francophone Catholic mission school and Mother Mary on display in many homes. Figure 4 shows a statue of Mother Mary wearing a salusalu (welcome necklace) in Vanuatu's national colours; she stands at the mission school overlooking the village below. Residents were either fluent or proficient in French, but almost always communicated in their local dialect or Bislama. The region would receive a higher proportion of French tourists due to the language opportunity (as is similar in other French-speaking parts of Vanuatu).

\footnotetext{
${ }^{18}$ Laplap is a traditional meal of root vegetables, grated to a pulp and cooked with meat and coconut milk in banana leaves under hot stones.

${ }^{19}$ Scholars of the Pacific have written extensively about the indigenisation of religion in the region, as a potential reason why the influence was so intense, widespread and long-lasting. There is a wealth of literature that is beyond the scope of this thesis (Tonkinson 1981; Lindstrom 2008; Lange 2006).
} 


\section{Figure 4: Mother Mary statue in Vanuatu national colours}

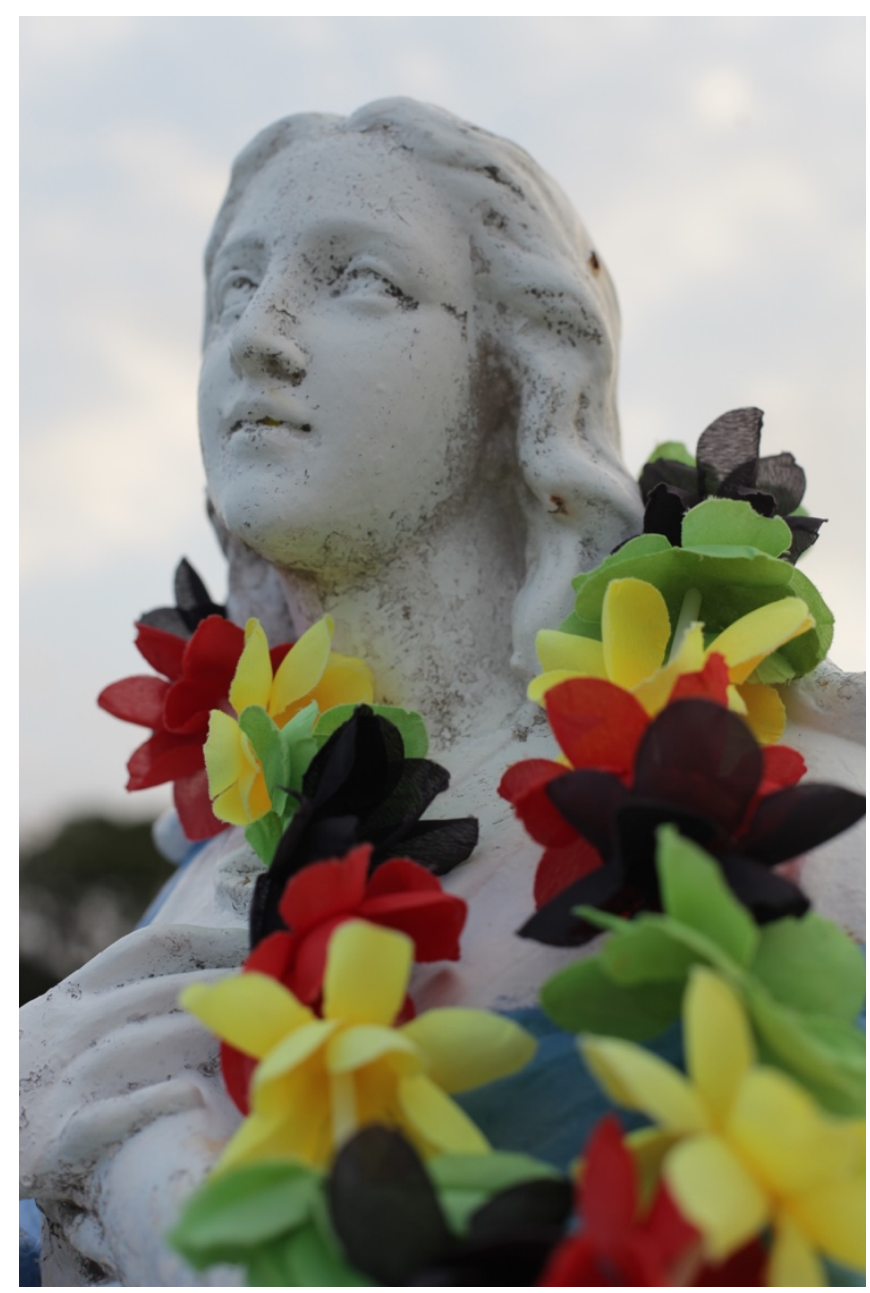

Source: Martin Bennett (2016b)

John Layard was the first anthropologist to write an ethnography in Malekula. ${ }^{20}$ Stone Men of Malekula (1942) was based on fieldwork Layard undertook on the Northeast island of Vao from 1914-1915. His studies centred around the maki (grade-taking) ceremonies that were central to social and cultural life. The book continues to be a "highly contentious source of knowledge for many Small Islanders" not only of Vao but extending to Atchin and further to the regions I did my fieldwork (Geismar 2009, 199). In an article about the book's continuing contestation and politics, Geismar points out the the resource is at the centre of land and leadership disputes in Vao, and photocopies of the book circulate the local populations.

The book has created a tangible platform for contestation, and facilitated both a consolidation and critique of anthropological and textual authority. Its absorption into the contemporary fabric of Small Island life accompanies an indigenous critique of the practice of anthropology as a knowledge-making discipline. It materializes the past in the present, and makes evident the contested nature of history in present-day discussions about land, status and kastom. (Geismar 2009, 200)

\footnotetext{
${ }^{20}$ Another anthropologist worth mentioning is Bernard Deacon whose posthumous publication was based on fieldwork notes and drawings in South West Bay (1934).
} 
In the 1960s and 70s, fuelled by a political consciousness and alignment with a distinctly Melanesian identity, ni-Vanuatu began movements towards independence. Thus began the transformation and positive re-evaluation of kastom, the first Prime Minister Walter Lini celebrating it as a more authentic way to move forward as opposed to foreign systems used under colonial administration. ${ }^{21}$ Following independence in 1980, kastom was frequently drawn upon by political parties as legitimisation for certain agendas and, according to Bolton, "became, by means of political discourse, constituted as a defining characteristic that united people throughout the archipelago" (2003, 15). Throughout the country proudly displayed in shops and homes are the national colours and the Y-shaped archipelago map on calico (Bolton 2003; Vaughan 2013). While the ambiguous and changing nature of kastom has caused confusion, it cannot be denied that it has fostered a strong sense of unity and nationalism over diverse and geographically distant islands that lasts today.

\section{Into the contemporary}

As I discussed in the Chapter 1, Vanuatu's role in the process of globalisation is complex and worthy of study. In relation to a focus on ples, it is particularly important to understand the dialectical process between ples and global flows that co-creates local contexts and phenomenoa (Trau 2012; Appadurai 1996). There are many avenues for exploration in this area, with a wealth of important literature in Vanuatu concerning migration (Lindstrom 2011), technology (Kraemer 2017; Meyerhoff 2016), gender (Rodman 2004; Bolton 2003; Cummings 2013; Jolly 1997), and the politics of material culture (Regenvanu 2008; Taylor and Rousseau 2012; Rousseau 2003; Geismar 2009). Since it is relevant to my topic of tourism and my observations in the field, in the following paragraphs I outline the changing economic environment in Malekula.

Like other Melanesian nations, Vanuatu's economy has often been described as a moral economy (McCormack and Barclay 2013b). The idea of a moral economy, first developed by E.P. Thompson (1971) and further popularised by James Scott (1976), aims to understand a predominantly subsistence farmer society, governed by a strong egalitarian ethic due to living so close to the margin of survival. The family, being at once a production and consumption unit, must make decisions based on safety and reliability which take precedent over long-term profit accumulation (Scott 1976:13). In times of crisis, community members rely on networks of kin and religion, sharing, reciprocity, and exchange. Trisia Farelly (2009, 320) writes that in Bouma, Fiji, the system of begging from family members is called 'ere'ere and keeps individuals from accumulating too much wealth. A similar form of demand sharing can be found in Vanuatu, which often puts people in a delicate balance between obligation and selfinterest. As Jermain told me in an interview, based on his father-in-law's wisdom: "If you lean on somebody's shoulder when you need it, that's ok. But if you lean on both they will drown. It is better to lean on each other, help each other."

Vanuatu is also often characterised as a gift economy as most famously theorised by Marcel Mauss ([1925] 1990). Mauss was ground-breaking in arguing that there is no such thing as a pure altruistic gift, and his ideas remain relevant today. In Vanuatu, gifts are bound by a three-fold obligation; to give, receive and reciprocate, becoming a foundational part of exchange and wealth redistribution (Mauss 1990, 17). Alain Caille (2010:183) draws on Mauss to suggest that:

the explanation for social actions does not lie in individual rationality or in over-arching holistic rules, but in networks, and in the trust that unites and binds together members of networks... it is the gift that creates networks and that it is the reproduction of those networks that inspires trust.

\footnotetext{
${ }^{21}$ Up until this point Kastom had been framed in opposition to skul (school) which was the primary arm of missionary conversion, and so signified a rejection of Christianity (Bolton 2003, 15).
} 
This context is important for my ethnographic analysis in Chapter 5 and 6, where I investigate how entrepreneurs forge reciprocal relationships with some tourists, as a form of ambiguous exchange during and after their encounter.

The transition from a fully subsistence economy to growing reliance on cash has had impacts on people's relationship with ples. A survey revealed that rice now makes up $50 \%$ of ni-Vanuatu diets, with the rest being island kakae (food) sourced from gardens (Mondragón 2013). This shift has inevitably changed the use and value of ples. Where people used to solely rely on the land for production and consumption, farmers must now juggle multiple commitments to provide, switching between money-making enterprises, growing food, and raising pigs for eating and gifting during kastom ceremonies. Cash-cropping has resulted in the repurposing of land for coconut or cacao plantations. Land ownership is patrilineal, and due to growing demand on cash-cropping brothers are having to alternate years that they use the land. I discuss land and its changing value through the process of commodification in more depth in Chapter 4.

Interestingly, money, while desired, is also seen as the reason behind many current social problems. Just as subsistence farming and all that this encompasses is equated with kastom, the infiltration of money and particularly commodification is equated with the loss of kastom. Money became an ambivalent concept used in a single word as the reason for difficulties in life from a lack of opportunities, to social problems like drinking too much kava, laziness, and land disputes. This sometimes became entangled with cross-cutting issues like gender, for example where kava consumption by women was a result of women having more access to cash and autonomy over how to spend it. People would also bemoan younger men who seemed only motivated to work for money, when before the community would work on projects together voluntarily. One participant who had seen the land alienation in Efate first hand told me that when land becomes money, these problems begin. On another occasion he said that money hemi spoilem yumi (money spoils us). Like Ashley Vaughan (2013), I found conversations on this topic very interesting because of my participants' critical selfawareness about their role in engaging with global capitalism.

While this contradiction over simultaneously wanting and bemoaning money made my fieldnotes messy and often contradictory, I came to realise this might fit into what Marshall Sahlins has called developman (1992). Develop-man describes the practice whereby Pacific peoples select what they want from capitalism, and transform their use of imported commodities and ideals through globalisation. On Malekula, residents only partially participate in the market economy, do not attach the same symbolic status to money as a capitalist consumer culture, and are still strongly influenced by tradition and kastom. One participant, Jack, explained it to me like this:

I talk to villages about how fathers should educate their children in order to maintain our culture. Because that is the most important thing money cannot buy. Our way of life, if you are hungry I will give food to you, if I am hungry I will come and eat at your kitchen...

The most important things now are: school fees, health, small things soap, that's all. After that we should keep the most important things and maintain our way of living. Then we will find we are satisfied. You will feel good, you can enjoy life. (Interview transcript $25^{\text {th }}$ September 2016)

Jack, and others I spoke to, upheld the islands as an escape from a life reliant on money in Port Vila or other countries. Although they acknowledged the pragmatic importance of cash, there was still a belief that by only using money for a few "essentials" ni-Vanuatu could maintain the culture and kastom that was most important. 


\section{Conclusion}

In this chapter I have introduced both the theoretical concept of ples and outlined how I use it to ground my ethnographic analysis throughout the thesis. As an indigenous epistemology, different aspects of ples fit well into many of my observations about the way ni-Vanuatu engage with and experience tourism on Malekula. I draw on academic understandings of place more generally as temporal, relational, and polyvocal, pointing to how they will frame the following chapters. The history and context of Malekula and Vanuatu given in this chapter have mainly served to show the temporality of ples. I explained how ni-Vanuatu demarcate time by using bifo, the missionary, colonial and anthropological influences, the independence movement, and the changing economy following Vanuatu's engagement with the global system. During all of this I have tried to show the fluidity of ples and time, not only how it is dynamic, but also how past events become integrated into the landscape and live on in the present, even if its interpretation and value continues to change. I will continue these ideas throughout the following chapters to show how entrepreneurs' everyday experiences of running a tourism bisnis are interwoven with their relationship to ples. The background information provided in this chapter is critical for gaining a holistic understanding of what was happening in 2016 within the tourism industry. A nuanced understanding of a place and its history, written as much as possible from the perspectives of indigenous people, must be the starting point of any ethnographic analysis of place and its impact on peoples' lives. The final section about the changing economic environment in contemporary Malekula provided context for my next chapter, where I discuss entrepreneurs' motivations for starting a bisnis and how this is the first step of them entering new and transformative negotiations with ples. 


\section{Chapter 4}

\section{Starting a bisnis: motivations and the building process}

In this chapter I examine entrepreneurs' motivations for and experiences of starting a tourism business in Malekula. A primary motivation for my participants was a self-reliant approach to income generation, which emerged from living in a ples where paid work was lacking and cash was increasingly necessary. It also provided an opportunity for ni-Vanuatu to build their prestige by having international encounters while remaining at home (as opposed to migrant work). I discuss how a touristic view of ples changes the land's value into a commodity that is bounded and commensurable, and the ramifications of this in Malekula. The ni-Vanuatu notion of collectively owned ples provides a backdrop and partial justification for the bungalow boom observed in the first decade of the 2000s. The boom led to stricter minimum standards and an accreditation scheme, which impacted the way that entrepreneurs made a touristic ples through building a bungalow to meet the standards. This chapter acknowledges Brigitte Bönisch-Brednich and Catherine Trundle's (2010, 9) assertion that "place is productive”, and shows that although ples can shape ni-Vanuatu actions and decisions, it is also a landscape where new practices emerge, a process which itself has a profound impact on the ples.

\section{Motivations: self-reliance at home}

The growing need for cash in everyday life and the lack of formal work opportunities on the islands is one of the most urgent issues facing Vanuatu today (Cox et al. 2007:14). It follows that income generation was the primary motivation for starting a tourism bisnis for all accommodation owners I spoke to, and many drew on ideas of self-reliance to further justify their decision to become an entrepreneur. Tutun Bungalow owners Joshua and Adara were particularly passionate about this issue, and our storian revolved around self-reliance and its necessity in the contemporary economy.

In the evening of the $25^{\text {th }}$ September I descended the steps to join a small gathering behind the restaurant kitchen. Joshua, Adara, their adopted daughter and her baby, and some other friends were sitting on chairs or on the pandanus mat storying. I sat down on the mat as Adara offered me sweetened tea and crackers. Adara was a small, confident woman with a warm and welcoming presence. Tutun was considered her business as she did the daily jobs of running it. Her husband Joshua worked at the nearby bank; he had not changed out of his uniform of shirt and black trousers and looked very smart. Joshua was a local activist on social issues, and I thought he spoke in an impassioned and at times poetic way. The conversation we were engaged in was about the drought in this area of Malekula. It hadn't rained for months, despite the fact that it was supposed to be the La Niña year that follows an El Niño. Two years of dry weather meant food crops were failing. It was hard to find island cabbage anywhere, market prices were high, and families were relying on rice to supplement meals. Joshua was well-travelled and knowledgeable about the rest of the world, which came through in his observations. He joked darkly, "we think of rice as island food, but it's not. It is grown in Malaysia and Indonesia, it is local food for 
them. But if those countries were also to have a drought right now... well then us here in Vanuatu, we'd all die!” Joshua went on "that's why," he pressed, "tourism is so important. It can provide us with a steady income, better than copra and cacao. So when times are hard like this drought, there is money to buy food."

In Vanuatu, subsistence self-reliance - the idea that the household can meet its material needs through farming - is a point of pride for island residents. This includes Joshua, who stressed later in our storian that "the best thing in Vanuatu that we are proud of is having our own food. That's why we must maintain it. We don't have money, but we can grow food... You won't find a life like this anywhere else in the world.” Ralph Regenvanu (2010) has implemented the idea into government policy and advocates self-reliance through revival of the kastom ekonomi - referring to indigenous modes of production and exchange for example yams, mats, and pigs (Taylor and Rousseau 2012; Regenvanu and Geismar 2011). John Taylor and Benedicta Rousseau point out that while self-reliance can align with neo-liberal ideas of providing for the individual, in Vanuatu the movement the concept "stands in contradistinction to that of good governance" and is nationalised by relying on informal state institutions such as "'the islands', the 'rural' or the 'grass roots'” $(2012,179)$.

In the academic literature these concepts have been described as "subsistence affluence", initially a term developed in a Papua New Guinea context (Fisk 1962; Stent and Webb 1975) but also extended to wider Melanesia including Vanuatu (Cox et al. 2007; Ellis et al. 2009). In my opinion the term is out-dated, and assumptions of wholly bounded and self-reliant societies make it inflexible to adapt to the modern day realities of globalised Pacific economies. Its continued use, according to John Conroy, "can still conjure up an image of languid island ease and plenty, while sometimes also encouraging a dangerous complacency" (2012:3). Joshua's understanding of self-reliance countered this as it is more flexible to the ples-based conditions of a hybrid cash and subsistence economy. He acknowledged the importance of cash, thus transforming the subject of self-reliance beyond food to include a money making mentality.

Money is needed most urgently for food in times of environmental crisis, but it is also required for other everyday expenses in even the most remote communities (Regenvanu 2010, 30). Essential costs that are a burden for many families are school fees and health care. Larger amounts of cash are needed for concrete houses or to enable travel within Vanuatu and overseas. Solar panel systems or generators require an investment but are increasingly in demand for running water, televisions, sound systems, fridges, and for charging devices. As Joshua pointed out, climate change and uncertainty is threatening the balance of the traditional economy in Vanuatu. Overall, I got a sense that although people value life on the island for its farming and decommodified lifestyle, money still plays a role in helping to fulfil people's desires and aspirations.

The lack of formal employment and precarious self-employment has led some to venture into tourism. Cash-cropping is the most widespread way to earn cash in Malekula, with cacao and copra (coconut meat used to make oil) harvested for export. Using only a bush knife to open fruits and extract the meat, and using the sun or fires to dry it out, the process is time-consuming and labour intensive. Many people turn to entrepreneurial pursuits like making bread, selling kava, running a store or a bungalow to supplement their farming. Only a select few hold government or private-sector jobs that provide a steady income. This is where the self-reliance theme continued as a motivation for tourism bisnis, as a way to provide an income for entrepreneurs and their children if they cannot find a job in the unstable economic environment.

Adara: In Vanuatu, like, many of the children go to school, but the government doesn't have enough work for all the children who have gone to school, come back, work. I no gat [It's not there]. Many 
children have the paper but, just... they stay in the village. Sometimes they go to Vila or Santo and try hard to find work. I no gat....

...That's why, like, it helps for us parents to - it's good if we set up some bisnis, so that our children - suppose they go school and then can't find a job. They can come back. Look after the bisnis, yes.

Joshua: Yes this is a problem in Vanuatu - the government doesn't prepare enough, they are more interested in the private sector. Because the government cannot do it by themselves. They cannot be the only one that provides employment. (Interview transcript $25^{\text {th }}$ September 2016)

Amongst many participants and the general public there was a dissatisfaction with the government's inability to address issues pertinent to islanders. While some complained about corruption and selfinterest, others commented on their tendency to only focus on urban areas. Furthermore, people did not expect the government to provide all the jobs, as Joshua said they are simply unable to. Therefore it was up to citizens to create their own economic opportunities, and to use a ni-Vanuatu metaphor "mekem rod blong mi" ("make my own road). ${ }^{22}$ In our storian, Hano drew on similar self-reliance ideas as a motivation: "Today, we can't find work anywhere, only the government will give work to you. But when we have a small business like this one, it's good. We give work to ourselves, so we keep busy.”

Another motivation for starting a bungalow was to meet and forge connections with people from around the world, something desired by many ni-Vanuatu as it contributed to status within the community. Owning a small business provided this opportunity without having the negative consequences of being far away from home during migrant work. Lani and Jameson especially emphasised this point during our storian.

As we approached Nowi bungalow in the tin outboard motor boat, the island looked like a low line of green until a few small wooden buildings came into focus. Removed from the island's village and with a retreat-like feel, I could see why Nowi had become a bit of a weekend haven for volunteers in the nearby area. Lani and Jameson catered almost entirely for expats and holiday makers, with return customers a point of pride. Over the drone of the motor Lani animatedly described some of her favourite and most interesting past guests, with her husband sitting behind and interjecting when necessary and possible. Lani wore a tie-dye singlet that day, the bright colours matching her vivacious personality. She often wore colourful numbers given to her by previous guests, each having its own story to tell. Lani and Jameson were pleased to hear I was from New Zealand, as they travel there every year to pick kiwifruit through the Recognised Seasonal Employer (RSE) scheme.

Vanuatu was one of the first Pacific countries to take advantage of New Zealand's RSE scheme launched in 2007 (Connell and Hammond 2009). The scheme offers work opportunities in the agriculture sector to rural ni-Vanuatu for a maximum of seven months per year. Although the primary motivation to migrate is income-generation, people were also keen to go overseas and experience a different place and culture, and make new friends. Migration is about more than just money, it is an important milestone for ni-Vanuatu that brings "connection, prestige, and thus an enlarged personhood" (Lindstrom 2011, 3). RSE and similar migration opportunities are highly sought after and inevitably many people miss out such as poorer individuals and women who are under-represented in statistics (Mckenzie and Winters 2008). For those who do obtain work in Port Vila or overseas the time away can be very difficult for both themselves and family at home.

Jameson and Lani have adult children and have embraced the challenges of travelling to New Zealand, but they still acknowledge the advantages of a home business. Their opinion was echoed by other

\footnotetext{
${ }^{22}$ See Ashley Vaughan (2013)and Margaret Mitchell (2002) for further exploration of the "road” metaphor in Vanuatu.
} 
participants who told me that a good thing about a tourism bisnis is that you can stay close to your community and family while your business travels over to you (see also Johnston et al. 2012). Bungalow owners expressed their love of meeting and getting to know new people from around the world. This is an alternative way to gain connection, prestige, and an enlarged personhood that Lindstrom $(2011,3)$ related to mobility and travel.

\section{Land commodification and the value of places}

This section analyses the process of land commodification through tourism, linking to wider conversations on how a place's value can change depending on perspective and over time. Knowledge and ownership of land is central to identity and culture in Vanuatu; it shapes and is shaped by kinship, social organisation and gender (Alatoa et al. 1984; Lindstrom 2011; Meyerhoff 2008; Regenvanu 2008; Simo 2010). Doreen Massey (1995) highlights how pasts shape the way a place is valued in the present, drawing attention to its temporality (introduced in Chapter 3). I use several examples from my fieldwork to illustrate how ples in Vanuatu holds diverse and multiple meanings to different people and through history, the result of which is an ongoing complex negotiation especially in relation to tourism.

On the $18^{\text {th }}$ of October 2016 my friend Naomi took me on a walk to visit one of her new gardens. We trod along a dusty path carved through the bush. I swung a bush knife by my side and Naomi pushed the wheelbarrow in which her young daughter sat under the shade of an umbrella. Every few minutes Naomi pointed out a cow tethered to a tree or a coconut plantation and told me who it belonged to. There were no fences to mark boundaries, but everyone who resided in these areas, even young children, had knowledge of the ples they belonged to. Land in Vanuatu is individually or collectively owned by a family or nasara and land tenure on the outer islands is still governed by the local kastom. ${ }^{23}$ On Malekula land inheritance is patrilineal, but can also be shared between families to form alliances or make peace after a conflict.

The value and nature of land itself can differ depending on its uses, history and potential future. This follows Massey's (1995) assertion that a place is not just defined spatially but also temporally. Naomi's newest garden, similar to the one pictured in Figure 5, provides an example of this. She had plotted out her section on the bed of a lak (lake) that had dried up from the El Niño year of drought. The remaining soil was fertile and ideal for planting tomatoes, lettuce, and island cabbage, all of which were struggling in regular gardens. Naomi showed me the boundaries of her section, which backed onto her mother in law's and beyond that an uncle's and many more plots people had cultivated. I asked Naomi how she came to acquire this piece of land, to which she replied "I just stood up on this section of land and said it was mine”. I learned that anybody was free to do this if they cleared their own area, because nobody owned the lak. Beyond the neatly planted section we stood on, a woman hacked at weeds almost as tall as herself with a bush knife, presumably clearing her area. The particularities of the space, its use for subsistence farming, and its temporary status (when monsoon rains hit it would be a lake again), gave this place a unique value which affected the rules for its use and ownership. The lak was evidence to me, as part of my understanding of land ownership more generally, that land can easily be collectively owned, shared, or not owned by anybody, depending on the context. However this does not work so well when the land can be capitalised for individual or collective profit, such as through tourism.

\footnotetext{
${ }^{23}$ Directly translating to dancing ground (Crowley 2003, 163), Tim Curtis identifies that in Malekula nasara is also "like a 'clan', in that it is an exogamous, social unit” $(1999,61)$.
} 


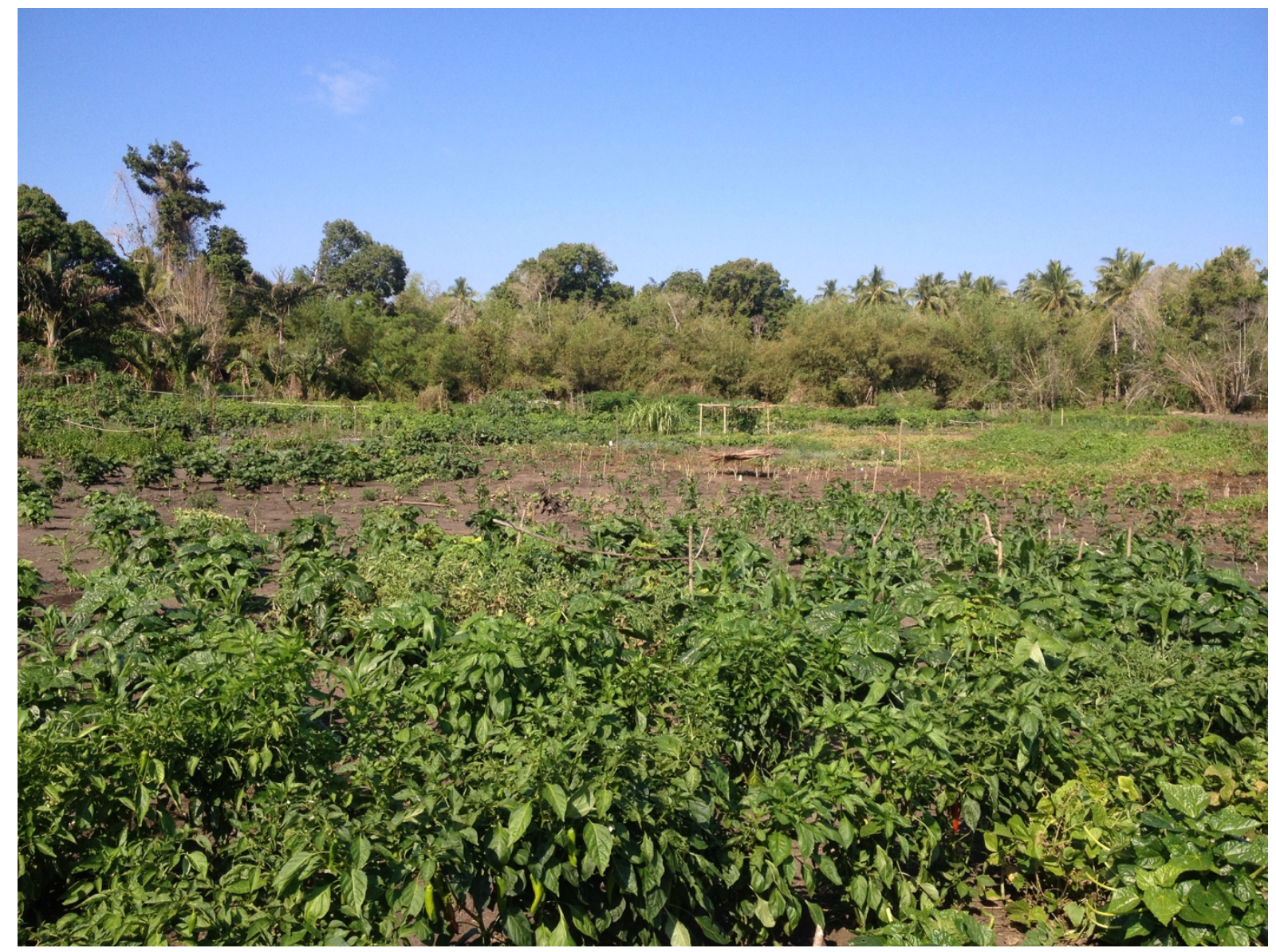

Source: Annabel Bennett (2016e)

The meaning and value of land is dependent not only on its physical characteristics, but also its history, spiritual significance and social organisation attached to it. An example to illustrate this is the nasara, sacred dancing grounds used bifo for namaki (pig-killing rituals) at grade-taking ceremonies, where namaki stones that symbolise the ritual still stand. As I discussed in Chapter 3, a participant walked me through her nasara, telling me about the history and meaning of this area to ni-Vanuatu. The ancestral clan communally own rights to this land, and although it is no longer used for the same purposes, the stones and gendered designation of space embody its important past. ${ }^{24}$ More recently, the grounds that are no longer actively used but continue to embody their past, have become valued by tourists and thus are transferred into the realm of the commodified tourism industry. At the former cruise ship destination, the sheer volume of people visiting the historical sights and bringing large amounts of money to the area, made management a huge challenge and resulted in a land dispute that by 2016 was still not resolved. In this instance, collectively owned land of historical and customary significance did not transfer smoothly into a different way of valuing land as a spectacle from which money can be made. By the time I visited, cruise boats were a distant memory (as I illustrate in the Chapter 3 opening vignette). Although tourists were able to visit the sites if escorted by a local and only visiting their own nasara, some community members no longer deemed it appropriate to run paid tours through the area.

\footnotetext{
${ }^{24}$ The gendered designation of space refers to the different areas that women and men sit during meetings, already mentioned in Chapter 3.
} 
For bungalow owners, the process of starting a business often began with them re-evaluating their land from a tourist perspective. Moris of Navul bungalow saw certain characteristics in his family's land and home that would be desirable to tourists, and this provided him his inspiration 20 years ago. He built his parents a new house on the property so he could renovate the house perched on the edge of a rocky cliff into a guest house with amazing ocean views. Moris' parents were not very happy about this at the time, and became even more perplexed when he did not receive any guests for a year. But Moris remained steadfast in his plan and eventually tourist numbers started to climb. When I visited, the bungalow was one of the busiest on the island. In his evaluation and decision, Moris changed the way he understood the value of his parents' house and the land it was on.

I discuss value in depth in Chapter 6, but briefly cover it here in relation to land commodification. Ryan Anderson (2011, Some notes on value) draws on David Graeber (2001) and Julia Elyachar (2005) to suggest that value is a relative measure of things, that places peoples' actions into "wider systems of meaning" in order to be understood. Therefore different groups, (tourists or locals for example) may give different values and meaning to the same place or object depending the broader symbolic meanings and social norms they draw from. When Malekula became an attractive tourism destination, residents such as Moris began to see their land from a different perspective and its value changed. This is not to say the land did not have value before it was a tourist destination. Similar to Anderson's (2014, 44) observations in Mexico, land and objects in Vanuatu were never worthless. Rather, value is a dynamic construct that can change through time depending on points of view. Touristic value is derived from a place having good views or beaches with safe swimming. Bungalow owners told me they were inspired to build where they did because of the proximity to the airport, a natural attraction like a waterfall, or a conservation area with lots of sea life.

When land becomes commodified, it transitions from being seen as worthless to valuable in the eyes of the state. In her ethnography of microenterprise in Cairo, Julia Elyachar (2005) argues that that transforming something's value into monetary terms makes it globally recognised but results in dispossession for local people. This can certainly be seen in Efate where sections of land are bought by expatriates to make resorts, resulting in indigenous people losing access to their life-giving land and ocean (Slatter 2006; Stefanova 2008). With more relevance to Malekula, dispossession means the disregarding of indigenous knowledge and meanings that ni-Vanuatu attach to land. Power comes into play when one way of valuing land is privileged over another. Through commodification land is "turned into individualised, legally-sanctioned, saleable pieces" (Anderson 2014, 54), and therefore fits uneasily with a society that may see land ownership as more fluid or collective. This can lead to social conflict, which in Vanuatu manifests in complicated and drawn out land disputes.

Coming in to land at Norsup airport passengers get a birds-eye view of a tarseal runway and the concrete shell of a terminal building without a roof. For any tourist that arrives in northeastern Malekula by air, this would be their first impression: a burned airport with only a square of corrugated iron for shelter. In fact, before 1995 the airport had a natangora roof with a waiting room, check in desk, and toilets. The building was set alight by arsonists during a long and messy dispute over the land on which Norsup airport was built (Joshua 2017). The government originally acquired the airfield land under the Land Acquisition Act (1992), which allows the government to acquire land for a public purpose in exchange for compensating the customary owners. This fundamentally changed the purpose and meaning of the land, which disrupted residents in the surrounding area. One friend told me that for many years during the heat of the dispute she and her neighbours were not allowed to cut across the land on the way to their gardens, adding a significant amount of time to their daily commutes. The Norsup airport land dispute differs from the previous stories told in this section. The land's contested status derived from a 
government decision made for the public good. I did not meet anyone who is resentful of the airport's instigation, it has increased opportunity, tourism, and mobility for all ni-Vanuatu. However, it was still built at least partly with tourism in mind, and thus stands as another example of how changing the value of a piece of land through ownership, purpose, or both, is a problematic process.

Ralph Regenvanu argues that there is a need for fundamental land reform in order to protect kastom law, customary owners, surrounding communities, and ultimately the nation as a whole.

Determining customary land ownership has become an obsession of government, reflecting its own obsession with promoting capitalist development. One of the principal resolutions of the National Land Summit was that the ownership of land by groups and not individuals was a 'rule of custom' described in article 74 of the Constitution that was common throughout Vanuatu, a view that is consistent with all anthropological accounts of Vanuatu's culture. (Regenvanu 2008)

The Norsup airport dispute, lasting two decades, is just one example of the way that land issues here become inscribed in a place. The broken terminal stands as an embodiment of a tumultuous past in the present day, as can be seen in Figure 6. Tourists with little knowledge of the context might see it and assume it is a rundown building with no money to fix it. Ni-Vanuatu, however, see the legacy of a conflict brought about by the prevailing notion of that place as valuable for industrial and tourist development.

\section{Figure 6: Norsup airport}

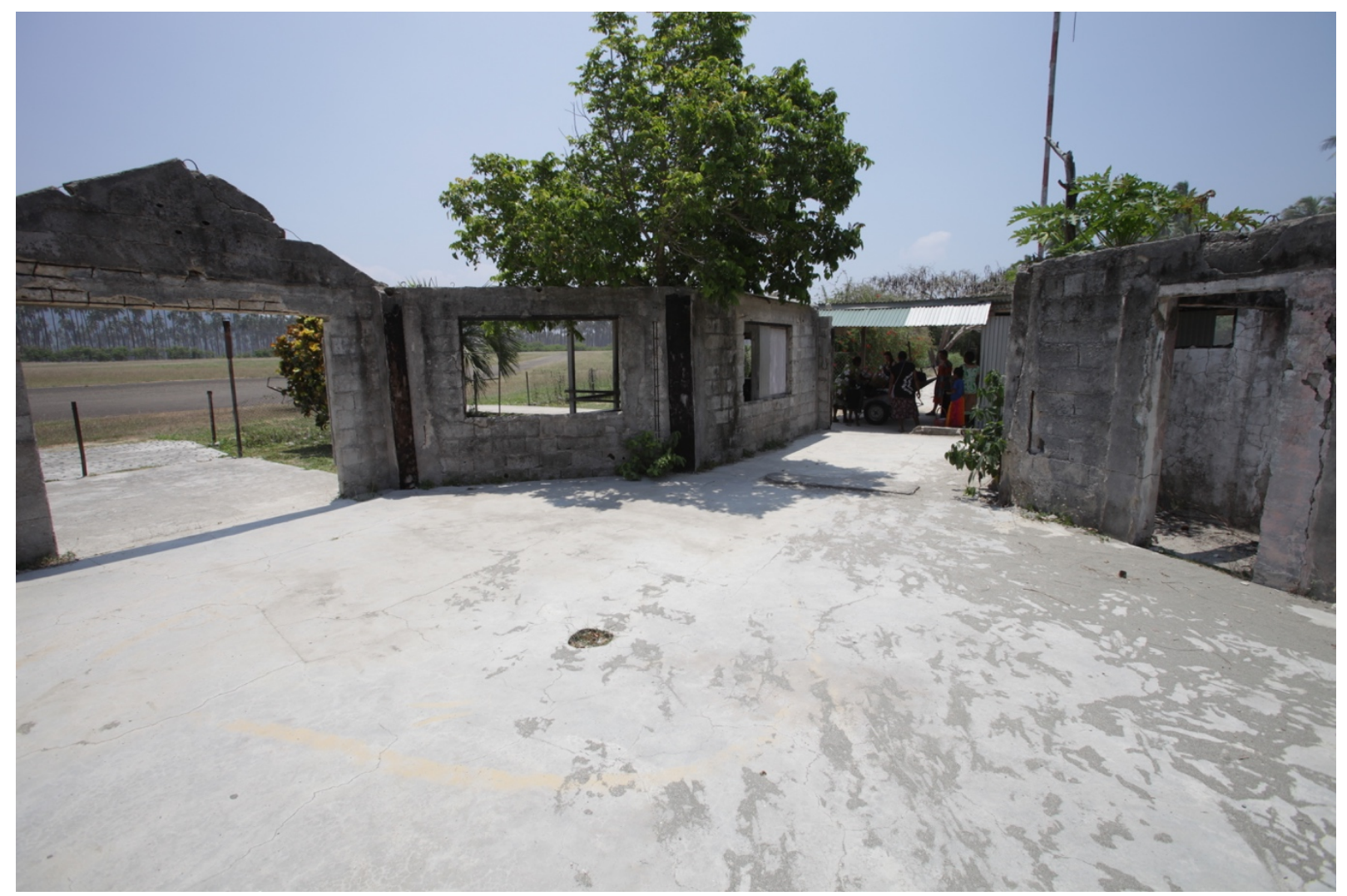

Source: Martin Bennett (2016c) 


\section{The bungalow boom}

I have argued that in Malekula, ples is understood as collectively owned. Even if a piece of land itself is owned by a small group or family, the neighbours and surrounding community still retain rights to be positively impacted by the use of that land (Regenvanu 2008, 63). It is this concept and its consequent shaping of ni-Vanuatu morality in island society that I argue has partly led to "copycat business" (Johnston et al. 2012:48). Copycat business describes the behaviour in Vanuatu when neighbours see a successful tourism business and set up another one almost exactly the same close by. Kalina from the tourism office told me about her experience of this:

...everyone comes to the office and says - as soon as they see an accommodation established in a community, and they see people suddenly coming, and they see there's cash flow, transactions are happening here - someone else goes and sets up another guest house just beside that one. And that sort of thing we don't want to encourage. (Interview transcript, 10 ${ }^{\text {th }}$ November 2016)

Copycat business, or monkey business as Kalina called it, implies deviant behaviour or the lack of economic rationality to participate effectively in a market economy. At the very least it was seen as undesirable in the tourism office. I, however, interpreted the phenomenon as acknowledging the complex rules of ples. Since ni-Vanuatu of a particular ples feel an equal ownership and stewardship of the culture, kastom, and history, it follows that they should feel an equal right to capitalise on that through tourism enterprise if given the opportunity. An emphasis on community and egalitarianism has led to many describing the rural economy on the island as a moral economy, which brings with it something of a "tall poppy syndrome" (Cox et al. 2007, 14). It would make sense then, that neighbours would not simply accept the economic disparity resulting from a successful business owner, and believe that they too can rightfully expect such benefits. Furthermore, it should not be assumed that entrepreneurs are purely motivated by economic factors. As I described earlier in this chapter, the increased personhood and status that comes from building relationships with foreigners could also be motivating ni-Vanuatu to start bungalows in close proximity to each other.

Since 2000 there has been a noticeable increase in small-scale accommodation providers on outer islands, what I call the bungalow boom (Johnston, Swain, and Howson 2012, 50; Scheyvens and Russell 2013, 31). Local participation in tourism through small business ownership was strongly pushed by the national government during the first decade of the 2000s, setting aside "reserved investments" for niVanuatu (see Chapter 1), alongside a Vanuatu Tourism Office marketing campaign called "Discover What Matters" promoting travel to the outer islands (Vanuatu Tourism Office 2016). Additionally, the government expanded its support by setting up provincial tourism offices, with the slogan Turism hemi bisnis blong yumi evriwan (Tourism is everybody's business) to encourage more local involvement. All these actions contributed to a bungalow boom. Building accommodation was a popular choice in rural areas due to their ease to build from local materials; ni-Vanuatu regularly built and took pride in their houses so it became a viable option for farmers to build tourist accommodation. Soon there were bungalows on most outer islands, but they were sitting empty for most of the year (Scheyvens and Russell 2013). In response, the government increased their regulation over the industry and introduced accreditation and minimum standards. This had wide ramifications for Malekulan entrepreneurs, which I discuss in the next section. 


\section{Building to the standards}

An entrepreneur's engagement with making ples is possibly clearest when building their tourist bungalow. I suggest that their building process is one of place making in that it takes investment, patience, and an element of risk. Added to this is an ongoing struggle over whose knowledge counts in the creation of an appropriate tourism enterprise, articulated through meeting minimum standards and accessing adequate training.

Matur was a very recently opened bungalow, which Enzo and Jasil - a young couple with three children - had built themselves. There were little signs of resourceful ingenuity everywhere like hammocks made from old fishing nets and a giant clam shell as a hand washing sink (see Figure 7). When I commented on this Enzo laughed and said "yes, here in Vanuatu we like to take white man ideas and turnem lil bit (change them a bit)". It was easy to see that a lot of hard work and thought had gone into every detail. It had taken Enzo and Jasil five years to build Matur. It all started when Enzo had the opportunity to go fruit picking in New Zealand, where he earned some money and saw some guest houses there that gave him the idea. They used this money to invest in materials like bamboo, timber and natangora roofing, all of which had to be bought in Lakatoro and transported by boat to the small island. For the next few years Enzo worked on a construction site on the mainland and they used that income to fund the build. It was a gradual process, making small investments only when they had the money. Jasil used the words "slow slow" to describe the building period and also post-opening trying to get their bisnis off the ground. She told me that Enzo was keen to go and work on a fishing boat again to supplement income but they wanted to get the bisnis well established first so she could run it solo. The family did not live at the bungalow site, but instead a 10 minute walk away in the village. They were planning to build a family home out by the bungalow so they could live there permanently, but "slow slow". 
Figure 7: Giant clam shell bathroom sink

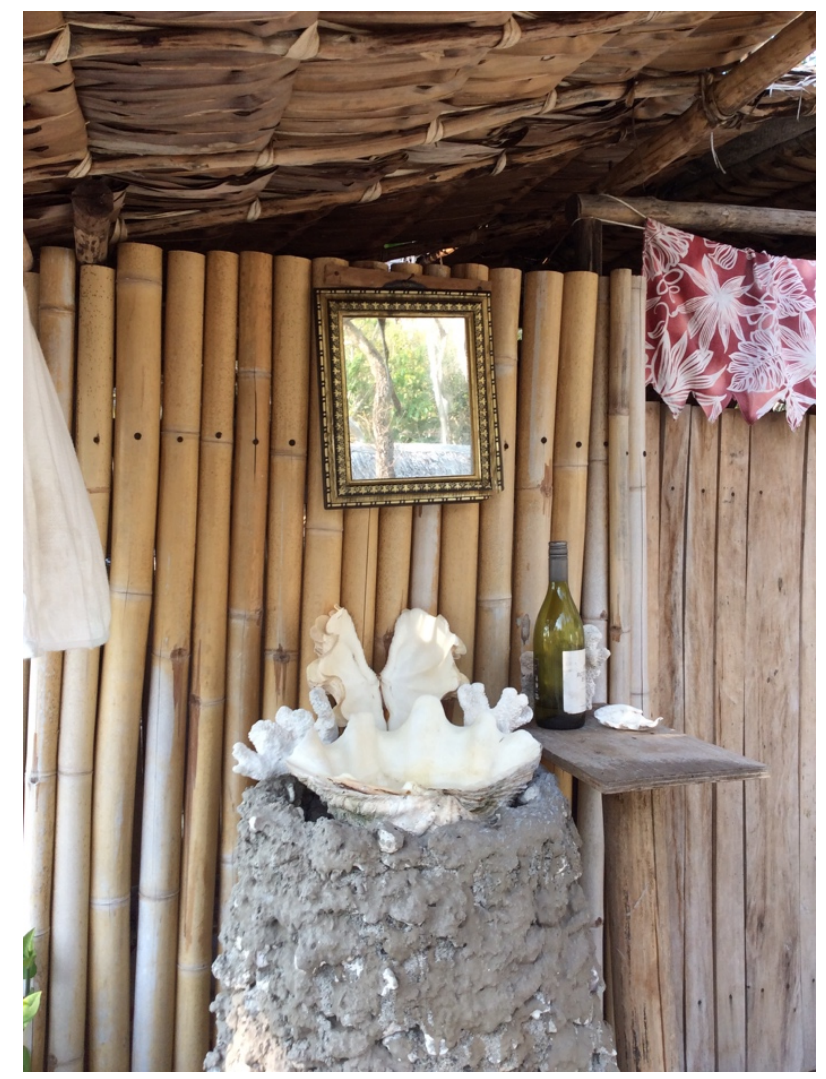

Source: Annabel Bennett (2016d)

From these interactions I realised that patience and persistence were important virtues when starting a tourist bisnis in Malekula. Jasil told me that while many people like tourism and have their own ideas of starting an enterprise, they often do not realise the investment and commitment it requires. She said you have to commit to it long-term, and never stop thinking about it. Every night you must plan what you are going to do the next day, then when you get up in the morning you must follow through and do it. This kind of mind-set contrasts to those associated with other island bisnis like a kava bar or store. These enterprises come and go, open and close as the entrepreneur's needs and opportunities change (see Curry 2007 for a Papue New Guinea example). Tourist bungalows generally took many years of planning and investment (Matur was not the only place built over a number of years), making them a more permanent fixture. I attribute this to the formalisation of the industry through the Department of Tourism provincial office and the minimum standards in place for small businesses.

In response to a boom in bungalow operators, the Department of Tourism developed minimum standards for small tourism enterprises in 2013. This included support documents and an accreditation scheme (Garoleo 2013; Department of Tourism 2017). Accreditation is needed to gain a business licence from the Provincial government, which in Malampa is monitored and enforced by the tourism office. In my participants' view, accreditation is associated with becoming part of the Malampa Travel call centre website and booking agency, allowing access to much needed marketing and promotion. The standards and guidelines aim to improve the quality of small tourism ventures, particularly bungalows, by targeting such decisions as location, building materials and fit-out. The guidelines state that:

Many tourists and visitors to outer islands and rural areas do not have unreasonably high expectations, as long as their basic needs are satisfied. For example, most people would expect a 
quiet and comfortable place to sleep, a toilet, a shower, access to food and fresh water, and that all of these facilities and services are clean and well presented. (Garoleo 2013, 10)

Despite these being identified as "basic needs" in a tourism context, most Malekula islanders cannot afford such luxuries, and depending on remoteness, providing these services is very challenging given the lack of existing infrastructure. Setting up alternative forms of electricity and water sources is an inhibiting large cost for entrepreneurs. Figures 8 and 9 show classic examples of rooms and facilities that meet the standards specified for a bungalow. All bungalow owners I spoke to had an alternative source of income before starting out or during their build. This shows that while tourism is promoted as an industry that benefits everyone, in terms of business ownership only families that are already wealthy can access this opportunity.

\section{Figure 8: Master bedroom set up to receive guests}

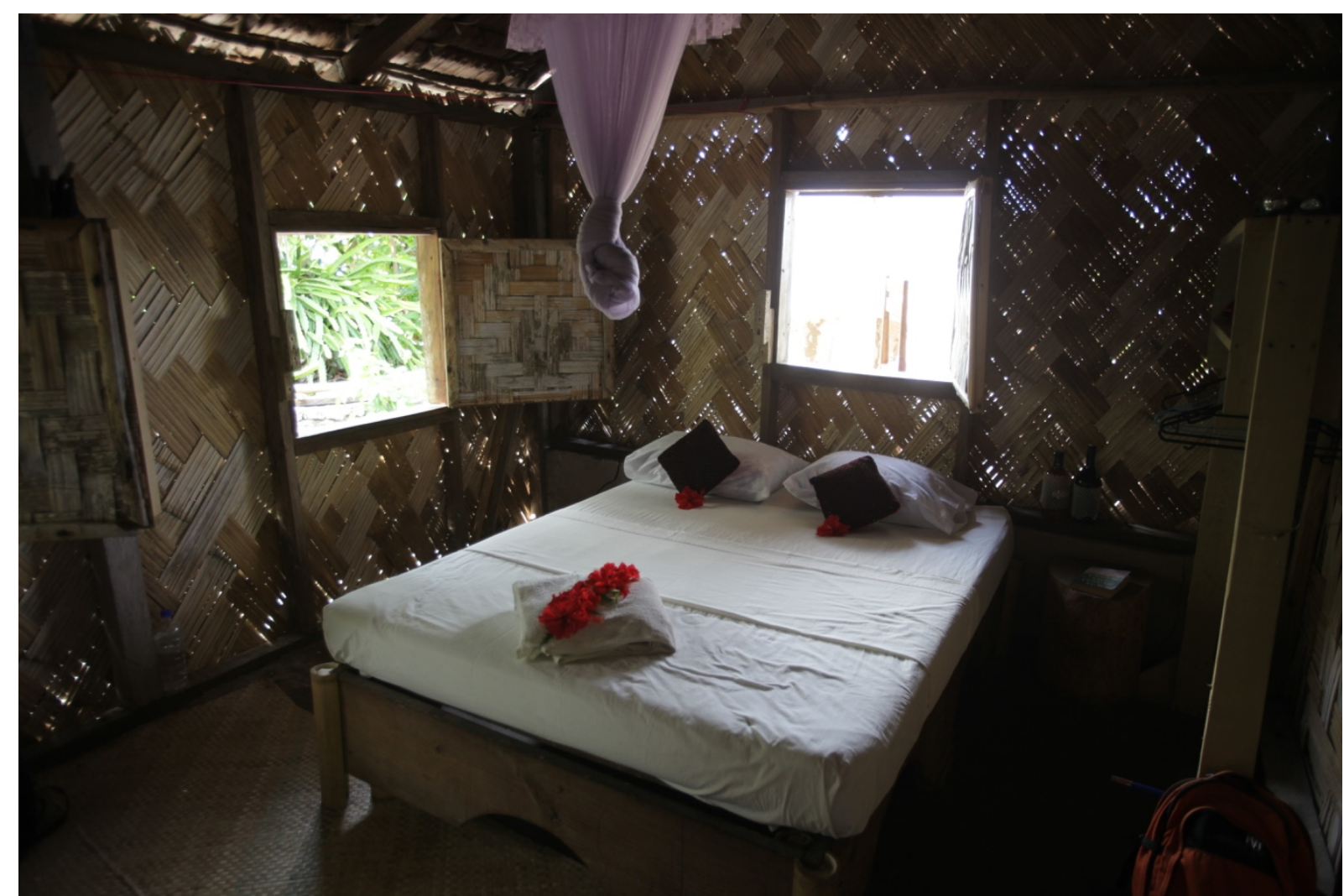

Source: Martin Bennett (2016a) 


\section{Figure 9: Bucket-flushing toilet with a soak-away septic system}

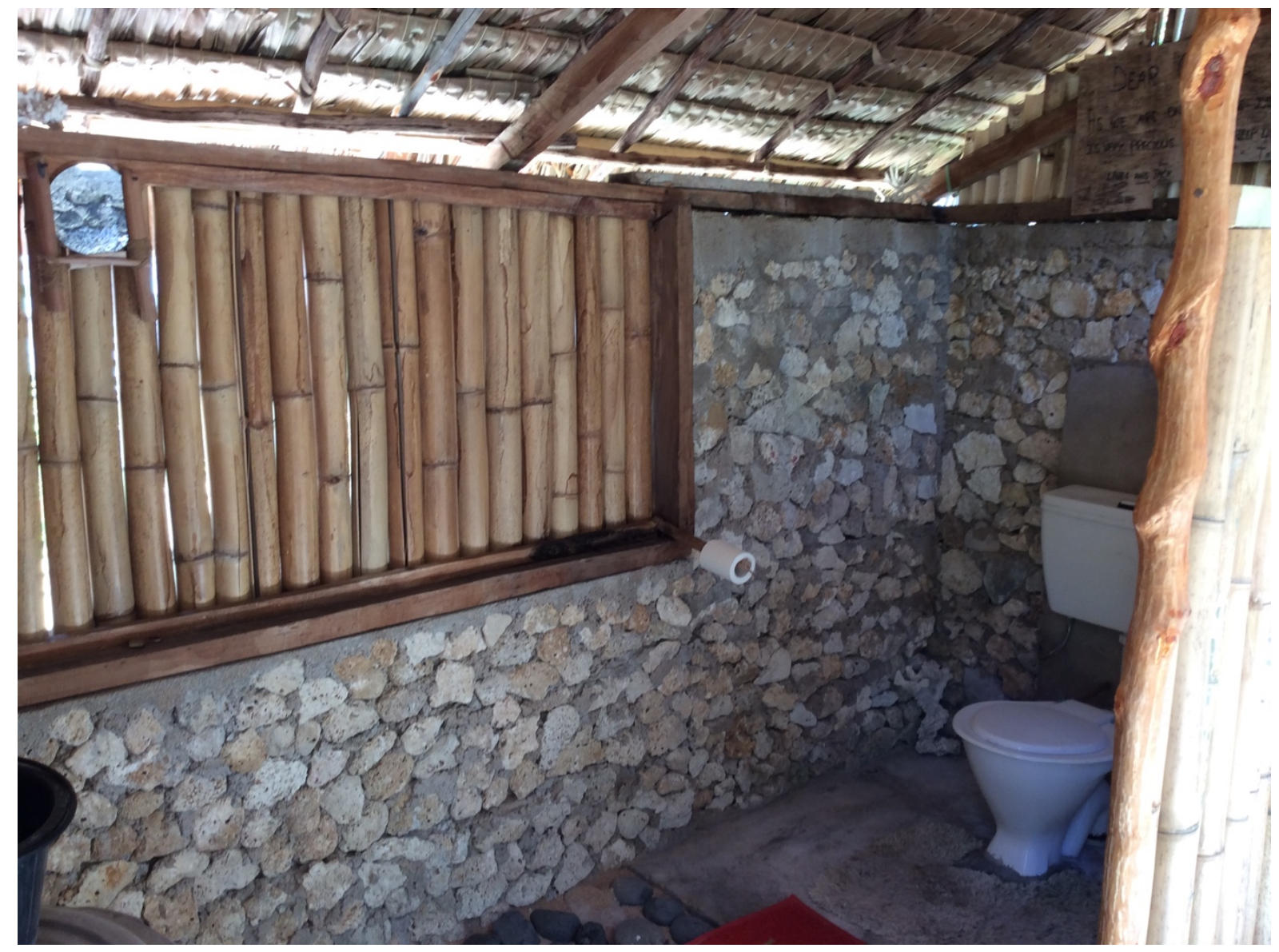

Source: Annabel Bennett (2016c)

Tourism office staff provide ongoing support and advice for entrepreneurs working to meet the minimum standards. Kalina informed me that locals often do not have knowledge of the fundamentals of building a bungalow:

So we have to teach them right from scratch. So we give them the measurements of the rooms, what the real wood actually required, what sort of things you need in the rooms what sort of facilities you need in the rooms. Things like toilets, room measurements, even putting a table in the room, cupboard in the room. Just the little things. People don't know. So we help them with that. Even choosing the right site to build the accommodation on. Those things they don't know. So they need to start from scratch and then we take them up. Once they are there then we teach them how to do the housekeeping, how to make a bed, how to do the cooking, what sort of food do you make... (Interview transcript $10^{\text {th }}$ November 2016)

This step-by-step support regarding layout, design and materials is reinforced in bungalow guidelines (Garoleo 2013). At times the privileging of expert knowledge undermines existing local environmental knowledge in the document, and does not recognise the practical reality on outer islands, for example when the author suggests an architect visiting the site to decide on the best position and structure of a house (Garoleo 2013, 20). For some participants such information was contradictory and confusing. For example, tourism is described as "the opportunity and ability to experience how local people live and to share some part of that life with them” (Garoleo 2013, 9), yet in order to receive tourists locals must change their ways of doing and building things to fit foreign expectations. This led some entrepreneurs in remote places with less access to consultation and support to build houses using concrete because of 
its association with modernity and wealth. In fact, the Department of Tourism recommends using local materials, but built in a design that differs significantly from traditional local housing (Garoleo 2013, 82-84). Contradictory information like this meant that some of my participants had to start over or make significant and expensive alterations to meet standards, which delayed their building process.

As well as the tourism office staff, many owners mentioned TVET (Technical Vocational Education and Training) as a source of training and support when getting their tourism business started. TVET is an AusAid initiative that has many branches, one of which is vocational tourism training for entrepreneurs (TVET 2017). They run workshops on cooking, social media, tour guiding, and bookkeeping. Bungalow operators Jermain and Valea from Mesal Bungalow were particularly grateful to TVET for these training opportunities and they attributed much of their tourist knowledge to the workshops they attended. During a storian, Valea told me that:

TVET training helped us a lot. Because say you don't go to school for it, you didn't learn to become a manager or something like this. So this kind of training helped us a lot so now you can make your business, look out for your expenses. So we have been to lots of TVET training. We can't miss one! They know us well, because any training we go to it. (Interview $5^{\text {th }}$ October 2016)

This kind of training can be understood in a development context as capacity building. Lynne Phillips and Suzan Ilcan describe the aims of capacity building as "assisting people to acquire particular skills and participate in activities that lead to social and economic change” (2004, 393). They argue that capacity building is a "technology of neoliberal governance" (394) that puts the responsibility on individuals to gain new knowledge and skills that link them into a market-oriented world. While training was highly sought after and appreciated by many participants, I was uneasy about its tendency to undermine existing knowledge. I asked a friend who worked at Mesal Bungalow about her tourism training in Santo. "It seems to me ni-Vanuatu women know how to cook so well from a young age, what did the tourism training in cookery teach you that you didn't already know?” I asked. She replied with a laugh "oh, you know, to prepare salads, decorate... hygiene too".

It is not my intention to criticise the valuable work that the provincial Department of Tourism, the Malampa Travel call centre, and TVET do. All of my participants stressed to varying degrees how much they have benefitted from and continue to rely on the support that these institutions provide. My analysis in this section has rather been aimed at the wider system of international tourism, and how this impacts on people at the village and provincial level when "making ples". In some participants' narratives there was a certain ambivalence towards tourism and its overarching expectations and management. Their contradictory accounts showed a strong willingness to meet standards and improve the quality of their bisnis, alongside a perhaps quieter confusion over the bureaucratic system into which they must fit.

\section{Conclusion}

In this chapter I discussed entrepreneurs' motivations for and experiences of starting a tourism business in Malekula. Ni-Vanuatu were motivated to start a tourism business in response to the changing surroundings of their place, which predominantly involved a growing influence of cash in the economy, and the adverse effects of climate change. The building process of making ples involved owners valuing their land differently, which led to complex and sometimes disputed negotiations. This was because different systems of value had to co-exist in a place when the prospect of tourism was introduced. The understanding that ples is collectively owned was partly responsible for the bungalow boom, which resulted in the Department of Tourism implementing stricter minimum standards for bungalows. This chapter has highlighted how places can be productive and encourage new activities (Bönisch-Brednich 
and Trundle 2010). By re-evaluating their situation through dwelling and building, residents entered into a complicated process of ples making. In the next chapter I shift my focus to how that same ples can constrain the people that live there, in non-physical and physical ways, interpreted by my participants as challenges that they must try to overcome or live with. 


\section{Chapter 5}

\section{Ples-based Challenges}

It's true, [tourism] is not a... it's a bisnis where it is hard.

You must stanap strong [be strong] to work in it.

(Olena, interview 24 $4^{\text {th }}$ September 2016)

In Chapter 4 I explained in depth how entrepreneurs, understand, make, and transform ples through tourism. In this chapter I show how ples equally shapes the actions, behaviours, and experiences of entrepreneurs to reveal more of the "relational context" of people and ples (Ingold 2000, 192). I analyse the challenges that those working in the tourism industry on Malekula face, that emerge from the ples in which their bisnis is embedded. During our recorded storian, which resembled a semi-structured interview, I found that my question about challenges invariably received enthusiastic and detailed responses from my participants. Partly because of this, I have dedicated a chapter to the topic in my thesis, but it also contributes to my overall argument by revealing how entrepreneurs' everyday experiences of running a tourism bisnis are interwoven with their relationship to ples. I divide the challenges broadly into: those that participants identified as being out of their control, marketing, the everyday challenges I noted during participant observation, and co-operation with the wider community. Some of these challenges are in various ways related to social capital, a theory developed by Pierre Bourdieu (1986) that I draw on to frame arguments in this chapter. I show how operators both expended social capital and worked to build and maintain it with new tourists and their existing wider community, which was a necessary part of their experience running a bisnis that is socially embedded in ples.

I use Bourdieu's definition of social capital, described in the English version of the chapter "Forms of Capital" (1986, 248-9), as "the aggregate of the actual or potential resources which are linked to possession of a durable network of more or less institutionalised relationship of mutual acquaintance and recognition... which provides each of its members with the backing of the collectively-owned capital, a 'credential' which entitles them to credit, in the various senses of the word". So being part of a network of connections, all of whom have their own social capital, is fundamental to individuals acquiring and expending social capital themselves. Bourdieu makes the vital point that these networks are "not a natural given, or even a social given" but rather they are continually maintained to "produce and reproduce lasting, useful relationships that can secure material or symbolic profits” (1986, 249). He writes that this is principally done through exchange, in a wide sense of the term, which builds and maintains friendships and trusting relationships. While Bourdieu goes on to explain the various ways that social capital can be built up by elite classes to concentrate their capital within an exclusive group, the above explanatory points are most appropriate to frame my own ethnographic analysis. Tourism operators build their connection with tourists by exchanging authentic experiences, and as a result are able to tap into their social capital by advertising through word of mouth, receiving gifts or maintaining 
longer-term relationships after the initial encounter ended. Likewise, they also actively engage in maintaining their web of social relations at the community level, so that they can expend social capital in this arena, and function as a successful business viewed appropriately by the community.

\section{"Beyond our control”}

Those working in the tourism sectors identified a couple of major events that resulted in a drop in tourist numbers and hurt their businesses significantly. These were Cyclone Pam in early 2015 and the degradation of the Bauerfield international runway in Port Vila causing Qantas and Air New Zealand to discontinue their services indefinitely in 2016. Cyclone Pam was devastating for some parts of Vanuatu, with Tanna and Efate being the worst hit. Malekula was not in the main path of the cyclone and escaped extensive damage. However, in the months following the disaster, tourism businesses started to feel the effects, as tourists were not choosing Vanuatu as a holiday destination. One bungalow did not receive a single international guest for 6 months in 2015. The Malampa Travel call centre recorded that the number of visitors dropped from 600 in 2014 to 425 in $2015 .{ }^{25}$ In early 2016, Air New Zealand, followed by Qantas (which has now resumed a code-share), discontinued their flights and code-share with Air Vanuatu due to runway degradation (ABC News 2017; NZ Herald 2016). Although Air Vanuatu still operated on this route, tourist numbers dropped drastically which harmed business all over the country. On my plane I was one of five or six internationals, the rest being ni-Vanuatu returning home from seasonal work. Some participants also identified the domestic flights and their unreliable nature as a deterrent for tourists to travel to outer islands. Hano told me during our storian that he had to deal with a number of guests whose flights were cancelled (sometimes a flight is cancelled if not enough seats are booked), ruining their plans and giving them a negative impression of their island experience.

Another challenge that participants conceived of having no control over was Malekula's remoteness from Port Vila and the rest of the world. A tour operator once asked me, "the rest of the world, they don't know about us here in Vanuatu do they? Because we are at the bottom, and a long way away" (Fieldnotes, 2016). He felt that the fact of being "unknown" to many posed a serious challenge for tourism business marketing. The opinion contrasts with a general tourist perspective that destinations are more desirable if they are remote, "untouched" or "off the beaten track" (Cole 2008, 145). However from a local perspective this was the major concern communicated to me throughout fieldwork, and one of the reasons why cruise boat tourism was so popular among ni-Vanuatu operators - because boats could more easily access remote locations.

During our storian, Joshua identified these challenges, particularly environmental ones, as "beyond our control. Nature has caused it. We can't... we must cope and find a way”. ${ }^{26}$ Tourism operators felt a lack of agency in relation to being able to impact them as an individual, but interestingly this did not weaken their commitment to the bisnis and hope for the future. They expressed to me a positivity that tourist numbers would increase, and the runway upgrade would soon be complete. Operators identified patience and perseverance as key attributes in maintaining a bisnis (especially in its early stages) in the context of structural limitations that were out of their control. Again, the phrase "slow slow" was frequently used in relation to these obstacles.

\footnotetext{
${ }^{25}$ The call centre numbers are only those bookings made through them. It does not account for direct bookings, so it can be assumed both these numbers are less than the total number of visits to Malekula.

26 "Control" was a motif that Johnson, Howson, and Swain (2012, 34) picked up on in the language of tourism operators on outer islands, and could be an area to explore in future research.
} 


\section{Marketing and social capital}

As a result of being located on a remote island, the biggest challenge my participants communicated to me was marketing their business. Their marketing strategies have changed over time in response to institutional and technological changes, but throughout this operators tended to expend their social capital as an effective way to market themselves through word of mouth and exchanging authentic experiences in the tourist encounters.

Nesa Bungalow owners Hano and Olena told me that they were one of the first accommodations on the island when they began over a decade ago. In the following conversation, I learned about what it was like starting a business before the institutional support of the provincial tourism office and the Malampa Travel call centre. The only engagement with government seemed to happen when purchasing a business licence.

Annabel: So did you get that [business licence] from the tourism office?

Olena: No, Malampa Province.

A: Did they help you set up this place?

Hano: No.

A: [pause, looks exchanged and A laughs nervously] so you just built it, paid, and then...

H: I just made it, then bought the licence. Then I had to advertise it myself. Yes I had to do it all.

O: The call centre came later

H: The call centre has been around for... only three years?

O: Three years.

A: So before the call centre came, how did you advertise?

O: We'd ring our friends, they'd come and go back -

H: - it's really hard because if we wanted to make a website - that costs money. 20,000VT for a website I think. I used to work at Air Vanuatu, so I've got some friends [there]. So we talked... They too have some... they are operators too in Vila. So I called them and told them we have a place like this, like this, like this... We worked together.

(Interview transcript, 24 ${ }^{\text {th }}$ September 2016)

This is quite a straightforward example of how Hano spent his own and his friends' social capital to expand his bisnis' influence in its early days of operating. Nonetheless, it depicts quite a common practice in Vanuatu: utilising inter-island connections and relationships between friends, colleagues, and kin. Maintaining these connections generally involves the exchange of food and mats, often institutionalised in a marriage or bride price payments. When flying or going by boat between islands I observed the vessel being loaded with these kind of items, travelling as freight to somebody who would pick them up at the destination. As Bourdieu (1986) points out, maintaining relationships takes ongoing effort, but means they can be utilised for social gain.

For operators in the 1990s and early 2000s, the only form of formal advertising was in the Lonely Planet Guide. Moris told me that his first advertisement through this medium happened unbeknown to him. The first guest they received was the guide author, but this information was not passed on to Moris (either because it was covert or a misunderstanding due to language barriers). The next guests who came 
said they had heard about Navul through the Lonely Planet, and showed it to Moris who turned to the back page to see a photo of his first guest as the author! The current Lonely Planet $7^{\text {th }}$ edition (D'Arcy 2012) has quite a comprehensive (if a little out-dated) section on Malekula that features most of the tourism operators, and a few tourists I met had made their choices based on this information.

The opening of the Malampa call centre in 2012 was pivotal for tourism operators, it provided a centralised website which gave each bisnis an equal advertising space and acted as a middle man for tourist bookings. The call centre also utilised their connections with national organisations and international travel agencies to promote on behalf of their clients. Rosalie explained the call centre structure to me as being a non-profit cooperative. The call centre takes a $10 \%$ commission from every booking they sell:

So the call centre is a booking agency. But it's a non-profit organisation owned by MIBTA, Malampa Island Bungalow Tourism Association. So every bungalow owner and tour operator, everybody owns the call centre. Business belongs to all of them. So I take bookings, because not everyone has telephones or access to the internet so we do that on behalf of them, make the sales. Then we pay them and take $10 \%$. (Interview transcript, $15^{\text {th }}$ October 2016)

While most tourism operators were satisfied with their internet presence being shared on the call centre website alone, Moris also advertised through AirBnB and Booking.com. Navul bungalow had a satellite which gave them Wi-Fi (not operational during my stay because of a major earthquake earlier in the year). Moris worked in Lakatoro where he had a connection to check emails and monitor the websites. He received a good number of guests through this site, but confessed to me that the administration in such a remote place can be taxing. Both websites take commission on sales, and one morning over breakfast, sitting cross legged on the worn pandanus mat in the big house, Moris told me about his current troubles with Booking.com. Their commission was 10\%, which Moris must pay via bank wire through Western Union at the bank in Lakatoro, because he did not have a credit card or internet banking. Sometimes this transaction cost 2000VT - far more than the money he was transferring. He would ideally like to let the commission add up and pay it in a single sum, but at this point it was not possible to do that. The morning that we spoke Navul had just had a no-show from tourists that had booked through Booking.com. I asked if he would be able to negotiate not paying the commission, to which he replied yes he would, but it would be difficult. It seemed that in this instance, the extra advertising that Booking.com provided was not worth the extra time and money invested in it for a Malekula operator.

Since I have only known tourism in Malekula with the presence of the call centre, this shaped my research questions in a particular way. My initial contact and bookings were all through the call centre, so they were the lens through which I experienced the field. Robert, a friend and participant, helped me break through this assumption that Malekula tourism "began" with the call centre by telling me stories of his involvement in tourism in the 1990s. Robert's late father and their extended family used to perform a cultural show on the small island off the mainland. This was in the days before cruise ships or websites, when there was a small community-run guest house on the island. I later made the connection that this was the tour described in Tilley's Performing Culture in the Global Village (1997). When I showed Robert the articles on my tablet and he identified his father in the photos, he looked at me with pride and said "see I told you I was already on the internet!". Robert was also involved with a guesthouse on the mainland which was no longer open during my visit. He told me about the "truck loads" of tourists that would come to stay there, that far outnumbered those who visit the current bungalows now. I had no way to validate this information but his perspective and memories were nonetheless important. It showed his nostalgia for the past, distrust of more recent marketing pursuits, and a slight pessimism over the current situation. Our storian highlights the temporal aspect of place, 
reminding us that places are never static (Massey 1995). It shows how the past makes the present but also how the present makes the past, as Robert's experience he shared with me was shaping his understanding of tourism's history in the area.

Tourists themselves, of course, have their own social capital, a fact which ni-Vanuatu operators were aware of and tried to forge a relationship that could make use of this. I noticed this when I attended a Small Nambas cultural tour, run by Nellie, with another couple staying at the guest house. One of the highlights was the kastom dancing performances, and for the last song Nellie asked us to join in. A young woman came to grab my hand and pull me into the group, smiling with encouragement while I timidly tried to stomp my feet in time with theirs. At the tour's conclusion, Nellie made a heart-felt speech thanking us for our attendance. She asked us to go back to our home country and spread the word about Malekula and the Small Nambas, and also that we were welcome back anytime ourselves. The whole experience including the concluding speech felt very intimate. A tourist told me afterwards that he does not usually take part in collective dances at things like this (he was a travel writer so had been to many cultural tours). But the Small Nambas had seemed so genuinely happy to perform that when they asked him to join in the dancing, even to his own surprise, he obliged. Here we see not just the utilisation of social capital to build business advertising networks, but also the subtle trading of capital. Tourists gained the satisfaction of more "authentic" experience, feeling an intimate and genuinely friendly connection with local people. In return they felt they wanted to go back and spread the word about the tour in their home countries. In this example tourism operators exchanged, “consciously or unconsciously" (Bourdieu 1986, 249), a certain experience for an opportunity to tap into tourist networks in their home country.

The ability ni-Vanuatu have to build fast and empathetic relationships with strangers was certainly a factor in what kept bringing me back to Vanuatu over so many years. It seemed to also have an effect on tourists, who all expressed a desire to help, while acting on this notion in a variety of ways (from bringing pre-bought gifts to leaving a good review on social media or donating to the church). I did notice that some bungalow owners were particularly skilled at building relationships, this giving them the chance to accumulate more social capital. Particular attributes such as speaking the tourists' language, an outgoing personality, experience with foreigners, or experience living in New Zealand or Australia certainly seemed to help. Occasionally a tourist who developed a close relationship with a family would leave a more substantial legacy like sending money over to help with school fees, returning regularly or paying someone's travel expenses to visit them in their home country. ${ }^{27} \mathrm{By}$ creating these long term friendships and reciprocal relationships ni-Vanuatu and tourists begin to build a trusting network of connectedness, which increases their resources of social capital.

Volunteers and researchers stationed on Malekula made up a significant proportion of accommodation guests, and were especially useful because of their access to desired markets in Port Vila or overseas. When Lani found out my partner was coming to visit at the end of my fieldwork, she exchanged a hopeful look with her husband before asking me if my partner could bring a Bluetooth speaker for them. As the plan progressed this multiplied to two speakers, Lani promising to meet us at the airport to make refund him the cost. I realised that Lani was pretty adept at making these kind of arrangements, she also had a volunteering couple who were in Vila for the weekend pick her up business cards, Tanna coffee and some other items she needed for the bungalow. When I returned to New Zealand I printed and laminated some marketing brochures to send back to cultural tours, and I saw evidence of other touristscome-friends who had done this in the past. Volunteers (in the tourism sector and outside of it), short-

\footnotetext{
${ }^{27}$ While this was not typical of every tourist by any means, it seemed to happen often enough that it emerged as a common thread when talking to a number of different tourism operators. Some of the visitors they described also fitted in the category of volunteers or missionaries who used their wider networks to make funding the trip possible.
} 
term missionaries, and "voluntourists" made up a significant part of owner's accounts of their experiences with guests. It was interesting to note that for foreigners who made their visit to Malekula for other reasons, their temporary or longer-term stay in tourism accommodation had an unplanned positive impact on the island industry. As an example of this, at Mesal Bungalows a group of visiting volunteer doctors from Australia stayed for eight days in 2016, and this was the difference between the business breaking even and running a loss that year (due to a drop in numbers following the out-ofcontrol events).

\section{Everyday challenges}

Everyday challenges for bungalow owners reflected how their bisnis was socially and physically embedded in ples. Entrepreneurs were forced to work within these constraints and find ways to cope, which sometimes involved relying on trust-based networks in the community. These negotiations might be seen as what Brigitte Bönisch-Brednich and Catherine Trundle $(2010,10)$ call "micro-politics", that is the daily struggles that illuminate "the relationship between place and subjectivity". I spent four weeks of my fieldwork at Navul bungalow where I was able to observe how Ellen negotiated the daily tasks of running a bisnis, so I draw principally from her stories in this section.

Running a bungalow, especially the food preparation side of things, was difficult for Ellen with lacking infrastructure to support her endeavours. Ellen had a gas stove as well as an open fire to cook on but a daily hindrance was not having a fridge. Ellen felt she should provide at least one meal per day of meat or fish for a guest, so she would have to catch a truck into Lakatoro to buy meat and ice for the ice-box. That would keep the meat cool until the evening but leftovers would be wasted. A one-way trip to Lakatoro costed 200VT (NZ\$3) plus extra for produce. The road from Navul to Lakatoro had mostly finished an upgrade funded by China Aid, making the journey 40 minutes. Other bungalows did not have such easy access and had to go by boat, or monsoon rains ruined roads. Unelco (a private enterprise and utilities concessionaire for electricity and water) were in the process of installing mains electricity up the East coast of the island, with planned completion by the end of 2016 (Calo 2015). The cables would follow the main road with occasional links to the lower road where there was some village settlement by the sea including Navul. However, this linkage was planned to stop two kilometres short of Navul bungalow, which frustrated Ellen. She told me she wanted to make an application to Unelco to ask that it be extended to her, because it was important to support local businesses like theirs that could benefit from electricity.

Coverage issues were a challenge in the running of a tourism bisnis. Consistent and reliable communication with the call centre would ensure a smooth booking process and experience for guests and hosts. Despite the growing use of mobile phones in everyday life in Vanuatu, there are many places still without network coverage on the outer islands. The country is dominated by two network companies: Digicel and Telecom Vanuatu (TVL). Most people had a mobile phone from each network or a model with a dual-SIM option. At Navul, you had to stand at the edge of the property overlooking the sea and point your mobile phone strategically toward the sky to get one bar of reception from Digicel. Ellen walked to that spot a couple of times a day to check her messages and make phone calls. Digicel was at the time constructing a tower a few kilometres away and residents in the nearby areas hoped that this would bring wider and more reliable coverage. The following two examples illustrate how the circumstances of ples impact on daily life at the bungalow.

On the $18^{\text {th }}$ of October Ellen had a booking for five tourists for lunch at the bungalow. That morning Ellen rose early and went to Lakatoro by truck to gather the fresh ingredients. Food preparation took all 
morning with the help of an Auntie and myself. By noon everything was ready, and Ellen had been down to the beach to re-confirm the booking with the call centre. Throughout the afternoon Ellen went back and forth to the beach to check her phone, but the message she got was "they are on their way now". She even received information that they were in the neighbouring village, but after an hour we all gave up hope that the group would arrive. There was some confusion over what had gone on, but there was no way to contact the tourists and Ellen concluded it must have been a misunderstanding.

On the afternoon of the $3^{\text {rd }}$ of October I went to interview a participant at his home, about a 40 minute walk away from Navul Bungalow. I got on well with his family and they invited me to stay for dinner. I accepted their offer, but I was torn. I knew it would be rude to decline and I also wanted an opportunity to build more rapport and have more interesting conversations. However I was also anxious that Ellen would be expecting me for dinner and I was keenly aware of the effort that went into guest meals. There was no mobile network where I was so I had no way of contacting her. I was put at ease when my friend returned from a dance practice by the river where he had run into Ellen's husband Moris and informed him about my new dinner plans. This had been communicated back to Ellen who knew she did not have to prepare dinner for me that night.

Serendipitous instances like this happened more times than I could count, to the point where for niVanuatu they are taken for granted and woven into the fabric of social life. While I always observed the connections and patterns of communicating information with interest and surprise, it was only on returning home and writing up my thesis that I realised the part this played in the daily functioning of a bisnis. When speaking to Rosalie at the call centre I discovered that strong networks were important at their level of organisation too. She told me that "sometimes in some remote areas where they cannot get connection, it's not clear or it's hard. So sometimes we ring but they don't answer so we have to write a note and give it to a driver from that village [laughs] and ask him to take it”. Ellen also used truck services to make deliveries so she did not personally have to make the trip to town; sometimes Moris would buy meat and put it on a truck to deliver to Navul Bungalow where Ellen was there to receive it. These uses of networks and expenditure of social capital, again, do not come naturally. As Bourdieu $(1986,52)$ stresses, they take "an unceasing effort of sociability", which in a Vanuatu context requires an intimate knowledge of, and participation in, practices that are appropriate to the ples. If a person knows the ples, the people, the kinship relations, and the rules of conduct, then they have access to a larger pool of social capital.

Commitment was a concept talked about a lot in relation to running a business for international tourists. ${ }^{28}$ Partly brought about by the nature of hospitality, but also because foreigners were seen as more work to look after, owners felt like they could not rest while they had guests. Their responsibilities included cooking, cleaning and housekeeping, organising tourists' daily activities, and being available at any time for questions or concerns that guests might have. The majority of this work fell on women to undertake, which they had to make time for as well as their existing household duties. Ellen, for instance, rose at four o'clock every morning to start cooking breakfast for her husband, five children, and any guests. She went to bed once all her jobs were done, usually after ten at night. Tourism work is gendered in Vanuatu, particularly when the role includes household and care tasks associated with women. Case studies from Vanuatu present micro-enterprise as an effective way to economically empower women within a strongly patriarchal society (Ellis et al. 2009). Ethnographic evidence on gendered work in other localities works to complicate this narrative (Hippert 2011). While becoming involved in business can be a positive thing for women, it can also overburden them as they must

\footnotetext{
${ }^{28}$ As opposed to domestic tourism and travel where bungalow owners identified they did not feel so much pressure or the need to be constantly available.
} 
conform to existing gender norms like being a mother and a wife, while simultaneously "empowering" themselves through paid employment. Women who I spoke to overall enjoyed their commitment to tourism bisnis, although they admitted it was hard work, they found the challenges rewarding.

The commitment required in the accommodation business particularly, impacted on owners' ability to participate in cultural events deemed important to the kastom and ples in Malekula. Taking part in ceremonies for births, marriages and deaths is an important part of maintaining kinship ties (in turn generating social capital) for ni-Vanuatu. Bungalow owners sometimes had to miss out on these events because of their business commitments, and even if they had a friend or family member to look after it on their behalf they would be anxious about how things were going while they were away. One time that this situation became clear to me during fieldwork was Malampa Day, the $10^{\text {th }}$ of October. The day had been long anticipated by the community and myself; it was a large event in Lakatoro with sports matches, kastom dancing and food stalls. Public transport was free for the day and it really felt like most of the surrounding area had shown up for the festivities. I was going with some friends, and Ellen was unsure if she would go (some guests had just stayed for the weekend and she was exhausted), but eventually decided to attend with Moris and the children. When I ran into Moris later in the day I asked him where Ellen was and he told me about the drama that had taken place. He had forgotten they had guests booked in for the night, and was only reminded when they called from Port Vila airport. Ellen had to race back to prepare the bungalow and something for dinner, while Moris would be heading to the airport soon to collect the tourists. Women struggle with competing gender roles defined by the local ples (participation in traditional events) and international development (participation in the market economy). It is an ongoing challenge to balance commitments required by being embedded in ples, while catering to a customer base whose values are removed from the ples.

\section{Co-operation and maintaining social capital}

Another challenge that arises from the ples a bungalow is situated is co-operation with other bisnis and the wider community. In light of the copycat business I elaborated on in Chapter 4, the tourism office now advocates diversification in the industry, and co-ordination between entrepreneurs to compliment and support each other. Diversifying tourism bisnis is seen mostly in the area of food suppliers and cultural tours, but co-operation remains a challenge and has the potential to raise tensions within a community, as I discuss at the end of this section. However, it is important for tourism operators to maintain community cohesion, because it is the strength of these networks that are a valuable source of social capital.

When people talked to me about the way that tourism businesses should complement each other rather than competing so as to spread the monetary benefits more widely, a commonly used example was food production. Such opinions arise from the large subsistence farmer population providing untapped potential to grow and sell local produce for tourists. ${ }^{29}$ Kalini described to me Malampa province's approach to the issue:

... if you are setting up a tourism business, an accommodation for example, whoever is planting the vegetables, the accommodation buys the vegetables from the farmer, and then feeds his visitors with them. Some are going out fishing - catch fish - sell to the guest house - sell to the restaurant; so that's

\footnotetext{
29 This idea of capitalising on the popularity of healthy, organic food is being pursued in Torba province, Vanuatu, where there is an ongoing conversation about banning “western junk food” (Roy 2017).
} 
what [“tourism is everybody's business"] means. Even someone getting a green coconut from the garden and then bringing it to the guest house and saying this is 20vt or 30vt. That's how we make business... (Interview transcript, $10^{\text {th }}$ November 2016)

I observed this happening to some extent, especially with a regular bread supplier for example. However much of the time, it was difficult for bungalow owners to form a steady and reliable relationship with producers due to the sporadic nature of guest visits. It was easier to go to the market to choose from a variety of fresh produce daily and buy meat from the only company supplier in Lakatoro. Closer to home, people relied on close family's gardens, or in the case of fresh fish took advantage of an opportunity to purchase from a neighbour. I did not see any formal links between bungalows and local suppliers, and from hearing participants' stories I do not think this was a particular priority for them.

Ensuring the commitment and consistency of cultural tours proved challenging in Malekula, and I spoke to both tour guides and bungalow owners about this. Cultural tours on Malekula were generally specific to a tribal group or extended family and displayed the songs, dances, food and traditional costumes of those peoples. In many cases it was a re-enactment of how people used to live before the arrival of missionaries and the colonial era, although some parts of the tour continued to be practiced into the present day. Tours cost between 3,500VT and 5000VT per person, with some tours requiring a minimum of two (a rule not always honoured). This would be split between the performers, which could be up to 16 to participate in the dances. One tour guide that I spoke to paid her performers 200VT each, which after paying commission to the bungalow that referred them or the call centre, left 750VT profit to support her family and maintain the bisnis. The unfortunate case with many dance performers (including for cruise ship visitors) was that although the initial sum paid to them as a group was large, once it had been divided up the amount was so little it seemed hardly worth putting in the effort for. Although performers still gladly participated when the opportunity arose, it was not a sole source of income for them so they would be taking part in a few different income generating activities. This resulted in not everybody being present when a tour was booked, especially in areas where tourist visits were sporadic or the booking was last minute. The inconsistency of numbers meant tours appeared to lack a sense of commitment or will to participate in the industry, although in this paragraph I have given an alternative explanation.

Bungalow owners responded to the challenging aspect of cooperation in various ways. Bungalows depended on surrounding tours to attract tourists to their particular destination and provide them interesting things to do while they stayed. As Jermain put it:

We don't have too many tours here. So if I make a bungalow I depend on the activities, the tours. If you have tours, more guests come and stay to go on the tours, if you don't have tours then you don't... So I just made some island night, activities like this, but it's not enough. And most of the places, hotel, resorts in Vila have an island night. So one guest prefers to stay in Vila and see island night, then come to the island and see island night.

... So we must use our culture. We have a Small Nambas tour here. We depend a lot on them. Otherwise, we don't have a choice. We must find more activities here that they don't have somewhere else. (Interview transcript, $5^{\text {th }}$ October 2016)

Jermain identified tours and other activities as crucial in creating a unique tourist product that would differentiate their ples from other destinations. It also provided diverse bisnis opportunities for the community and a way to foster cooperation. However until this could happen, Jermain felt he needed to provide his own tours offered by the bungalow itself like the island night (there was also a garden tour). On arrival at Mesal I was given a brochure with the internally and externally offered tours, and 
Jermain explicitly stated that booking the Small Nambas tour would have to be done at least a day in advance to give them enough notice. I noted this as a responsible and important way to acknowledge the practical, ples-based issues of group performances. Other bungalow owners would choose to develop a close relationship with a tour, sometimes owned by a family member, and agree to take more last minute bookings for them.

The difficulties of cooperation described in this section have led some people in the community to become dissatisfied with tourism. From either having a business fail, receiving sporadic customers, or being the victim of corruption or misunderstanding, some have developed a more cynical view of tourism on Malekula. This is not to say they are fundamentally against the idea, but rather, as one community member described to me: "tourism has two sides to it". On the one side it is good, it is a great way to make money in an economy and land situation that is rapidly changing. But on the down side, she countered, poor management has led to negative outcomes for some.

Tensions and politics are inevitable in any community, and I was not surprised to encounter many differing opinions on the ways that tourism has helped or harmed certain members of the communities on Malekula. What interested me was the ways in which tourism operators actively worked to maintain social relations to address any potential grievances or bad feelings. Many emphasised how tourism still can benefit everyone, and gave me examples to back this up. Ellen sends money to her family regularly, maintaining kinship ties and supporting family members living on other islands. She also spends money at markets, gives generously to the church and gives money as gifts or loans to people in need who come to her with a request. Moris turned on his generator each Saturday during the drought and ran the water pump for any member of the public to come and collect water (rather than pumping manually from a well). Other bungalows paid a fee to run a collectively owned generator, or charged to visit a conservation area and gave the money to a community fund. The contribution of economic capital through gifting or other forms of exchange, I conclude are crucial in maintaining community cohesion and keeping an open space for tourism enterprises to thrive. If bisnis owners can keep trust in relationships and networks, then they can continue to access and accumulate the social capital that being a valuable and engaged member of the community offers them.

\section{Conclusion}

This chapter has been dedicated to a topic that repeatedly came up when talking to business owners: the various challenges of running a tourism business in Malekula. I framed these as ples-based challenges because they all relate in some way to operating within the realities of their ples. This created obstacles of geographical, social, environmental, and technical scope, that ni-Vanuatu responded to and coped with. I showed how, in their daily lives, tourism entrepreneurs engaged in "micro-politics" (BönischBrednich and Trundle 2010, 10), in their interactions with ples, which Tim Ingold (2000 192) reminds us is always a relational process. In Chapter 4 I explained in depth how entrepreneurs, understand, make, and transform ples through tourism, and in this chapter I have shown how ples equally shapes the actions, behaviours, and experiences of entrepreneurs. In some of the cases I outlined, participants expended, accumulated, and maintained social capital through various means. Creating a connection with tourists by exchanging intimate feelings of authenticity was important in providing a link that entrepreneurs could later use to increase their tourist traffic through tourists' own resources of social capital, or benefit from longer-term friendships of mutual exchange. Entrepreneurs also maintained social capital in the village by carefully balancing community commitments, co-operation, and the successful everyday functioning of their bisnis. Although, in these terms, it might seem that I portray entrepreneurs as economically strategic, or acting in cunning self-interest, this is not my intention. Bourdieu (1986, 250) reminds us that not only can these exchanges in social capital happen 
unconsciously, they are a necessary component of social life and part of the challenge of working within certain realities. 


\section{Chapter 6}

\section{The politics of value in the tourist encounter}

It was dusk and the clear sky was just turning a soft pastel orange. Anders, a European travel writer and I ambled along the road, chatting about our days as I led him to the kava bar I sometimes attended. We both wore baggy and light clothing appropriate for the cool night air and mosquitos that came with it. Anders had gone on several tours during his stay as part of his job to write a piece for a tour guide about Malekula. But he had not yet tried kava, so this evening we were going to change that. A lantern hanging on a post illuminated that the kava was ready (it was made fresh daily) so we walked through the clearing and up to the small serving window of a wooden hut. The kava drinking was not overly ceremonial, we skulled our "shells" from black plastic bowls, grimaced, and sat down on a nearby bench. The familiar subdued air hung over the kava bar, with sounds of soft murmurings and spitting. Some men started conversations with us, either speaking in English or in Bislama and I translated. We migrated to a different kava bar and lounged on a bench constructed around a tree trunk. A few shells in, Anders confessed to me that this was probably his best experience of Malekula so far. And it was not just the mild narcotic going to his head; he explained to me that this was the first time he had felt he was taking part in the real daily life of villagers. He had run into some difficulty when asking to see some villages to get a glimpse of real life on another tour he attended. That night, then, he had inadvertently received the very experience he was so searching for: something that felt natural and authentic.

- Fieldnote vignette, 2016

Authenticity and commodification have been two favourite themes in literature that explores tourists, their motivations, and experiences during their travel, particularly in "developing countries" (Cohen 1988; Cole 2007; MacLeod 2006). Stroma Cole (2007, 944) argues that while earlier studies of authenticity and commodification "have been fascinating from a theoretical perspective, they have failed to address issues fundamental to destination communities", such as host interpretations and uses of the concept, and the "competing voices" surrounding this in a tourism setting. In this chapter I focus on the tourist encounter, giving tourist perspectives attention and putting them into interaction with local host perspectives to show how a politics of value can ensue. To approach the problems of authenticity and commodification in a way that pays close attention to ples, I employ the concept of value. David Graeber writes that value has been talked about in social theory in three different ways: 
1. "values" in the sociological sense: conceptions of what is ultimately good and proper, or desirable in human life

2. "value" in the economic sense: the degree to which objects are desired, particularly, as measured by how much others are willing to give up to get them

3. "value" in the linguistic sense, which goes back to the structural linguistics of Ferdinand de Saussure (1966) and might be most simply glossed as "meaningful difference" (Graeber 2001, 1)

In this chapter I use the first two ways to frame my analysis of authenticity and commodification in the Malekula tourist encounter. Graeber draws on Clyde Kluckhohn's earlier work on value to highlight a key characteristic of value as not just what people desire, but what is seen as desirable, or, "what they ought to want" (Graeber 2001, 3; Kluckhohn 1951, 195-6). It is this distinction, according to Ryan Anderson (2011) that moves the conception of value "beyond questions of supply, demand, and taste to embrace what people feel is socially and morally just". On the grounds that value is not an in-built in characteristic, but produced through human action, Graeber (2001, 11-12) argues that his approach is necessarily more dynamic than previous, what he calls static, interpretations. ${ }^{30}$ Graeber (2001) and Anderson (2011) argue that if values are produced within a wider system of meaning, then this brings about a politics of value, which is ultimately, "not even the struggle to appropriate value; it is the struggle to establish what value is" (Graeber 2001:88). ${ }^{31}$ Determining value over objects, experiences, and places during the tourist encounter is a subjective and culturally specific endeavour. Thus, perspectives may sometimes align, and sometimes compete, as I explore in relation to tourists and locals. I recognise that the terms 'tourist' and 'local' do not signify homogenous entities, but my purpose of treating them as such here is to draw attention to the politics that surfaced when different perspectives on value converged in a social and monetary transaction.

\section{Authenticity}

Michelle MacCarthy (2014; 2016) conducted ethnographic fieldwork in the Trobriand Island village tourism industry, and drew conclusions in her articles that sometimes strongly relate to my own findings on Malekula. MacCarthy $(2016,339)$ identifies what she sees as the major controversy of the concept authenticity: that it is used both as "an analytical concept employed by academics and as a trope employed by non-academics". MacCarthy $(2016,340)$ traces the history of authenticity in academic studies of tourism to Dean MacCannell's 1976 book The Tourist. MacCannell argued that tourism is a ritualised search for a purer way of life believed to be lost in modern society, and in another work he introduced the idea of a "staged back region" where tourists believe they are discovering a real and more intimate version of social life (MacCannell 1973, 596). Many authors have since continued on this academic analysis of authenticity in conversation with MacCannell's texts (Bruner 2005, 1991; Cohen 1988; Tilley 1997). The lay use of authenticity in tourism promotion is, of course, decidedly less critical. If something, someone, or an experience is authentic, it is generally valued as better than something "fake" or "inauthentic" and thus becomes a primary desire for many in their tourist endeavour. In my own fieldwork I found that how something becomes authentic can vary across individuals, and depends on what they value. For some this might be through experiencing MacCannell's back region in their destination, like the tourist in the opening fieldnote vignette, who found the kava outing more satisfying than any of his organised tours. Others, however, enjoyed the

\footnotetext{
${ }^{30}$ To illustrate this Graeber refers to the formalist-substantivist debate in economic anthropology (Hann and Hart 2011; Polanyi 1957), that he believes remains unresolved and relates to value. In his view, while formalist approaches are rational, calculated, and based on individual desire (like the economic sense of value), substantivist approaches are socially embedded but far too abstract (like the linguistic or Saussurean sense of value). He concludes that value must take its starting point from action (Graeber 2001, 46-7).

${ }^{31}$ In formulating this argument, Graeber takes inspiration from Terrence Turner (1979), distinguishing his own politics of value from what he calls “Appadurai’s neoliberal version” (Graeber 2001, 88; Appadurai 1986).
} 
staged tours because of the authentic knowledge they appreciated gaining of the ways ni-Vanuatu used to live before Europeans came. I explore this in more depth in the following section.

MacCarthy (2016, 341) tries to avoid converging the lay and academic interpretations of the term by asserting that authenticity is always a social construction. Similarly, Cole (2007, 945), in understanding that "authenticity has no objective quality", borrows from Gianna Moscardo and Philip Pearce (1999, 418) to describe it simply as "a value placed on a setting by the observer". John Taylor $(2001,8)$ similarly moves away from debates over authenticity towards what he calls sincerity in tourism, which produces value on local terms. The important thing to note from these conclusions in relation to my own argument is that authenticity is not inherent in an object, place, or experience, but is rather produced and projected by human actors: much like value. Rather than determining whether authenticity is really ever attainable or not, my analysis looks at authenticity as the goal itself that tourists see as desirable in order to give their holiday experience more value (in Graeber's first, sociological sense of the term). The politics of value becomes relevant precisely because there are multiple and conflicting ideas on what makes a tourist experience authentic.

\section{Reviewing the value of experience}

I now use some ethnographic examples of tourist experiences of authenticity in Malekula, gained from meeting tourists during fieldwork and taken from online reviews. They show that determining the value of experience through authenticity is messy and multiple, including a desire for the "undiscovered", the unique and original, feelings of genuine intimacy, and a sense of adventure by "roughing it".

Tourists travelling to Malekula will most likely have their first encounter with the place through pictures, media and marketing of the destination through tourism advertising. Most tourists I met had booked their holiday as part of a package either through Malampa Travel call centre or their home country. A few had made their own way to the island either following the Lonely Planet Guide (D'Arcy 2012) or being recommended by other operators in Port Vila. Vanuatu strategically markets itself as "within easy reach", making it accessible to travel to especially from Australia, while retaining the mystery of an untouched location "waiting to be discovered" (Vanuatu Tourism Office 2017a). Like other tropical island destinations, it is not uncommon to see "paradise" used frequently in marketing material, as well as in tourist accounts. Mild weather, sandy beaches, a slow pace, and a sense of a lifestyle supposedly untainted by capitalism, all contribute to what tourists value and expect from Vanuatu (Vanuatu Tourism Office 2017a).

Once in Vanuatu, the strategic marketing continues where each destination island takes on its own persona based on what tourist product it specialises in. For example, Espirito Santo offers amazing diving, beaches, and blue holes; Ambrym is the "black island" because of its volcano and black magic; Pentecost is famous for the land diving. Malekula is the island of "kastom and adventure" and this pretty well matched what every tourist I met was there to see (Vanuatu Tourism Office 2017b). Many came hoping to learn about the kastom and rituals of people in Malekula and get a taste of island life, with some venturing on mutli-day treks for even more adventure.

Possibly the most popular tour on the island is the Small Nambas tour at Rano, previously introduced in Chapter 1. The tour has been running for 15 years, Nellie's father started it and now she has inherited the tour guide role. The tour involves several kastom danis (dance) performances with "real" songs from the past, and a display of the way ni-Vanuatu in the area used to live before Europeans, such as cooking, fire lighting, weaving, and sand drawing. Nellie stressed that all the songs and dances used in their performance were originals (i.e. not made up especially for the tourist spectacle). This point reflects what many tourists valued and desired as something more real or genuine in their experience, and perhaps Nellie had picked up on this desire in order to include it in her spiel. All performers wore their traditional dress and, as Christopher Tilley $(1997,85)$ observed at a similar tour twenty years earlier, "virtually all signs of modernity have been erased". A notable exception to this on our tour was Nellie, 
who wore an island dress and acted as both the language and cultural translator, almost like a link between the past and present. At the end of the tour there was a community dance that everyone could join. I participated in the tour with two German tourists staying at the same accommodation as me. They were an intrepid couple who had done part of the Man Bush trail in southern Malekula before travelling up north. Christian noted how impressed he was by the ni-Vanuatu keeping their traditions alive. He had a related concern over this culture being "lost" in the future.

Nellie, like other bisnis owners on Malekula, has an online presence on tourism review websites. The reviews posted on them proved to be illuminating of how tourists evaluated authenticity and what they valued overall in their visit. Two reviewers wrote that the Small Nambas cultural tour was one of the highlights of their time in Malekula. Other reviewers reflected satisfaction from gaining knowledge about another way of living, even if they acknowledged that the show was performed and totally constructed for tourists they still valued the experience immensely. I noticed that a division between past and present was at times murky and ambiguous, with comments using words like traditional and talking about older ways, interspersed with a feeling that they have experienced real village life in the present. I agree with Tilley that "in a highly equivocal way the Small Nambas are both 'here' and 'there', of the present and of the past. This impression is only possible to convey, because of the location of the show in a remote Pacific island which has supposedly escaped the full ravages of modernity" $(1997,86)$. Overall, tourists felt they were getting an authentic experience made richer because they felt that through performing, ni-Vanuatu were helping to conserve their traditional culture.

Another marker of authenticity from a tourist perspective was being able to develop a close and personal relationship with local people, most often the accommodation hosts and tour guides. Reviewers writing about bungalows and tours on Malekula expressed gratitude for being welcomed into families in such a personal way. MacCarthy (2016, 346) and MacCannell (1973, 591-2) both identify intimacy as an important factor in people's experience of a place and ultimately how authentic they feel it was. This also came through in some reviews when writers explained the activities they did and meals they ate as something they shared with guests. Using the personal names of hosts and making promises to come back in their reviews, were evidence for how much relationships made an impact on tourists' holiday experiences. The primacy of intimacy as a valued aspect of tourist experience could also be a move towards a more morally-oriented "sincerity" put forward by Taylor $(2001,8)$. This shows that, as Graeber $(2001,9)$ suggests, value emerges from action within a web of social relations, and continues to exist within this web to maintain meaning.

Some tourists I met, while they enjoyed the cultural tours that were organised for them, were intent on going one step further in their authentic tourist experience. MacCarthy $(2016,33)$ calls this "touring real life" where visitors take part in the everyday activities of locals to get a sense of how life is interestingly not too different from participant observation for the anthropologist. MacCannell (1973) calls it a back region, hidden behind the staged façade of a tour. One time this kind of tourism became apparent in my fieldwork was when a couple from New Caledonia and an young Austrian woman were staying at the bungalow. The Austrian woman was going to the Small Nambas tour that day, and the New Caledonian couple, having already attended the tour the day before, were going to a neighbour's house to help make laplap. I was not actually there for the day or evening as I was staying with another family in the nearby village, but Ellen recounted the events for me after all the tourists had left. Ellen was impressed that the couple had really enjoyed making laplap and rather than just giving it a go, they ended up rosrosem (very finely grating) all of the manioc (cassava) themselves! When they shared the laplap all together that evening, Ellen told me with a laugh that the couple had even teased the Austrian woman about how they had experienced the "real Vanuatu" that day rather than just going on a tour. ${ }^{32}$ When Ellen took the New Caledonian couple to the airport they were very sad to leave, and apparently

\footnotetext{
32 The Austrian woman was originally supposed to also help with the laplap but her Small Nambas tour was rescheduled to the afternoon so it clashed. The teasing was part of a wider conversation about the day.
} 
wished to come back the following year and stay for a month more in the style that I was doing it. Staying for longer in one place seemed to be an important component of a more authentic experience; Anders in particular said to me on our walk home after kava "you sure do know how to travel” referring to my longer stay in one place.

The last way that tourists reviewed their experience as authentic was by feeling they had been on an adventure, or were "roughing it". Staying in less comfortable or luxurious accommodation is, for some, not just a cost saving mechanism, but enjoying the experience of living differently to normal gives a sense of excitement and adventure. Malekula accommodation, located in a village with limited electricity and no internet or cell phone coverage, could certainly offer this kind of experience to those who were looking for it. A few reviewers commented on this, and connected the feeling of "roughing it" to the point of discomfort with achieving greater authenticity. This served to change something that might be understood as a negative - roosters crowing close to all night - into an adventure endured and even enjoyed as part of the holiday. Many reviewers included a warning for travellers who might be expecting more of a luxury experience, that this would not be found on Malekula. This was interesting because by doing this, previous tourists were already helping to filter the appropriate target audience based on what their holiday had meant to them.

\section{Local perspectives on authenticity}

I now move on to discuss how some ni-Vanuatu understood authenticity through their own sense of ples, one of which was describing Malekula to me as paradise. I found it interesting that this sense of ples as paradise was shared by both locals and visitors, and epitomised in the marketing. However I did notice that the way ni-Vanuatu talked about their ples as paradise diverged from how tourists understood it. Many locals framed Malekula as paradise compared to Port Vila where you live a life reliant on money (see Chapter 3 for more on this ples-based lifestyle distinction). In Malekula there was still a prevailing subsistence farming lifestyle which made many people feel freer as they could get what they needed from their land, which led them to conclude that they lived in paradise. ${ }^{33}$

Another alignment in the way that locals and tourists valued authenticity was the real life experience. The Small Nambas tour guide Nellie and her husband would sometimes invite guests to their house for a meal after the tour, especially if the tourists were French-speaking (reminiscent again of MacCannell's (1973) backstage). One night when Nellie's husband was walking me back to the bungalow after dinner, he told me how he thought having dinner with tourists was really important so that they could get a sense of real life in Vanuatu, not just from the tour but also from drinking kava and sharing dinner with them afterwards. He said he would usually buy a takeaway bottle of kava and give a shell to the guests to try and then they would eat a laplap that Nellie had prepared. He thought it was important for tourists not only to see but also participate in life as it is really lived for ni-Vanuatu. Moris also drew on the concept of real life authenticity in our storian when explaining what he hoped his bungalow could provide for guests. He resisted making (what he saw as) unnecessary renovations on his guest house to make it appear more glossy and flashy, and believed that what was more important to tourists was an experience of what life is actually like in Vanuatu, and the relationships they can build with people while getting this more authentic experience.

One final local perspective on authenticity which seemed altogether more complex than the tourist perspective was that of the accurate knowledge and representation of a particular ples in the performed tours. This perspective came from a participant living in Southern Malekula, who had very strong opinions about the way culture was marketed to tourists; he was also developing his own cultural tour at the time. He was ambivalent about the way that culture was grouped into one homogeneous entity for the sake of tourism, for example the Small Nambas, which in reality encompassed a large

\footnotetext{
${ }^{33}$ It was difficult to discern how their use of the word "paradise” was influenced by (and influenced) the tourist's use of it, and further research might investigate the negotiations occurring here.
} 
geographical area of diverse cultural practices (Layard 1942; Tilley 1997). He also made a distinction between the authenticity of groups that no longer practice what they perform, and his family who still practice male circumcision and grade-taking rituals (which were to make up a significant part of his tour). Tilley $(1997,80)$ has also noted the "bricolage of different knowledges: memories of [local] islanders, the work of Layard, information from the Port Vila cultural centre and its former director" that ni-Vanuatu draw on to create their cultural image for tourists. The participant was particularly concerned with authentic knowledge, claiming that "if you asked someone else about the history of this ples, or about the kastom stories, they would not be able to answer you. Because they don't know. But my father passed on this knowledge to me so that's why I can answer these questions for you". So his knowledge of the place provides justification for authenticity and thus should be valued more by tourists. By presenting different ways that actors understood value, I have shown how a politics of value can emerge when those involved in the encounter hold different values about what the experience means, and should mean, to them and others.

\section{Commodification and value}

Commodification is most commonly understood as objects or land becoming valued in monetary terms, usually alongside their integration into a market economy, and so would be associated with Graeber's $(2001,1)$ second category of value: an economic, rational, or formalist sense. However, Graeber goes on to argue that it is far more complex than this, and commodification cannot be understood purely in economic terms. When assigning value to something, questions arise such as how much one is willing to pay, and how much one is justified in charging for a product. These questions cannot be answered using rational economising logic alone; actors always draw on their cultural assumptions to make these evaluations. In this section I explore these issues as they applied to my participants in the field to show that a politics of value can eventuate on the ground when conflicting understandings of value exist in the same place.

As I explained in Chapter 4, earning money as part of a self-reliant lifestyle played a large role in the ples-based motivations that led entrepreneurs to become involved in tourism. Kevin Meethan $(2001,5)$ points out that "tourism is one aspect of the global processes of commodification rather than a separate self-contained system”. This statement is important in supporting my point that tourism operators in Malekula are not commodifying culture and land in a vacuum. Rather they are situated in a complex history of a changing economy and globalisation that has led to money being a necessary part of material lifestyles, but with very few ways to earn enough. Tourism provides a way to help with this, but still Malekula receives comparatively few tourists, with some accommodation providers receiving less than ten customers a year. Understandably the individual pricing must be higher to cover costs and make the enterprise worthwhile, which results in noticeably higher prices in Vanuatu than a tourist might encounter travelling in other "developing countries" in the region of Southeast Asia for example.

In Chapter 3 I identified the moral economy in Malekula which continues to regulate economic and social behaviour in certain ways. This is particularly apparent in the tourist encounter when it comes to a demand-sharing ethic or tall poppy syndrome as Cox et al. $(2007,14)$ call it. This operates in a very egalitarian society that values equality and frowns on selfishness (see also MacCarthy 2014). Locals carry their own assumptions that all tourists are rich, which is not entirely unfounded considering the price of airfares to Vanuatu, and Malekula even more so. Therefore it makes sense to ni-Vanuatu that tourists should pay a higher price for products because they have more to give. This creates somewhat of a double standard in pricing similar to that observed (and much debated) in some Southeast Asian 
destinations, although possibly not as widespread or as extreme in most cases. ${ }^{34}$ The dual price is most apparent with transport, for which pricing is ambiguous and fluid at the best of times. If you are white and do not speak the local language, a charter price is a lot higher, and can increase further if tourists wish to be seated inside the cabin and with air conditioning.

In line with this theory of sharing and giving in relation to what you have, I experienced and heard about the same changes in price happening in the other direction. For example, with my long-term stay in a bungalow we negotiated a lower price and I no longer paid for meals, as the owners understood I was working to fit the cost into my fieldwork scholarship budget. Lani told me a few different stories of when she altered the pricing of her accommodation to fit with the amount of money tourists had. On one occasion she had a man who insisted he sleep in a hammock outside because he could not afford accommodation, and she dropped her price to 1000VT per night (a third of its advertised price). This generosity is extended on the basis of trust and a general value of giving that is jointly influenced by Christian and traditional values. However, if this is abused it is viewed as lowly behaviour, something I realised when Ellen scathingly told me about a tourist who had pretended she did not have much money to get cheap accommodation at her bungalow, but turned out to be very rich. These examples show that determining value for a bisnis owner is not a purely profit maximising endeavour. It also includes social considerations for the other party involved in the transaction, which are grounded in understandings of what is "good and proper" (Graeber 2001, 1; Kluckhohn 1951).

As the above examples suggest, pricing is fluid and ambiguous on the island, and this is often extended to tourism product pricing. There are no signs stating how much things are except in grocery stores. Prices are simply known by the people of the ples, and can be discovered only through asking - for example, kava shells are sold in increments of 50VT and a truck ride from Lakatoro to Norsup is $100 \mathrm{Vt}$ per person plus extra for bags. When I travelled with a local family, friend, or knew the driver, sometimes my fare was free, discounted, paid for by someone else, or I paid for myself and others. Paying was negotiated in the moment, and depended on a number of factors like who had paid last time and who had the correct amount of change if necessary. I think most foreigners (myself included) would feel lost and uncomfortable in this kind of situation, especially coming from a Western material culture where prices are clearly stated, usually non-negotiable, and are bound into a single transaction leaving no future obligation or ongoing relationship. Naturally this can lead to tourists paying a higher price for products because they are not embedded in the existing economic system. Another example of price fluidity was when tourism operators lowered the price when selling a product like a tour or day trip on behalf of another operator. There were a couple of instances where this happened and it caused some confusion for both hosts and guests, and resulted in the tour operators ultimately not receiving the price they wanted for their product. ${ }^{35}$

Having a gift economy impacts the way locals understand the material value of a tourist transaction. As I explained in Chapter 3, gift giving involves a three-fold obligation, to give, receive, and reciprocate (Mauss [1925] 1990, 17). Thus gift giving builds a long term and reciprocal relationship that cannot be bound into a single no-strings-attached transaction like the capitalism model does through the market economy. The gift relationship is brought into the tourist encounter, in that I argue tourism operators are giving their ples, friendship, and generosity, in exchange for cash but also an ongoing relationship with tourists that continues after they leave. The gift economy does not have to involve a monetary

\footnotetext{
${ }^{34}$ Two blog posts cited here contest the issue of tourist dual pricing attractions (Goats on the Road 2013; Lost With Purpose 2017). It is worth noting that the Goats on the Road bloggers completely change their opinion a few years later and state in their post that they are ashamed of their previous opposition to this practice.
}

\footnotetext{
${ }^{35}$ I talked to a few people about this issue which, while rare, did cause some tension between tourism operators in the area. However I was unable to confidently say what motivated operators to on-sell tours for a lower price. In following with my assertion in Chapter 2 - that all ethnographic accounts are inevitably partial - I have included this observation in my discussion, but have only mentioned it as an aside.
} 
relationship (although it can and has been, see Chapter 5), but could also take the form of keeping in touch via letters or phone calls, or returning someday in the future bringing gifts of items that cannot be bought in Malekula. I continue to send gifts to my family members in Vanuatu, and make an effort to fulfil their requests when I visit. So although sometimes I paid less on the island, I realised it was because I was being brought into a reciprocal relationship, whereby I was obligated to then send over things on my return to New Zealand.

Next I discuss how tourists themselves have evaluated their transactions in Malekula, drawing on perspectives gained either through conversations with tourists and reading online reviews. One of the interesting themes that emerged through my fieldwork and in the literature is that tourists have a tendency to see commodification as a ruining force in the subsistence communities they visit (Cole 2008, 144; MacCarthy 2014, 12). This was certainly evident in the grimaces that came from guests I told about the cruise ships that used to frequent Malekula once a month. While they could not imagine anything much worse than 2000 Australians descending on a small island population of 200 for a day, the locals actually found it a great way to contain their tourist encounter to a single day, making enough money to support the family for a month. ${ }^{36}$ Still, for foreigners the very idea seemed to shatter an illusion of an island society that still lived harmoniously and happily untainted by capitalism and the global economy. I sensed an inner conflict in tourists that ironically they were the reason behind their own worry about spoiling tourist locations (Walley 2004, 231; Cole 2008). But most seemed to console themselves by asserting that they were practicing a different kind of tourism - be that alternative, eco, or slow tourism - that both made their experience more authentic and relieved them of the guilt about the perceived negative effects.

Money has become a universal value for exchange, which has made it inevitably impersonal and slightly abstracted from the transactional relationship. Tourists are left with a feeling that they are more of a customer than a guest, and buying a product automatically gives it less personal meaning and authenticity (MacCarthy 2014, 1). Having a more intimate tourist encounter, as is usually the case in Malekula, and then having to pay for it, can sometimes sit uneasily with tourists who feel they have been ripped off. Not only have they been robbed of their sense of authenticity from the experience, but they may feel they are being charged a price that seems unjust because it does not fit with their own moral evaluation of what the experience was worth in a social and financial sense. This relates back to Graeber's assertion that value determines what one considers morally just or worthy $(2001,4)$. The cross-cultural misunderstanding is so common in Vanuatu that even the Lonely Planet warns that "your host is like a favourite uncle", who offers extras without specifying payment at all, but visitors are advised to always "ask how much it will be, because it's unlikely to be free" (Harewood 2009, 104). In making this point I am not implying that all tourists reacted indignantly towards paying for a service, indeed some tourists were happy to pay a higher price, understanding how important their contribution was to the bisnis and economy. Many tourists commented on how much more expensive the islands where than what they had anticipated, but mostly in the context of wishing they had brought more cash with them as there is no way to withdraw cash on Malekula. My opinion on this is that perhaps the politics of value is accentuated by the types of tourists Malekula as a destination attracts. In many ways, the experiences, sense of "roughing it" and adventure, and the immersive accommodation style would be well suited to younger backpackers. However the price of getting to the island makes them a minority in tourist numbers, moreover if they do make it to Malekula they do not usually have the budget to participate fully in all the tourist activities on offer.

I noticed that one way tourist and local perspectives about the value of a transaction aligned were in stories of visitors who developed a long-term relationship with the ni-Vanuatu with whom they originally stayed. This I have already explained in Chapter 5, and earlier in this chapter, and to reiterate

\footnotetext{
${ }^{36}$ Cole (2008) notes a similar paradox, that hosts in Indonesia use tourism money to work towards desired "development” but this means they simultaneously lose their "primitiveness" that is the very attraction tourists came to experience.
} 
while it was certainly not every tourist, I listened to five different stories, leading me to note it as significant during my fieldwork. I think this shows that for some tourists, experiencing an intimate and personal encounter with local people and business owners allowed themselves to be drawn into the more long-term reciprocal gift economy in Malekula, something that may not be the norm in a capitalist society. In these instances, the politics of value was resolved because due to feeling an intimate and authentic relationship between host and guest, the tourist honoured the local expectations of reciprocal gift-giving, and both parties felt mutually satisfied. 


\section{Conclusion}

This chapter has provided ethnographic evidence to support my argument that multiple understandings of a place can lead to tensions over determining value in the tourist encounter. Drawing on Graeber (2001), I identified value in two ways, the sociological and the economic, and showed how these converge in discussions about authenticity and commodification. The value of objects, places, and experiences are determined through a process of meaning making, for which actors must draw on their wider cultural understandings to decide. This was visible on Malekula in tourists' hunt for authenticity through various means, and tourism operators' desire to strategically produce an authentic experience in the ways that were consistent with their own understandings of ples. The politics of value is particularly evident in the different interpretations of cash transactions and what prices, or ways to determine price, are justified. Due to quite contrasting economic contexts, tourist and local expectations can conflict, but as I also explained, when an intimate and long-term relationship is formed, this can be resolved. Overall this chapter contributed to my assertion that the value of tourism is negotiated in close relationship to the ples in which they occur, and different values can co-exist but sometimes conflict or align. 


\section{Chapter 7}

\section{Conclusion: Living with contradictions}

This thesis has attempted to prioritise local voices in the study of tourism, and to recognise that these voices are diverse and multiple. Historically, tourism studies have focussed either on tourist motivations or the potentially negative impacts on the host community. While non-academic perspectives produced by the World Tourism Organization (2017), for example, laud tourism as a tool for empowering the poor and sustainable economic growth, academic studies have tended to be very critical of tourism's potential to benefit poor communities (Greenwood 1989; Pattullo 2003; T. D. Wilson 2008). My thesis contributes to a small but growing area of literature that allows local perspectives to come to the fore of tourism accounts, and complicates the assumption that international tourism is either a positive change or a force for ruin in local (particularly rural) communities (Adams 2006; Alexeyeff and Taylor 2016; Cheer 2014; G. Gmelch 2012; Trau 2012, 2013). On Malekula, nobody I spoke to regarded tourism spoiling their culture as a pressing issue. They asked important questions about commodification and what this meant for the future of their ples, but they were also realistic about the fact that it was happening and could not be reversed. Above all, I saw in my participants a resilience, patience, and positivity for the future that I truly admire. Their stories offer new insights into the way a global mobility phenomenon like tourism is understood, shaped and represented in a local setting.

My analysis was grounded in a ni-Vanuatu understanding of ples and how this interacted with tourism in participants' everyday lives. Ples relates closely to how ni-Vanuatu live their lives. It structures their identity and relations with others, their understandings of kastom and history, and their legitimacy as people of the land. I drew predominantly on Tim Ingold (2000) and Doreen Massey (1995) who write about place to suggest that ni-Vanuatu engage in a relationship with their landscape, meaning it is dynamic and always in a process of being made and re-made. I argued that ni-Vanuatu bungalow owners (and tour operators) are in a process of "making ples" because they are coming to new understandings of what their ples can mean to tourists, and re-making a version that will attract tourists to Malekula. This is by no means a one-way process, as Ingold $(2000,347)$ reminds us, people "build from within the world, not upon it".

In Chapters 3 and 4 I gave an introduction to Malekula and the way the environment - physical, economic, and social - is changing in ways that ni-Vanuatu must adapt and respond to. Entrepreneurs were motivated to start their own tourism bisnis as a direct response to these changing conditions of ples. They embarked on a re-evaluation of what their land and history could mean, as part of building a place that met national standards of quality within their environment. Further, I showed how complications can arise when ples, which is collectively owned and shared, must be to various extents individualised in order to be commodified for tourism purposes. Whether the tensions may be over collectively owned land or culture, I showed how they played out in terms of the bungalow boom and land disputes on Malekula.

Chapter 5 was dedicated to my participants' experiences of challenges they face in the running of their tourism bisnis, ones that I felt they strongly wanted to convey to me during our storian. I gave critical attention to real issues that people struggle with on a daily basis, and highlighted the importance of these experiences in relation to my overall argument. While entrepreneur experiences were continually shaped by ples-based challenges, they also worked within these constraints to endure or overcome them. In some instances, they would accumulate, expend, and maintain social capital in order to continue 
operating as a successful bisnis that must simultaneously address local, national and global expectations.

In Chapter 6 I analyse the idea that senses and meanings of a place are multiple and contested in the tourist encounter. Ples never held a singular meaning for ni-Vanuatu before tourism, but the arrival of more international tourists made these differences more pronounced and produced what I called a "politics of value" (following Graeber 2001, 88). Tourists and locals had their own culturally informed ideas about value, in a social and economic sense, which had to be negotiated during the tourist encounter.

In this thesis I have taken a global phenomenon - tourism - and analysed how it plays out in a local setting - ples - choosing the physical locus of this analysis to be bisnis and bungalows. Tourism bisnis is a unique way that ni-Vanuatu engage with global capitalism in their everyday lives. For many, a bisnis is just one income-generating source in an array of paid work that ni-Vanuatu use to achieve selfreliance - an important value especially on outer islands. I noticed that bisnis owners occupied a role where they faced many challenges, satisfying tourists' demands and expectations, as well as trying to achieve success on their own terms and maintain cooperation and community cohesion. I was impressed by how they managed to do this, often with very few resources or external support.

Malekulans' opinions on tourism, or any topic for that matter, were far from homogenous, and I tried to write their diversity, messiness, and contradictions into this ethnography. This turned out to be far more difficult than I had anticipated. Academics often try to make their data fit into categories, however abstract, in order to connect, compare, explain, or understand an aspect of society. Human beings, however, in their reality have an extraordinary ability to live with contradictions. On Malekula, this manifested itself in an often-ambivalent opinion about tourism itself; to re-quote a participant who expressed it as "turism i gat two sides blem" ("tourism has two sides to it"). On the one hand, she saw tourism offering a way to make money in a rapidly changing economic environment, but on the other, the management of it has led to land disputes, unequal distribution of benefits, and jealousy. Ni-Vanuatu continued to live and cope with contradictions of ples, not wanting to lose kastom or qualities that are distinctly ni-Vanuatu, but also wanting to function successfully in the new money economy as it is now a necessity in daily lives of most ni-Vanuatu. Entrepreneurs felt some combination of limitation and empowerment as a result of their involvement in tourism. Values too can contradict, conflict, and align, yet continue to co-exist in one place. It is these contradictions that make tourism such an ambivalent area of study, so much so that ambivalence and ambiguity were key themes in the recent edited volume Touring Pacific Cultures (Alexeyeff and Taylor 2016).

In this thesis I provided a detailed, ethnographic study of locally-owned tourism in Vanuatu. The existing work on tourism in Vanuatu focusses on the foreign domination of the industry, the lack of regulations, and a very concerning land-alienation issue (Slatter 2006; Scheyvens and Russell 2013; Stefanova 2008). These are valuable topics that demand attention, however the studies usually relegate locally-owned tourism ventures to an anecdotal side note. There have been few ethnographic investigations in Vanuatu that present local tourism-owners' voices (important exceptions include Cheer 2014 and Trau 2013). I have given academic value to these entrepreneurs' stories, and the complexity of their experiences. As Olena said, tourism is hard work; building and running a tourism bisnis on Malekula is not easy. I gave an empathetic account of my participants' struggles and achievements in this thesis. Further research into the ways that global tourism is negotiated in a local Vanuatu setting from the perspectives of entrepreneurs, would be welcomed as a way to build understanding of local people's experiences. Growth in this area of study could contribute to informing future tourism policy in Vanuatu, the way that foreign organisations choose to implement tourism development projects in the outer islands, and be of interest to the tourism industry in general. 
I conclude that ples is a useful concept in Vanuatu to understand the relationships between local and global that manifest in a particular setting. In my thesis I analysed negotiations between the local economy and global capitalism, and the politics of value determination in the Malekula tourism industry. Ples provides an important grounding for studies of tourism from the perspective of local people as it deservedly recognises their agency and has the specific aim of understanding events from a ni-Vanuatu point of view. 


\section{References Cited}

ABC News. 2017. 'Qantas to Resume Code-Sharing Flights to Port Vila in a Huge Boost for Vanuatu Tourism’. Pacific Beat - ABC News. May 17. http://www.abc.net.au.

Adams, Kathleen M. 2006. Art as Politics: Re-Crafting Identities, Tourism, and Power in Tana Toraja, Indonesia. University of Hawaii Press.

Alatoa, Hannington, Peter Larmour. 1984. Land Tenure in Vanuatu. Suva, Fiji; Port Vila, Vanuatu: University of the South Pacific.

Alexeyeff, Kalissa, and John Taylor, eds. 2016. Touring Pacific Cultures. Canberra: ANU Press.

Anderson, Astrid. 2011. Landscapes of Relations and Belonging: Body, Place and Politics in Wogeo, Papua New Guinea. New York: Berghahn Books.

Anderson, Ryan. 2011. 'Value, Social Conflict, and Tourism’. Savage Minds. December 23. https://savageminds.org/2011/12/23/value-tourism/.

_ 2014. 'The Value of a Place: Development Politics on the East Cape of Baja California Sur, Mexico’. PhD diss., University of Kentucky

Appadurai, Arjun. 1986. 'Introduction: Commodities and the Politics of Value'. In The Social Life of Things: Commodities in Cultural Perspective, edited by Arjun Appadurai, 3-63. New York: Cambridge University Press. 1996. Modernity at Large Cultural Dimensions of Globalization. Minneapolis, Minnesota: University of Minnesota Press.

Barclay, Kate, and Jeff Kinch. 2013. 'Local Capitalisms and Sustainability in Coastal Fisheries: Cases from Papua New Guinea and Solomon Islands'. In Engaging with Capitalism: Cases from Oceania, edited by Fiona McCormack and Kate Barclay, 107-38. Research in Economic Anthropology; v. 33. Bingley, UK: Emerald.

Beech, Nic, Paul Hibbert, Robert MacIntosh, and Peter McInnes. 2009. “"But I through We Were Friends?” Life Cycles and Research Relationships’. In Organizational Ethnography Studying the Complexities of Everyday Life, edited by Sierk Ybema, Dvora Yanow, Harry Wels, and Frans Kamsteeg, 181-197. London; California: SAGE.

Bennett, Annabel. 2016a. A Private Bungalow Room, Malekula. JPEG.

2016b. Beachfront Bungalow on a Coral Island. JPEG.

_ 2016c. Bucket-Flushing Toilet with a Seep-Away Septic System. JPEG.

2016d. Giant Clam Shell Bathroom Sink. JPEG.

2016e. Lak Lepsur in the Dry Season. JPEG. 2016f. 'Gaining Access and the Right to Research'. Vicanthropology. July 14. https://vicanthropology.wordpress.com/2016/07/14/gaining-access-and-the-right-to-research/. 
Bennett, Martin. 2016a. Master Bedroom Set up to Receive Guests. JPEG.

2016b. Mother Mary Statue in Vanuatu National Colours. JPEG.

2016c. Norsup Airport. JPEG.

Bernard, H. Russell. 2011. Research Methods in Anthropology Qualitative and Quantitative Approaches. 5th ed. Lanham, MD: AltaMira.

Besnier, Niko. 2009. Gossip and the Everyday Production of Politics. Honolulu: University of Hawai'i Press. http://site.ebrary.com/lib/vuw/Doc?id=10386627.

Boellstorff, Tom, and Bonnie Nardi. 2012. Ethnography and Virtual Worlds : A Handbook of Method. Princeton, USA: Princeton University Press. http://site.ebrary.com/lib/alltitles/docDetail.action?docID=10587957.

Bolton, Lissant. 1999. 'Introduction'. Oceania 70 (1): 1-8.

2003. Unfolding the Moon: Enacting Women's Kastom in Vanuatu. Honolulu: University of Hawai'i Press.

Bönisch-Brednich, Brigitte, and Catherine Trundle. 2010. 'Introduction: Local Migrants and the Politics of Being in Place'. In Local Lives: Migration and the Politics of Place, edited by Brigitte Bönisch-Brednich and Catherine Trundle, 1-14. Farnham, Surrey, England : Ashgate Publishing Company.

Bourdieu, Pierre. 1986. 'The Forms of Capital'. In Handbook of Theory and Research for the Sociology of Education, edited by John Richardson, 241-258. Westport, Conn: Greenwood.

Bruner, Edward M. 1991. 'Transformation of Self in Tourism'. Annals of Tourism Research 18 (2): 238-50. doi:10.1016/0160-7383(91)90007-X. 2005. Culture on Tour: Ethnographies of Travel. Chicago: The University of Chicago Press.

Caille, Alain. 2010. 'Gift'. In The Human Economy, edited by Keith Hart, Jean-Louis Laville, and Antonio David Cattani, 180-186. Cambridge: Polity.

Casey, Edward. 2001. 'Between Geography and Philosophy: What Does It Mean to Be in the PlaceWorld?' Annals of the Association of American Geographers 91 (4): 683-693. doi:10.1111/0004-5608.00266.

Cassidy, Frances, and Les Brown. 2010. 'Determinants of Small Pacific Island Tourism: A Vanuatu Study’. Asia Pacific Journal of Tourism Research 15 (2): 143-153. doi:10.1080/10941661003629953.

Chagnon, Napoleon A. 1968. Yanomamo, the Fierce People. New York: Holt, Rinehart and Winston. Cheer, Joseph Martin. 2014. 'Tourism and the Neotraditional: An Ethnography of Tourism and Traditional Culture in Vanuatu'. PhD diss., Melbourne: Monsah University.

Clifford, James. 1986. 'Introduction: Partial Truths'. In Writing Culture: The Poetics and Politics of Ethnography, edited by James Clifford and George Marcus. Berkeley: University of California Press. 
Cohen, Erik. 1987. ““Alternative Tourism”-A Critique’. Tourism Recreation Research 12 (2): 1318. doi:10.1080/02508281.1987.11014508.

1988. 'Authenticity and Commoditization in Tourism'. Annals of Tourism Research 15 (3): 371-386. doi:10.1016/0160-7383(88)90028-X.

2004. Contemporary Tourism: Diversity and Change. Boston: Elsevier.

Cole, Stroma. 2007. 'Beyond Authenticity and Commodification'. Annals of Tourism Research 34 (4): 943-60. doi:10.1016/j.annals.2007.05.004.

2008. Tourism, Culture and Development: Hopes, Dreams and Realities in East Indonesia. Clevedon, UK ; Buffalo, NY: Channel View Publications.

Connell, John, and Jeremy Hammond. 2009. 'Iso Iso: The First Ni-Vanuatu Guest Workers in New Zealand'. Pacific Economic Bulletin 24 (1): 83-95.

Conroy, John D. 2012. ‘A Guide to Subsistence Affluence’. SSRN Scholarly Paper ID 2059357.

Rochester, NY: Social Science Research Network. http://papers.ssrn.com/abstract=2059357.

Convery, Dr Ian, Gerard Corsane, and Peter Davis. 2012. Making Sense of Place: Multidisciplinary Perspectives. Woodbridge: Boydell Press.

Corsane, Gerard, and D Jared Bowers. 2012. 'Sense of Place in Sustainable Tourism: A Case Study in the Rainforest and Savannahs of Guyana'. In Making Sense of Place: Multidisciplinary Perspectives, edited by Ian Convery, Gerard Corsane, and Peter Davis. Woodbridge: Boydell Press.

Cox, Marcus, Hannington Alatoa, Linda Kenni, Anna Naupa, Gregory Rawlings, Nikunj Soni, and Charles Vatu. 2007. 'The Unfinished State: Drivers of Change in Vanuatu'. AusAID. http://oxfamblogs.org/fp2p/wp-content/uploads/2015/12/Unfinished-State-Vanuatu-DOCFinal-Report-April-07.pdf.

Crick, Malcolm. 1989. 'Representations of International Tourism in the Social Sciences: Sun, Sex, Sights, Savings, and Servility’. Annual Review of Anthropology 18: 307.

Crowley, Terry. 2003. A New Bislama Dictionary. 2nd ed. Suva, Fiji : Port Vila, Vanuatu: Institute of Pacific Studies; Pacific Languages Unit.

Cummings, Maggie. 2013. 'Looking Good: The Cultural Politics of the Island Dress for Young Women in Vanuatu’. Contemporary Pacific 25 (1): 33-65,217. doi:10.1353/cp.2013.0007.

Curry, George. 2007. 'Doing “Business” in Papua New Guinea: The Social Embeddedness of Small Business Enterprises'. In International Handbook of Research on Indigenous Entrepreneurship, edited by Leo Paul Dana and Robert Brent Anderson, 470-84. Cheltenham: Edward Elgar.

Curtis, Tim. 1999. ‘Tom’s Tambu House: Spacing, Status and Sacredness in South Malakula, Vanuatu’. Oceania 70 (1): 56-71. doi:10.1002/j.1834-4461.1999.tb02989.x.

D’Arcy, Jayne. 2012. Lonely Planet: Vanuatu \& New Caledonia. 7 edition. Footscray, Vic.: Lonely Planet. 
Deacon, Arthur Bernard. 1934. Malekula: A Vanishing People in the New Hebrides. London: George Routledge \& Sons.

Department of Tourism. 2017. 'Vanuatu Tourism Operator Minimum Standards | Vanuatu Department of Tourism'. Accessed March 16.

http://tourism.gov.vu/about_minimum_standards.php.

Dick Hobbs, and Richard Wright. 2006. The SAGE Handbook of Fieldwork. London: SAGE Publications Ltd.

Ellis, Amanda, Chakriya Bowman, Jozefina Cutura, and Clare Manuel. 2009. Women in Vanuatu Analyzing Challenges to Economic Participation. Directions in Development. Washington: World Bank Publications.

'Elota, ca., Roger Keesing. 1978. 'Elota's Story: The Life and Times of a Solomon Islands Big Man. St. Lucia, Qld.: University of Queensland Press.

Elyachar, Julia. 2017. Markets of Dispossession : NGOs, Economic Development, and the State in Cairo. Durham: Duke University Press

Emerson, Robert, Rachel Fretz, and Linda Shaw. 2011. Writing Ethnographic Fieldnotes. Second Edition. Chicago and London: The University of Chicago Press.

Farrelly, Trisia. 2009. ‘Business va’avanua: Indigenous Development as Cultural Hybridity in Boumā National Heritage Park, Fiji'. Doctoral Thesis, Massey University. http://www.massey.ac.nz/massey/expertise/profile.cfm?stref=914150.

Farrelly, Trisia, and Unaisi Nabobo-Baba. 2014. ‘Talanoa as Empathic Apprenticeship’. Asia Pacific Viewpoint 55 (3): 319-30. doi:10.1111/apv.12060.

Fisk, E. K. 1962. 'Planning in a Primitive Economy. Special Problems of Papua New Guinea'. Economic Record 38 (84): 462-478. doi:10.1111/j.1475-4932.1962.tb01443.x.

Garoleo, Charley. 2013. ‘Bungalow Standards Guide’. Port Vila: Department of Tourism. https://tourism.gov.vu/assets/docs/posters/BungalowGuideline.pdf.

Geertz, Clifford. 1973. 'Thick Description: Toward an Interpretive Theory of Culture'. In The Interpretation of Cultures: Selected Essays, 3-30. New York: Basic Books

1973a. 'Deep Play: Notes on the Balinese Cockfight'. In The Interpretation of Cultures: Selected Essays, 412-55. New York: Basic Books.

Gegeo, David Welchman, and Karen Ann Watson-Gegeo. 2001. “'How We Know”: Kwara’ae Rural Villagers Doing Indigenous Epistemology’. The Contemporary Pacific 13 (1): 55-88. doi:10.1353/cp.2001.0004.

Geismar, Haidy. 2009. 'Stone Men of Malekula on Malakula: An Ethnography of an Ethnography’. Ethnos 74 (2): 199-228. doi:10.1080/00141840902940468.

Gmelch, George. 2012. Behind the Smile the Working Lives of Caribbean Tourism. 2nd ed. Bloomington: Indiana University Press. 
Gmelch, Sharon. 2004. 'Why Tourism Matters'. In Tourists and Tourism: A Reader, edited by Sharon Gmelch, 3-22. Long Grove, Ill.: Waveland Press.

Goats on the Road. 2013. 'Tourist Pricing: Is It Right Or Wrong?' Goats On The Road. https://www.goatsontheroad.com/tourist-pricing-right-wrong/.

Graburn, Nelson. 2004. ‘Secular Ritual: A General Theory of Tourism’. In Tourists and Tourism: A Reader, edited by Sharon Gmelch, 23-34. Long Grove, Ill.: Waveland Press.

Graeber, David. 2001. Toward an Anthropological Theory of Value: The False Coin of Our Own Dreams. New York: Palgrave.

Greenwood, Davydd. 1989. 'Culture by the Pound: An Anthropological Perspective on Tourism as Cultural Commoditization'. In Hosts and Guests the Anthropology of Tourism, edited by Valene L. Smith, 171-85. Philadelphia: University of Pennsylvania Press.

Gupta, Akhil, and James Ferguson. 1997. 'Discipline and Practice: “The Field” as Site, Method, and Location in Anthropology'. In Anthropological Locations: Boundaries and Grounds of a Field Science, 1-46. University of California Press.

Hann, Chris, and Keith Hart. 2011. Economic Anthropology. Cambridge: Polity.

Hannerz, Ulf. 2010. Anthropology’s World: Life in a Twenty-First Century Discipline. London; New York: Pluto Press.

Harewood, Jocelyn. 2009. Lonely Planet: Vanuatu \& New Caledonia. 6 edition. Footscray, Vic.: Lonely Planet.

Harper, Douglas. 2002. 'Talking about Pictures: A Case for Photo Elicitation'. Visual Studies 17 (1): 13-26. doi:10.1080/14725860220137345.

Hau’ofa, Epeli. 1975. ‘Anthropology and Pacific Islanders’. Oceania 45 (4): 283-89. doi:10.1002/j.1834-4461.1975.tb01871.x.

— 1994. 'Our Sea of Islands'. The Contemporary Pacific 6 (1): 148-61. 1998. 'The Ocean in Us'. The Contemporary Pacific 10 (2): 392-410.

Heidegger, Martin. 1971. Poetry, Language, Thought. Translations and Introd. by Albert Hofstadter. New York: Harper \& Row.

Hippert, Christine. 2011. 'Women’s Spaces, Gender Mainstreaming, and Development Priorities: Popular Participation as Gendered Work in Rural Bolivia’. Women’s Studies International Forum 34 (6): 498-508. doi:10.1016/j.wsif.2011.07.004.

Huffer, Elise, and Ropate Qalo. 2004. 'Have We Been Thinking Upside-Down?: The Contemporary Emergence of Pacific Theoretical Thought'. The Contemporary Pacific 16 (1): 87-116. doi:10.1353/cp.2004.0011.

Hume, Lynn, and Jane Mulcock. 2012. 'Introduction: Awkward Spaces, Productive Places’. In Anthropologists in the Field. Columbia University Press.

Hurston, Zora Neale. 1942. Dust Tracks on a Road: An Autobiography. J. B. Lippincott Company. 
Ingold, Tim. 2000. The Perception of the Environment: Essays on Livelihood, Dwelling and Skill. London; New York: Routledge.

Jackson, Michael. 1995. At Home in the World / Michael Jackson. Durham: Duke University Press. Calo, Jean-Baptiste. 2015. '700 Rural Households in Malekula Will Have Access to Electricity in May 2016'. Vanuatu Info Online. July 21. https://vanuatuinfooline.wordpress.com Johnston, Andrew, Peter Swain, and Kelle Howson. 2012. Tourism Blong Yumi Evriwan: The Role of VSA Volunteers in Supporting Indigenous Tourism Development in Vanuata July 2009 to August 2012. VSA Case Study Series, no. 05. Wellington, Aotearoa New Zealand: VSA. Jolly, Margaret. 1992. 'Custom and the way of the land: Past and present in Vanuatu and Fiji'. Oceania 62 (4): 330-354. doi:10.1002/j.1834-4461.1992.tb00361.x. 1997. Women of the Place: Kastom, Colonialism and Gender in Vanuatu. Routledge. 1999. 'Another Time, Another Place’. Oceania 69 (4): 282-99. doi:10.1002/j.18344461.1999.tb00374.x.

Joshua, Jane. 2017. 'Norsup Airport Land Is Now Public Land’. Vanuatu Daily Post. Accessed January 11. http://dailypost.vu/news/norsup-airport-land-is-now-public-land/article_a49ff0a5aee6-5379-94ea-4915effd6ce2.html.

Kluckhohn, Clyde. 1951. 'Values and Value-Orientation in the Theory of Action: An Exploration in Definition and Classification'. In Toward a General Theory of Action, edited by Talcott Parsons and Edward Shils, 388-433. New York: Harper \& Row.

Kraemer, Daniela. 2017. “'Do You Have a Mobile?” Mobile Phone Practices and the Refashioning of Social Relationships in Port Vila Town'. The Australian Journal of Anthropology 28 (1): 3955. doi:10.1111/taja.12165.

Land Acquisition Act. 1992. http://mol.gov.vu/images/docs/Land\%20Acquisition.pdf.

Lange, Raeburn. 2006. Island Ministers: Indigenous Leadership in Nineteenth Century Pacific Islands Christianity. Canberra: Macmillan Brown Centre for Pacific Studies.

Larcom, Joan. 1980. 'Place and the Politics of Marriage: The Mewun of Malekula, New Hebrides/Vanuaaku'. PhD Diss., Stanford University.

Layard, John. 1942. Stone Men of Malekula: Vao London: Chatto \& Windus.

Lightner, Sara B. 2007. 'Ples Blong Olgeta Sista: Ni-Vanuatu Catholic Sisters Navigating Places and Spaces'. MA, University of Hawai'i.

Lindstrom, Lamont. 2008. 'Melanesian Kastom and Its Transformations'. Anthropological Forum 18 (2): 161-78. doi:10.1080/00664670802150208.

2011. ‘Vanuatu Migrant Lives in Village and Town’. Ethnology 50 (1): 1-15.

Lost With Purpose. 2017. ‘Unsustainable Tourism: Why Dual Pricing Is Unfair’. Lost With Purpose. https://www.lostwithpurpose.com/dual-pricing/.

MacCannell, Dean. 1973. 'Staged Authenticity: Arrangements of Social Space in Tourist Settings'. American Journal of Sociology 79 (3): 589-603. doi:10.1086/225585. 
1976. The Tourist: A New Theory of the Leisure Class. New York: Schocken Books.

MacCarthy, Michelle. 2014. “'Like Playing a Game Where You Don’t Know the Rules”: Investing

Meaning in Intercultural Cash Transactions Between Tourists and Trobriand Islanders'.

Ethnos. doi:10.1080/00141844.2014.939099.

2016. ‘Touring "Real Life”? Authenticity and Village-Based Tourism in the Trobriand Islands of Papua New Guinea’. In Touring Pacific Cultures, edited by Kalissa Alexeyeff and John Taylor, 333-58. ANU Press.

MacLeod, Nicola. 2006. 'Cultural Tourism: Aspects of Authenticity and Commodification'. In Cultural Tourism in a Changing World: Politics, Participation and (Re)Presentation, edited by Melanie K. Smith and Mike Robinson, 177-91. Clevedon, UK ; Buffalo, NY: Channel View

Madden, Raymond. 2010. Being Ethnographic: A Guide to the Theory and Practice of Ethnography. London: SAGE.

Malinowski, Bronislaw. 1922. Argonauts of the Western Pacific: An Account of Native Enterprise and Adventure in the Archipelagos of Melanesian New Guinea. New York: Routledge.

Massey, Doreen. 1995. 'Places and Their Pasts'. History Workshop Journal, no. 39: 182-92.

Mauss, Marcel. (1925) 1990. The Gift: Forms and Functions of Exchange in Archaic Societies, with a forward by Mary Douglas. Translated by W. D. Halls. London and New York: Routledge.

McCormack, Fiona, and Kate Barclay. 2013a. Engaging with Capitalism: Cases from Oceania. Bingley, U.K.: Emerald.

2013b. 'Insights on Capitalism from Oceania'. In Engaging with Capitalism: Cases from Oceania, edited by Fiona McCormack and Kate Barclay, 1-27. Bingley, U.K.: Emerald. Mckenzie, David, and L. Winters. 2008. 'Who Is Coming from Vanuatu to New Zealand under the New Recognised Seasonal Employer (RSE) Program?’ IDEAS Working Paper Series from RePEc.

Meethan, Kevin. 2001. Tourism in Global Society. New York: Palgrave.

Meyerhoff, Miriam. 1999. 'Sorry in the Pacific: Defining Communities, Defining Practices’. Language in Society 28 (2): 225-38.

2008. 'Claiming a Place: Gender, Knowledge and Authority as Emergent Properties'. In The Handbook of Language and Gender, edited by Janet Holmes and Miriam Meyerhoff, 302-26. John Wiley \& Sons.

_ 2016. 'Film, Phones and Faraway Places: A Modern Tale of Language Maintenance’. Inaugural Lecture at Victoria University of Wellington. Wellington, Aotearoa New Zealand. Mitchell, Jonathan, and Caroline Ashley. 2010. Tourism and Poverty Reduction: Pathways to Prosperity. Tourism, Environment and Development. London; Sterling, VA: Earthscan. Mitchell, Margaret Jean. 2002. 'Roads, Restlessness, and Relationships: An Urban Settlement in Postcolonial Vanuatu’. Ph.D., Canada: York University. 
Mohamud, Ossob. 2013. 'Beware the Voluntourists Intent on Doing Good’. The Guardian. https://www.theguardian.com/.

Mondragón, C. 2013. 'A Weft of Nexus: Changing Notions of Space and Geographical Identity in Vanuatu, Oceania'. In Boundless Worlds: An Anthropological Approach to Movement, edited by Peter Wynn Kirby. Berghahn Books.

Moscardo, Gianna, and Philip L. Pearce. 1999. 'Understanding Ethnic Tourists'. Annals of Tourism Research 26 (2): 416-434. doi:10.1016/S0160-7383(98)00101-7.

Mostafanezhad, Mary. 2013. 'The Geography of Compassion in Volunteer Tourism'. Tourism Geographies 15 (2): 318-37. doi:10.1080/14616688.2012.675579.

Nash, Dennison. 1996. Anthropology of Tourism. New York: Pergamon.

Nationsonline. 2017. 'Vanuatu Map’. http://www.nationsonline.org/maps/vanuatu_map.jpg. Accessed 1st May 2017.

New Zealand Ministry of Foreign Affairs and Trade. 2016. ‘Aid Partnership with Vanuatu’. https://www.mfat.govt.nz/en/aid-and-development/our-work-in-the-pacific/vanuatu/.

NZ Herald. 2016. 'Air New Zealand Pulls Vanuatu Flights over Safety Issues’. NZ Herald - Business. http://www.nzherald.co.nz/business/news/article.cfm?c_id=3\&objectid=11578227.

Ottenberg, Simon. 1990. 'Thirty Years of Fieldnotes: Changing Relationships to the Text'. In Fieldnotes: The Makings of Anthropology, edited by Roger Sanjek, 139-60. Ithaca: Cornell University Press.

Pattullo, Polly. 2003. Last Resorts: The Cost of Tourism in the Caribbean. New York: NYU Press.

Phillips, Lynne, and Suzan Ilcan. 2004. 'Capacity-Building: The Neoliberal Governance of Development'. Canadian Journal of Development Studies 25 (3): 393-409. doi:10.1080/02255189.2004.9668985.

Polanyi, Karl. 1957. 'The Economy as Insituted Process'. In Trade and Market in the Early Empires; Economies in History and Theory, edited by Karl Polanyi, Conrad Arensberg, and Harry Pearson, 243-70. Glencoe, Ill.: Free Press.

Rabinow, Paul. 1977. Reflections on Fieldwork in Morocco; with a Foreword by Robert N. Bellah. Berkeley: University of California Press.

Regenvanu, Ralph. 1999. ‘Afterword: Vanuatu Perspectives on Research’. Oceania 70 (1): 98-100. doi:10.1002/j.1834-4461.1999.tb02992.x. 2005. 'The Changing Face of "Custom " in Vanuatu'. People and Culture in Oceania 20: 3750.

2008. 'Issues with Land Reform in Vanuatu.' Journal of South Pacific Law 12 (1): 63.

Regenvanu, Ralph, and Haidy Geismar. 2011. 'Re-Imagining the Economy in Vanuatu : An Interview with Ralph Regenvanu’. In Made in Oceania: Social Movements, Cultural Heritage and the State in the Pacific, edited by Edvard Hviding and Knut Mikjel Rio. Wantage England: Sean Kingston Publishing. 
Rodman, Margaret. 1987. Masters of Tradition: Consequences of Customary Land Tenure in Longana, Vanuatu. University of British Columbia Press.

1992. 'Empowering Place: Multilocality and Multivocality’. American Anthropologist 94 (3): 640-56. doi:10.1525/aa.1992.94.3.02a00060.

2004. 'Traveling Stories, Colonial Intimacies, and Women’s Histories in Vanuatu'. The Contemporary Pacific 16 (2): 233-57. doi:10.1353/cp.2004.0056.

Rousseau, Benedicta. 2003. 'Vanuatu Stael: Kastom and Creativity’. Cambridge Anthropology 23 (3): 79-80.

_ 2012. 'Provincialising Lakatoro: Orienting sociality through a state institution in Vanuatu'. The Australian Journal of Anthropology 23 (2): 197-211.

Roy, Eleanor Ainge. 2017. 'South Pacific Islands Ban Western Junk Food and Go Organic’. The Guardian, February 3, sec. World news. https://www.theguardian.com

Sahlins, Marshall. 1992. 'The Economics of Develop-Man in the Pacific'. Res: Anthropology and Aesthetics 21 (1): 12-25. doi:10.1086/RESv21n1ms20166839.

Salazar, Noel B. 2010. Envisioning Eden: Mobilizing Imaginaries in Tourism and Beyond. New York: Berghahn Books.

_ 2012. 'Community-Based Cultural Tourism: Issues, Threats and Opportunities'. Journal of Sustainable Tourism 20 (1): 9-22. doi:10.1080/09669582.2011.596279.

Scheyvens, Regina. 2007. 'Exploring the Tourism-Poverty Nexus'. Current Issues in Tourism 10 (23): 231-54. doi:10.2167/cit318.0.

Scheyvens, Regina, and Matt Russell. 2013. 'Sharing the Riches of Tourism in Vanuatu'. Massey University School of People, Environment \& Planning.

Scott, James C. 1976. The Moral Economy of the Peasant: Rebellion and Subsistence in Southeast Asia. New Haven: Yale University Press.

Simo, Joel. 2010. 'Land and the Traditional Economy: "Your Money, My Life” Hu i Kakae Long Basket Blong Laef?’ In In Defence of Melanesian Customary Land, edited by Tim Anderson and Gary Lee, 40-44. Sydney: Aid/Watch.

Slatter, Claire. 2006. 'The Con/Dominion of Vanuatu? Paying the Price of Investment and Land Liberalisation - a Case Study of Vanuatu's Tourism Industry’. Oxfam New Zealand.

Smith, Valene L. 1989. Hosts and Guests the Anthropology of Tourism. 2nd ed.. Philadelphia: University of Pennsylvania Press.

Sofield, Trevor. 2003. Empowerment for Sustainable Tourism Development. Emerald Group Publishing.

Stefanova, Milena. 2008. 'The Price of Tourism : Land Alienation in Vanuatu'. 43686. The World Bank. 
Stent, W., and L. Webb. 1975. 'Subsistence Affluence and Market Economy in Papua New Guinea'. The Economic Record 51 (136): 522.

Stronza, Amanda. 2001. 'Anthropology of Tourism: Forging New Ground for Ecotourism and Other Alternatives’. Annual Review of Anthropology 30: 261-83.

Taylor, John. 2001. 'Authenticity and sincerity in tourism'. Annals of Tourism Research 28 (1): 7-26.

2008. The Other Side: Ways of Being and Place in Vanuatu. University of Hawai'i Press.

2015. 'Sorcery and the Moral Economy of Agency: An Ethnographic Account'. Oceania 85 (1): 38-50. doi:10.1002/ocea.5072.

Taylor, John, and Benedicta Rousseau. 2012. 'Kastom Ekonomi and the Subject of Self-Reliance: Differentiating Development in Vanuatu'. In Differentiating Development: Beyond an Anthropology of Critique, edited by Soumhya Venkatesan and Thomas Yarrow. New York: Berghahn Books.

Technical and Vocational Education and Training. 2017. 'Business Development Services'. Vanuatu TVET Sector Strengthening Program. http://www.vanuatutvet.org.vu/. Accessed $10^{\text {th }}$ June 2017.

Thompson, E. P. 1971. 'The Moral Economy of the English Crowd in the Eighteenth Century'. Past and Present 50 (1): 76-136. doi:10.1093/past/50.1.76.

Tilley, Christopher. 1997. 'Performing Culture in the Global Village'. Critique of Anthropology 17 (1): 67-89. doi:10.1177/0308275X9701700105.

Tomlinson, Matt. 2004. 'Perpetual Lament: Kava-Drinking, Christianity and Sensations of Historical Decline in Fiji'. Journal of the Royal Anthropological Institute 10 (3): 653-673.

Tonkinson, Robert. 1981. 'Church and Kastom in Southeast Ambrym’. In Vanuatu: Politics, Economics, and Ritual in Island Melanesia, edited by Michael R. Allen, 237-67. Acad. Press.

Trau, Adam M. 2012. 'Beyond Pro-Poor Tourism: (Re)Interpreting Tourism-Based Approaches to Poverty Alleviation in Vanuatu’. Tourism Planning \& Development 9 (2): 149-64. doi:10.1080/21568316.2011.630750.

2013. 'World Heritage at Chief Roi Mata's Domain: The Global-Local Nexus of Community Heritage Conservation and Tourism Development in Vanuatu'. PhD diss., University of Western Sydney.

Turner, Rochelle. 2015. ‘Travel \& Tourism Economic Impact 2015 Vanuatu’. World Travel \& Tourism Council.

Turner, Terence. 1979. ‘Anthropology and the Politics of Indigenous Peoples’ Struggles’. Cambridge Anthropology 5 (1): 1-43.

Van Maanen, John. 2011. Tales of the Field: On Writing Ethnography. 2nd ed. Chicago: University of Chicago Press.

Vanuatu Government. 2013. 'Vanuatu Strategic Tourism Action Plan’. http://tourism.gov.vu/assets/docs/VSTAP_FINAL_Feb_2014.pdf. Accessed 3rd April 2017. 
Vanuatu National Statistics Office. 2009. ‘Census’. http://www.vnso.gov.vu/index.php/census-andsurveys/censuses. Accessed 20th May 2017.

Vanuatu National Statistics Office (VNSO). 2016. 'Home’. Vanuatu National Statistics Office. http://www.vnso.gov.vu/. Accessed 20 20 th 2017.

Vanuatu Tourism Office. 2016. ‘Vanuatu: Discover What Matters’. http://vanuatutravel.info/.

—. 2017a. '\#DiscoverVanuatu'. Vanuatu Travel. http://vanuatutravel.info/. Accessed $20^{\text {th }}$ May 2017.

—_. 2017b. ‘Malekula \& Ambrym'. Vanuatu Travel. http://vanuatutravel.info/index.php/discoverthe-islands/malekula-ambrym. Accessed $20^{\text {th }}$ May 2017.

Vaughan, Ashley. 2013. 'The Gift and the Road: Exploring the Meanings of Health and Illness in Tautu, Vanuatu’. PhD diss., University of Hawai'i.

VIPA. 2010. 'Vanuatu Investment Promotion Authority (VIPA): Key Sectors and Opportunities'. http://www.investvanuatu.org/Sectors/tourism.html. Accessed 8th December 2016.

Walley, Christine. 2004. Rough Waters: Nature and Development in an East African Marine Park. Princeton: Princeton University Press.

Warrick, Olivia. 2009. 'Ethics and Methods in Research for Community-Based Adaptation: Reflections from Rural Vanuatu’. Participatory Learning and Action, no. 60: 76-87.

Wilson, Oli. 2014. 'Ples and Popular Music Production: A Typology of Home-Based Recording Studios in Port Moresby, Papua New Guinea’. Ethnomusicology Forum 23 (3): 425-444. doi:10.1080/17411912.2014.975142.

Wilson, Tamar Diana. 2008. 'Economic and Social Impacts of Tourism in Mexico'. Latin American Perspectives 35 (3): 37-52. doi:10.1177/0094582X08315758.

Wittersheim, Éric. 2011. 'Paradise for Sale. The Sweet Illusions of Economic Growth in Vanuatu’. Le Journal de La Société Des Océanistes, no. 133: 323-32. doi:10.4000/jso.6515.

World Tourism Organization. 2017. '2017 International Year of Sustainable Tourism for Development’. http://www.tourism4development2017.org. Accessed 5 th June 2017.

Yang, Shu-Yuan. 2013. 'Envy, Desire, and Economic Engagement Among the Bugkalot (Ilongot) of Northern Luzon, Philippines’. In Engaging with Capitalism: Cases from Oceania, edited by Fiona McCormack and Kate Barclay, 199-223. Bingley, UK: Emerald.

Zakaria, Rafia. 2014. ‘Opinion: The White Tourist’s Burden’. Al Jazeera. http://america.aljazeera.com/. Accessed $6^{\text {th }}$ June 2017. 


\section{Appendix: Interviews}

Participant A: $27^{\text {th }}$ October 2016, recorded, 1hr 30mins

Participant B: $25^{\text {th }}$ October 2016, not recorded, 45mins

Participant C: $3^{\text {rd }}$ October, recorded, $1 \mathrm{hr}$

Hano and Olena: $24^{\text {th }}$ September, recorded, 50mins

Kalina: $10^{\text {th }}$ November 2016, recorded, $1 \mathrm{hr} 10 \mathrm{mins}$

Moris: $1^{\text {st }}$ October, not recorded, 50mins

Joshua and Adara: $25^{\text {th }}$ September, recorded, $1 \mathrm{hr} 15 \mathrm{mins}$

Lani: $27^{\text {th }}$ September, not recorded

Valea and Jermain: $5^{\text {th }}$ October, recorded, $1 \mathrm{hr}$

Enzo and Jasil: $29^{\text {th }}$ September, not recorded

Roaslie: $15^{\text {th }}$ October, recorded, 50mins 